\title{
APRIL limits atherosclerosis by binding to heparan sulfate proteoglycans.
}

Tsiantoulas D, Eslami M, Obermayer G, Clement M, Smeets D, Mayer FJ, Kiss MG, Enders L, Weißer J, Göderle L, Lambert J, Frommlet F, Mueller A, Hendrikx T, Ozsvar-Kozma M, Porsch F, Willen L, Afonyushkin T, Murphy JE, Fogelstrand P, Donzé O, Pasterkamp G, Hoke M, Kubicek S, Jørgensen HF, Danchin N, Tabassome S, Scharnagl H, März W, Borén J, Hess H, Mallat Z, Schneider P, Binder C

Nature 597, 92-96.

doi.org/10.1038/s41586-021-03818-3

Publisher's web site: https://www.nature.com/articles/s41586-021-03818-3 
APRIL limits atherosclerosis via binding to heparan sulfate proteoglycans

3 Dimitrios Tsiantoulas ${ }^{1 *}$, Mahya Eslami ${ }^{2}$, Georg Obermayer ${ }^{1,3}$, Marc Clement ${ }^{4}$, Diede Smeets ${ }^{1}$, 4 Florian J. Mayer ${ }^{1}$, Máté G. Kiss ${ }^{1,3}$, Lennart Enders ${ }^{3}$, Juliane Weißer ${ }^{3}$, Laura Göderle ${ }^{1,3}$, Jordi 5 Lambert $^{4}$, Florian Frommlet ${ }^{5}$, André Mueller ${ }^{3}$, Tim Hendrikx ${ }^{1}$, Maria Ozsvar-Kozma ${ }^{1,3}$, Florentina 6 Porsch $^{1,3}$, Laure Willen ${ }^{2}$, Taras Afonyushkin ${ }^{1,3}$, Jane E. Murphy ${ }^{4}$, Per Fogelstrand ${ }^{6}$, Olivier 7 Donzé $^{7}$, Gerard Pasterkamp ${ }^{8}$, Matthias Hoke ${ }^{9}$, Stefan Kubicek ${ }^{3}$, Helle F. Jørgensen ${ }^{4}$, Nicolas 8 Danchin $^{10}$, Tabassome Simon ${ }^{11,12}$, Hubert Scharnagl ${ }^{13}$, Winfried März ${ }^{13,14}$, Jan Borén ${ }^{6}$, Henry 9 Hess $^{16}$, Ziad Mallat ${ }^{4,17 \S}$, Pascal Schneider ${ }^{2 \S}$, Christoph J. Binder ${ }^{1,3 *}$

${ }^{1}$ Dept. of Laboratory Medicine, Medical University of Vienna, Vienna, 1090, Austria

${ }^{2}$ Department of Biochemistry, University of Lausanne, Epalinges, CH-1066, Switzerland

${ }^{3}$ CeMM Research Center for Molecular Medicine of the Austrian Academy of Sciences, Vienna, 1090, Austria

${ }^{4}$ Division of Cardiovascular Medicine, Department of Medicine, University of Cambridge, Cambridge, CB2 OSZ, UK

${ }^{5}$ Center for Medical Statistics, Informatics and Intelligent Systems, Medical University of Vienna, Vienna, 1090, Austria

${ }^{6}$ Institute of Medicine, University of Gothenburg, Göteborg, 40530, Sweden

${ }^{7}$ Adipogen Life Sciences, CH-1066 Epalinges, Switzerland

${ }^{8}$ University Medical Center Utrecht, 3584 CX Utrecht, Netherlands

${ }^{9}$ Department of Internal Medicine II, Medical University of Vienna, Vienna, 1090, Austria

${ }^{10}$ Assistance Publique-Hôpitaux de Paris (AP-HP), Hôpital Européen Georges Pompidou, Department of Cardiology, 75015 Paris, France; Université de Paris, 75006 Paris, France

${ }^{11}$ AP-HP, Hôpital Saint Antoine, Department of Clinical Pharmacology and Clinical Research Platform of East of Paris (URCEST-CRB-CRC), 75012 Paris, France

${ }^{12}$ Sorbonne-Université (UPMC-Paris 06), 75012 Paris, France

${ }^{13}$ Clinical Institute of Medical and Chemical Laboratory Diagnostics, Medical University of Graz, A-8036

Graz, Austria

${ }^{14}$ Medical Clinic V, Medical Faculty Mannheim, University of Heidelberg, D-68167 Mannheim, Germany

${ }^{15}$ Synlab Holding Deutschland GmbH, 86156 Augsburg, Germany

${ }^{16}$ Translational Innovation Platform Immunology, Merck KGaA, Darmstadt, 64293, Germany

${ }^{17}$ Université de Paris and INSERM U970, Paris Cardiovascular Research Center, Paris, France

$\S$ these authors contributed equally 


\section{SUMMARY}

43 Atherosclerotic cardiovascular disease (CVD) is the leading cause of mortality worldwide ${ }^{1,2}$.

44 Atherosclerotic plaque formation is initiated upon trapping of low-density lipoprotein (LDL) in

45 the subendothelial space of large and medium size arteries that initially involves binding of LDL

46 to heparan-sulfate proteoglycans (HSPGs) ${ }^{3}$, followed by a chronic inflammation and remodelling

47 of the artery wall ${ }^{3}$. A Proliferation Inducing Ligand (APRIL), a cytokine produced by many cell

48 types, binds to $\mathrm{HSPGs}^{4}$, but the physiology of this interaction is largely unknown. Here, we show

49 that genetic ablation or antibody-mediated depletion of APRIL aggravates atherosclerosis in mice.

50 Mechanistically, we demonstrate that APRIL confers atheroprotection via binding to heparan

51 sulfate (HS) chains of heparan-sulfate proteoglycan 2 (HSPG2), which limits LDL retention,

52 macrophage accumulation and necrotic core formation. Indeed, antibody-mediated depletion of

53 APRIL in mice expressing HS-deficient HSPG2 had no effect on atherosclerosis development.

54 Consistent with these data, treatment with a specific anti-APRIL antibody that promotes the

55 binding of APRIL to HSPGs reduces experimental atherosclerosis. Furthermore, the serum levels

56 of a previously unknown form of human APRIL protein that binds to HSPGs, which we termed

57 non-canonical APRIL (nc-APRIL), are associated independently of traditional risk factors with

58 long term (10- to 12-year follow up) cardiovascular mortality in patients with atherosclerosis. Our

59 data reveal hitherto unknown properties of APRIL that have broad pathophysiological implications

60 for vascular homeostasis.

61

62

63 
65 APRIL is encoded by the tumour necrosis factor ligand superfamily member 13 gene (Tnfsf13) and is produced by myeloid cells and stromal cells ${ }^{5}$. APRIL is involved in antibody class switching ${ }^{6}$ and plasma cell survival ${ }^{7,8}$ in mice and humans through its binding to two receptors TACI (transmembrane activator and CAML interactor) and BCMA (B cell maturation antigen), respectively, with the same APRIL-binding site ${ }^{9}$. Patients with coronary artery disease have increased APRIL levels in plasma compared to sex- and age-matched healthy individuals ${ }^{10}$,

71 however its role in atherosclerosis remains elusive.

72 To investigate the effect of APRIL in atherosclerosis, we generated LDL receptor-deficient mice 73 that lack APRIL ( $\left.\mathrm{Ldlr}^{-/-} \mathrm{April}^{-/-}\right)$. $\mathrm{Ldlr}^{-/} \mathrm{April}^{-/-}$mice fed an atherogenic diet developed increased 74 plaque size (Fig. 1a) in the aortic root despite similar body weight, cholesterol and triglyceride 75 levels in plasma (Fig. 1d and Extended Data fig. 1a) compared to their littermate controls. 76 Moreover, aortic root plaques of $\mathrm{Ldlr}^{-/} \mathrm{April}^{-/-}$mice displayed enhanced necrotic core and acellular 77 area (Fig. 1b and Extended Data fig. 1b) and macrophage content (Fig. 1c). Smooth muscle cell content (Extended Data fig. 1c) and collagen deposition (Extended Data fig. 1d) of plaques in the aortic root, and plaque size in the thoraco-abdominal aorta were not affected (Extended Data fig. 1a). Notably, APRIL deficiency did not alter the numbers of splenic B cell (Fig. 1e), T cell (Extended Data fig. 1e) and peritoneal B cell subsets (Extended Data fig. 1f) or the proportions of circulating monocytes in peripheral blood (Extended Data fig. 1g). Besides total IgA, which was moderately reduced (consistent with previous findings ${ }^{6}$ ), total IgM, IgG1, IgG2b, IgG2c and IgG3 levels in plasma were similar between $\mathrm{Ldlr}^{-/-} \mathrm{April}^{-/}$and $\mathrm{Ldlr}^{-/-} \mathrm{April}^{+/+}$mice (Fig. 1f). These data suggest that APRIL confers an atheroprotective effect, independently of circulating cholesterol levels or B cell immunity.

Although TACI binds APRIL, it also binds with high affinity to the B cell activating factor (BAFF) ${ }^{11}$, which mediates the atheroprotective effect of TACI signaling ${ }^{12}$. Since BCMA has much higher affinity for APRIL than for BAFF ${ }^{13}$, we investigated the role of BCMA in the atheroprotective properties of APRIL. Ldlr $r_{-/}$mice lacking BCMA in the hematopoietic system $\left(\mathrm{Ldll}^{-/}\right.$hem-Bcma $\mathrm{CH}^{-/}$ ) (Extended Data fig. 2a) displayed similar plaque size in the aortic root and thoraco-abdominal

92 aorta compared with $\mathrm{Ldll}^{-/}$hem-Bcma ${ }^{+/+}$controls (Extended Data fig. $2 \mathrm{~b}$ and Extended Data fig. 93 2c). Body weight (Extended Data fig. 2c), triglyceride (Extended Data fig. 2c) and total cholesterol 94 levels (Extended Data fig. 2d) in plasma were not different between the groups. In contrast to 
APRIL-deficient mice, $\mathrm{Ldll}^{-/} h e m-\mathrm{Bcma}^{-/}$mice had increased splenic B cell numbers (Extended

96 Data fig. 2e) whereas T cell numbers were similar between $L d l r^{-1-h e m-B c m a-/}$ mice and $L d l r^{-1}$ hem-

$97 \mathrm{Bcma}^{+/+}$controls (Extended Data fig. 2f). Peritoneal B-2 cells - in contrast to B-1 cells - were also

98 increased in $\mathrm{Ldll}^{-1-} \mathrm{Bcma}^{-/}$mice (Extended Data fig. $2 \mathrm{~g}$ ). Hematopoietic BCMA deletion also

99 altered immunoglobulin levels in plasma (Extended Data fig. 2h). All together, these data suggest

100 that the atheroprotective properties of APRIL are not dependent on BCMA signalling.

101 Next, we investigated whether APRIL mediates its atheroprotective effects locally within the

102 atherosclerotic plaque microenvironment. According to the Genotype-Tissue Expression (GTEx)

103 project ${ }^{14}$, APRIL gene expression levels are particularly high in human healthy arteries (Extended

104 Data fig. 3a), which indicate that APRIL is produced in the arterial microenvironment. We show

105 that the Tnfsfl3 transcripts are present in intermediate to high levels within the total transcriptome

106 of isolated primary vascular smooth muscle cells from the aortic arch or thoracic aorta of healthy

107 mice (Extended Data fig. 3b) and remain stable even under cell culture conditions (Extended Data

108 fig. 3c). Similarly, we found that human umbilical artery smooth muscle cells also express Tnfsf 13

109 and its expression is not affected by typical pro-atherogenic stimuli (Extended Data fig. 3d).

110 In line with these results, we found that in human atherosclerotic plaques from the Athero-Express

111 clinical study ${ }^{15}$, APRIL protein content is approximately $0.5 \%$ of the total plaque protein amount

112 (Fig. 2a). To further explore the protective properties of APRIL in atheroma formation, we probed

113 APRIL in human carotid and coronary arteries with and without atherosclerosis. APRIL, which

114 was present in both carotid and coronary arteries (Fig. 2b), was particularly enriched at the

115 basement membrane of the vascular endothelial cell layer as well as on their cell surface in both

116 atherosclerotic and non-atherosclerotic specimens (Fig. 2c, d). Next, we found that both

117 recombinant mouse and human multimeric flag-tagged APRIL protein (thereafter referred to as

118 flag-APRIL) bind to human umbilical vein endothelial cells (HUVECs) and this was completely

119 abrogated in the presence of heparin (Extended Data Fig. 4a, b) showing that APRIL binds to the

120 endothelium via its heparan sulfate biding site ${ }^{4}$. To identify the endothelial proteins interacting

121 with APRIL, we conducted an anti-flag pull-down assay with HUVECs treated with flag-APRIL

122 and flag-control constructs followed by protein identification by mass-spectrometry. We identified

123 heparan sulfate proteoglycan 2 (HSPG2 or Perlecan) as an interactor of APRIL (Extended Data

124 fig. 4c). HSPG2 is an essential and highly enriched component of basement membranes ${ }^{16}$ and has

125 been shown to promote atherosclerotic plaque formation ${ }^{17,18}$. We validated the interaction of 
APRIL and HSPG2 by ELISA using HSPG preparations isolated from mouse basement 127 membranes (Extended Data fig. 4d). Furthermore, we found that APRIL co-localised with HSPG2 in the subendothelial basement membrane of human arteries with (Pearson's Coefficient $r=0.785$ )

129 or without atherosclerosis (Pearson's Coefficient $r=0.687$ ) (Fig. 2e). In addition, exogenously 130 added murine multimeric flag-APRIL to cryosections of mouse carotid artery (Extended Data fig. $1314 \mathrm{e}$ ) could bind preferentially to arterial areas that were enriched in HSPG2 and the binding of 132 APRIL to the artery wall was meditated exclusively via its HSPG-binding site as it was completely 133 inhibited when APRIL was pre-incubated with heparin (Extended Data fig. 4f). Furthermore, a 134 Surface Plasmon resonance (Biacore) analysis showed that both total human $\left(\mathrm{K}_{\mathrm{D}}=0.24 \times 10^{-6} \mathrm{M}\right)$ 135 and mouse APRIL $\left(\mathrm{K}_{\mathrm{D}}=1.6 \times 10^{-6} \mathrm{M}\right)$ bind with affinity to heparan sulfate (Extended Data fig. 4g). 136 To investigate whether APRIL mediates its atheroprotective effects via binding to HSPG2, we 137 treated Apolipoprotein E deficient mice, which express HSPG2 lacking heparan sulfate chains 138 (Apoe ${ }^{-/} \mathrm{Hspg}^{d 3}$ ), and control mice with either a depleting mouse anti-mouse APRIL (clone 108; 139 Extended Data fig. 5a, b, c) or an isotype antibody for seven weeks, while the mice were fed an 140 atherogenic diet for the last six weeks of the study. In agreement with the proatherogenic role of 141 genetic deficiency of APRIL (Fig. 1), antibody-mediated depletion of APRIL increased 142 atherosclerosis in Apoe $e^{-/-} H \operatorname{spg} 2^{w t}$, while it had no effect in Apoe ${ }^{-/-} H \operatorname{spg} 2^{d 3}$ mice (Fig. 2f, g). Plasma 143 cholesterol levels were similar among all experimental groups (Fig. 2h). It has been previously 144 shown that regular chow diet-fed $\mathrm{Apoe}^{-/-} \mathrm{Hspg}^{d 3}$ mice develop reduced atherosclerosis compared 145 to control mice ${ }^{18}$. Here, we extend these findings showing a similar result for Apoe $e^{-/-} H s p g 2^{\text {wt }}$ and 146 Apoe $^{-/} H_{s p g} 2^{d 3}$ mice (that received the isotype antibody) fed an atherogenic diet (Fig. 2f, g), 147 despite plasma cholesterol levels $>1,000 \mathrm{mg} / \mathrm{dL}$ (Fig. 2h). These data reveal the mechanism by 148 which APRIL impacts atherosclerosis and highlight the importance of HSPGs in the pathogenesis 149 of atherosclerosis, even in conditions of extreme hypercholesterolemia.

150 An important function by which heparan-sulfate chains of HSPG2 exhibit their proatherogenic 151 effect is via facilitating the LDL retention in the subendothelial space ${ }^{18}$, which is a rate-limiting 152 step for the development of atherosclerotic plaques ${ }^{19}$. Pre-treatment of sections of a mouse carotid 153 artery with APRIL decreased arterial retention of native LDL (isolated from healthy human 154 donors), which was detected with an anti-ApoB antibody (Extended Data fig. 6a). We obtained 155 similar data using HEK293 wild-type cells (that are decorated with HSPGs), which were incubated 156 with human LDL in the presence of different amounts of recombinant human APRIL (Extended 
157 Data fig. 6b). In vivo, we show that $L d \mathrm{Lr}^{-} \mathrm{April}^{-/}$mice (described in Fig. 1) display increased ApoB 158 content in their atherosclerotic plaques compared to the controls (Extended Data fig. 6c). Taken 159 together, these data show the HSPG-binding site of APRIL exhibits atheroprotective properties by 160 limiting LDL retention in the subendothelial space. However, HSPGs are also involved in other 161 biological processes that are implicated in atherogenesis, such as monocyte adhesion, smooth muscle cell proliferation and matrix protein arrest ${ }^{20,21}$, which could be modulated by APRIL. We 163 found that lesions of $\mathrm{Ldlr}^{-1}$ April ${ }^{--}$mice have increased macrophage content (Fig. 1c). While we 164 consider this to be a consequence of enhanced disease stage, an additional effect may be mediated 165 through direct impact of the APRIL-HSPGs interaction on immune cell adhesion and arrest. In 166 support of our findings that the protective effect of APRIL is exerted locally in the artery wall, 167 overexpression of human APRIL in T cells, does not alter plaque size in Apoe ${ }^{-/}$mice ${ }^{22}$.

We hypothesized that an intervention that preserves or promotes APRIL binding to HSPGs while blocking its interaction with BCMA and TACI would be beneficial in atherosclerosis. First, 170 we tested a mouse TACI-Ig (a decoy TACI receptor that blocks the TACI/BCMA binding site of 171 APRIL ${ }^{23}$ ). TACI-Ig did not affect atherosclerosis in Apoe $e^{-/}$mice fed an atherogenic diet (Fig. 3a, 172 b). It is important to note that TACI-Ig also targets BAFF, which we have recently shown to exhibit 173 an atheroprotective role in experimental atherosclerosis ${ }^{24}$. In agreement with BAFF-depleting 174 activities ${ }^{24}$, treatment with TACI-Ig led to a strong depletion of follicular and marginal zone B 175 cells in the spleen (Extended Data fig. 7a-c) and atheroprotective B-1 B cells ${ }^{25-27}$ in the peritoneum 176 (Extended Data fig. 7d, e), and to reduced levels of atheroprotective IgM antibodies ${ }^{28,29}$ in plasma 177 (Extended Data fig. 7f).

178 To target only APRIL, we treated Apoe ${ }^{-/}$mice with an anti-mouse APRIL antibody (clone Apry179 1-1; Extended Data fig. 7a, b, c) that targets selectively the BCMA/TACI-binding site of APRIL $180{ }^{23}$ and simultaneously increases the binding to HSPGs (Fig. 3c) without affecting stability and 181 levels of APRIL in plasma in vivo (Extended Data fig. 7g). Notably, treatment with anti-APRIL 182 antibody did not affect B cell and IgM humoral responses besides a partial reduction of marginal 183 zone B cells (Extended Data fig. 7a-f). Furthermore, treatment with the anti-APRIL antibody 184 Apry-1-1 (which was initiated two weeks prior to the onset of the atherogenic diet feeding) reduced 185 atherosclerosis in both aortic root and thoraco-abdominal aorta (Fig. 3a, b) without affecting 186 plasma cholesterol levels triglycerides or body weight (Extended Data fig. 7h). 
187 By validating different ELISA systems for the detection of human APRIL, we discovered that 188 human serum contains an additional and previously unknown form of APRIL, thereafter termed non-canonical (nc) APRIL. This was evidenced when APRIL was depleted from sera or from an APRIL standard either with TACI-Ig, a known inhibitor of APRIL and BAFF that binds the immune receptor (BCMA/TACI)-binding site of APRIL, or with an anti-APRIL antibody 192 (Aprily2) that recognizes APRIL by immunohistochemistry and Western blot (Fig. 2b-e, Fig. 4b). 193 Only TACI-Ig, but not Aprily2, could deplete the signal in an APRIL ELISA (ELISA 1). 194 Conversely, only the Aprily2 antibody, but not TACI-Ig, could deplete the signal in another APRIL-specific ELISA (ELISA 2) (Fig. 4a, b, c). To confirm this, we performed additional 196 depletion experiments using different anti-human APRIL antibodies whose specificities for 197 APRIL protein were characterized by epitope mapping (Extended Data fig. 8a-g). We found that 198 APRIL detected in serum by ELISA 2 could be depleted by several monoclonal antibodies 199 (Aprily1,2,5,6,8) recognizing at least two different epitopes, without affecting the detection of the 200 canonical form of APRIL (c-APRIL) by ELISA 1 (Extended Data fig. 8h). Moreover, human 201 APRIL depletion in serum by antibodies (clones: Mahya1 and 110.6) and biologicals (Atacicept; 202 human TACI-Fc fusion protein) that are directed against c-APRIL did not affect the detection of 203 nc-APRIL by ELISA 2 (Extended Data fig. 8i). Thus, both ELISAs are specific but recognize 204 different forms of APRIL. Notably, ELISA 2 recognizes a non-canonical APRIL (nc-APRIL) 205 unable to bind the immune receptor TACI. However, both nc-APRIL and c-APRIL bind to 206 heparan-sulfates with equivalent affinities of $\mathrm{K}_{\mathrm{D}}=6.3 \times 10^{-7} \mathrm{M}$ and $\mathrm{K}_{\mathrm{D}}=2.6 \times 10^{-7} \mathrm{M}$ respectively 207 (Extended Data fig. 4g). Flag-tagged c-APRIL and nc-APRIL displayed markedly different sizes 208 upon gel filtration under native conditions. c-APRIL eluted as a trimer and nc-APRIL as a much 209 larger multimer (Extended Data fig. 8j-n). Furthermore, nc-APRIL and c-APRIL are encoded by 210 the same gene, as deletion of the TNFSF13 gene by CRISPR/Cas9 in U937 cells resulted in loss 211 of both nc-APRIL and c-APRIL proteins in the supernatant (Extended Data fig. 8o, p). In addition, 212 both nc-APRIL and c-APRIL can be produced by the same transcript as transfection of 293T cells 213 with a plasmid containing a cDNA for wild-type Fc-hAPRIL led to the production of both nc214 APRIL and c-APRIL in the supernatant (Fig 4d, e). We then characterized purified human 215 recombinant non-canonical and canonical Fc-hAPRIL by "bottom-up" MS-based proteomics and 216 found two different C-terminal tryptic peptides, an abundant one from which the C-terminal 217 leucine residue was released by trypsin, and a minor one in which the C-terminal leucine was still 
218 attached. While most tryptic peptide fragments were equally abundant for c-APRIL and nc-APRIL

219 the miscleaved fragment was not detectable in nc-APRIL by high-sensitivity targeted parallel 220 reaction monitoring, suggesting that the C-terminus of nc-APRIL might have already been 221 truncated (Extended Data fig. 9a-c). As the C-terminus of APRIL is structurally important 222 (Extended Data fig. 9d), we investigated the effect of C-terminal amino acid truncations in 223 determining the ratio of c-APRIL to nc-APRIL. To examine this, Fc-APRIL with a C-terminal 224 truncation of 1 amino acid (-1C) was transfected in 293T cells and led to the exclusive production 225 of nc-APRIL in the supernatant, while the more abundantly produced wild-type Fc-APRIL 226 contained both c- and nc-APRIL (Fig. 4d, e). Similar data were obtained with C-terminal 227 truncations of 2, 3, or 4 amino acids (Fig. 4d, e). Nc-APRIL proteins that were produced upon 228 truncations of $1,2,3$, or 4 amino acids also failed to bind the receptor BCMA (Fig. 4f), which is 229 consistent with nc-APRIL lacking the binding site to TACI and BCMA. We also confirmed in 230 additional human samples that both nc- and c-APRIL exist in human serum, with nc-APRIL 231 present at higher levels compared to c-APRIL (Fig. 4g and Supplemental fig. 1). Taken together, 232 these data indicate that different forms of APRIL exist in vivo that may have distinct roles in health 233 and disease. In addition, as c-APRIL and nc-APRIL could be also formed from the same wild-type 234 amino acid sequence, it raises the hypothesis that APRIL may belong to the group of metamorphic 235 protein, which are protein that switch between different folding states ${ }^{30}$.

236 To examine a potential role of APRIL in human atherosclerotic CVD, we quantified serum nc237 APRIL and c-APRIL levels in 785 individuals with neurologically asymptomatic carotid 238 atherosclerosis that were enrolled in the prospective clinical ICARAS study ${ }^{31}$ (Supplementaltable 239 2). Kaplan-Meier analyses demonstrated a significant increase in cardiovascular mortality with 240 decreasing serum nc-APRIL levels (Fig. 4h). After adjustment for well-established cardiovascular 241 risk factors in the cox proportional hazard model, patients within the first tertile displayed a 242 significantly increased risk of all-cause mortality (Extended Data fig. 10a) and cardiovascular 243 mortality (Extended Data fig. 10a) compared with patients within the third tertile. In contrast, 244 serum c-APRIL levels were not associated with cardiovascular or all-cause mortality (Extended 245 Data fig. 10b). Next, we quantified nc-APRIL levels in the serum of 1,514 patients with 246 symptomatic and angiographically-documented coronary artery disease that were enrolled in the 247 LURIC prospective clinical study ${ }^{32}$ (Supplementaltable 3). Kaplan-Meier analyses demonstrated 248 a statistically significant increase in cardiovascular mortality with increasing serum nc-APRIL 
levels in a 10-year follow-up (Fig. 4i), even after adjustment for multiple well-established 250 cardiovascular risk factors (Extended Data fig. 10c;). Similar results were obtained for all-cause 251 mortality (hazard ratio $=1.15,95 \%$ confidence interval $=1.05-1.25, \mathrm{P}=0.002$ ). Moreover, we 252 also show that high nc-APRIL levels in the serum of 974 patients with acute myocardial infarction 253 included in the FAST-MI clinical study ${ }^{33}$ are independently associated with death in a 2-year 254 follow-up (Extended Data fig. 10d). Taken together, we show that circulating nc-APRIL levels are 255 independently associated with cardiovascular mortality in three different clinical studies and 256 thereby provide epidemiological evidence for the relevance of APRIL in human atherosclerotic 257 CVD.

258 In conclusion, we show that APRIL confers atheroprotection via binding to heparan sulfates in the 259 arterial intima. It is likely that the stoichiometric relationship of this interaction may change and 260 be modulated by additional factors (such as chemokines reacting with HS-chains) with progression 261 of the disease. Future studies will investigate the therapeutic value of targeting APRIL in 262 atherosclerotic CVD.

\section{REFERENCES:}

2651 World Health Organization. Global status report on noncommunicable diseases 2014. xvii, 280 pages (World Health Organization,, Geneva, Switzerland, 2014).

2. World Health Organization, Noncommunicable diseases country profiles 2018, ISBN: 978 924151462 0. (2018).

3. Gistera, A. \& Hansson, G.K. The immunology of atherosclerosis. Nat Rev Nephrol 13, 368-380 (2017).

4. Ingold, K., et al. Identification of proteoglycans as the APRIL-specific binding partners. $J$ Exp Med 201, 1375-1383 (2005).

5. Vincent, F.B., Morand, E.F., Schneider, P. \& Mackay, F. The BAFF/APRIL system in SLE pathogenesis. Nat Rev Rheumatol 10, 365-373 (2014).

6. Castigli, E., et al. Impaired IgA class switching in APRIL-deficient mice. Proc Natl Acad Sci U S A 101, 3903-3908 (2004).

7. Huard, B., et al. APRIL secreted by neutrophils binds to heparan sulfate proteoglycans to create plasma cell niches in human mucosa. J Clin Invest 118, 2887-2895 (2008).

8. McCarron, M.J., Park, P.W. \& Fooksman, D.R. CD138 mediates selection of mature plasma cells by regulating their survival. Blood 129, 2749-2759 (2017).

9. Hymowitz, S.G., et al. Structures of APRIL-receptor complexes: like BCMA, TACI employs only a single cysteine-rich domain for high affinity ligand binding. J Biol Chem 280, 7218-7227 (2005).

10. Sandberg, W.J., et al. The tumour necrosis factor superfamily ligand APRIL (TNFSF13) is released upon platelet activation and expressed in atherosclerosis. Thromb Haemost 102, 704-710 (2009). 
287 11. Mackay, F. \& Schneider, P. Cracking the BAFF code. Nat Rev Immunol 9, 491-502 (2009).

288 12. Tsiantoulas, D., et al. B Cell-Activating Factor Neutralization Aggravates Atherosclerosis. 289 Circulation 138, 2263-2273 (2018).

290 13. Patel, D.R., et al. Engineering an APRIL-specific B cell maturation antigen. J Biol Chem

14. Consortium, G.T., et al. Genetic effects on gene expression across human tissues. Nature 550, 204-213 (2017).

15. Hellings, W.E., Moll, F.L., de Kleijn, D.P. \& Pasterkamp, G. 10-years experience with the Athero-Express study. Cardiovasc Diagn Ther 2, 63-73 (2012).

16. Lord, M.S., et al. The multifaceted roles of perlecan in fibrosis. Matrix Biol 68-69, 150166 (2018).

17. Vikramadithyan, R.K., et al. Atherosclerosis in perlecan heterozygous mice. J Lipid Res 45, 1806-1812 (2004).

18. Tran-Lundmark, K., et al. Heparan sulfate in perlecan promotes mouse atherosclerosis: roles in lipid permeability, lipid retention, and smooth muscle cell proliferation. Circ Res 103, 43-52 (2008).

19. Skalen, K., et al. Subendothelial retention of atherogenic lipoproteins in early atherosclerosis. Nature 417, 750-754 (2002).

20. Sarrazin, S., Lamanna, W.C. \& Esko, J.D. Heparan sulfate proteoglycans. Cold Spring Harb Perspect Biol 3(2011).

21. Parish, C.R. The role of heparan sulphate in inflammation. Nat Rev Immunol 6, 633-643 (2006).

22. Bernelot Moens, S.J., et al. Impact of the B Cell Growth Factor APRIL on the Qualitative and Immunological Characteristics of Atherosclerotic Plaques. PLoS One 11, e0164690 (2016).

23. Haselmayer, P., Vigolo, M., Nys, J., Schneider, P. \& Hess, H. A mouse model of systemic lupus erythematosus responds better to soluble TACI than to soluble BAFFR, correlating with depletion of plasma cells. Eur J Immunol 47, 1075-1085 (2017).

24. Tsiantoulas, D., et al. BAFF Neutralization Aggravates Atherosclerosis. Circulation (2018).

25. Kyaw, T., et al. B1a B lymphocytes are atheroprotective by secreting natural IgM that increases IgM deposits and reduces necrotic cores in atherosclerotic lesions. Circ Res 109, 830-840 (2011).

26. Gruber, S., et al. Sialic Acid-Binding Immunoglobulin-like Lectin G Promotes Atherosclerosis and Liver Inflammation by Suppressing the Protective Functions of B-1 Cells. Cell Rep (2016).

27. Rosenfeld, S.M., et al. B-1b Cells Secrete Atheroprotective IgM and Attenuate Atherosclerosis. Circ Res 117, e28-39 (2015).

28. Lewis, M.J., et al. Immunoglobulin $\mathrm{M}$ is required for protection against atherosclerosis in low-density lipoprotein receptor-deficient mice. Circulation 120, 417-426 (2009).

29. Tsiantoulas, D., et al. Increased Plasma IgE Accelerate Atherosclerosis in Secreted IgM Deficiency. Circ Res 120, 78-84 (2017).

30. Dishman, A.F., et al. Evolution of fold switching in a metamorphic protein. Science 371, 86-90 (2021).

31. Schillinger, M., et al. Inflammation and Carotid Artery--Risk for Atherosclerosis Study (ICARAS). Circulation 111, 2203-2209 (2005). 
32. Winkelmann, B.R., et al. Rationale and design of the LURIC study--a resource for functional genomics, pharmacogenomics and long-term prognosis of cardiovascular disease. Pharmacogenomics 2, S1-73 (2001).

33. Puymirat, E., et al. Acute Myocardial Infarction: Changes in Patient Characteristics, Management, and 6-Month Outcomes Over a Period of 20 Years in the FAST-MI Program (French Registry of Acute ST-Elevation or Non-ST-Elevation Myocardial Infarction) 1995 to 2015. Circulation 136, 1908-1919 (2017).

\section{FIGURE LEGENDS}

Figure 1. APRIL deficiency promotes atherosclerotic lesion formation in $\mathbf{L d l r ^ { - / }}$ mice. $L d l r^{-/}$ $\mathrm{April}^{+/+}$or $\mathrm{Ldlr}^{-/} \mathrm{April}^{-/}$mice were fed an atherogenic diet for 10 weeks. (a) Representative photomicrographs of H\&E-stained aortic root lesions (50x) and dot plot of the average lesion size in the aortic origin expressed as $\mu \mathrm{m}^{2} / \mathrm{section}\left(\mathrm{n}=9 \mathrm{Ldll}^{-/} \mathrm{April}^{+/+}\right.$mice and $\mathrm{n}=12 \mathrm{Ldll}^{-/} \mathrm{April}^{-/}$ mice; $\mathrm{P}=0.041$ ). (b) Dot plot showing the average percentage of the necrotic core size normalized to lesion size $\left(\mathrm{n}=9 \mathrm{Ldlr}^{-/} \mathrm{April}^{+/+}\right.$mice and $\mathrm{n}=12 \mathrm{Ldll}^{-/} \mathrm{April}^{-/}$mice; $\left.\mathrm{P}=0.009\right)$, (c) Representative photomicrographs and dot plot showing the average percentage of the Mac-2+ area normalized to DAPI+ area of the lesion $\left(\mathrm{n}=8 \mathrm{Ldlr}^{-/} \mathrm{April}^{+/+}\right.$mice and $\mathrm{n}=12 \mathrm{Ldlr}^{-/} \mathrm{April}^{-/}$mice; $\mathrm{P}=0.047)$. (d) Dot plot showing total plasma cholesterol $\left(\mathrm{n}=10 \mathrm{Ldlr}^{-/} \mathrm{April}^{+/+}\right.$mice and $\mathrm{n}=12$ $\mathrm{Ldlr}^{-1} \mathrm{April}^{-/-}$mice). (e) Representative flow cytometry plots on $\mathrm{B} 22 \mathrm{O}^{+} \mathrm{CD} 43^{-}$gated cells and dot plots of absolute numbers of follicular/transitional stage 2 (FO/T2), marginal zone (MZ,) CD21 ${ }^{+}$ $\mathrm{CD} 23^{-}$, transitional stage 1 (T1), newly formed (NF) and B-1 (defined as B220 ${ }^{\text {low }} \operatorname{IgM}^{+} \mathrm{CD}^{+} 3^{+}$) B cells in the spleen ( $\mathrm{n}=10 \mathrm{Ldlr}^{-/} \mathrm{April}^{+/+}$mice and $\mathrm{n}=12 \mathrm{Ldlr}^{-/} \mathrm{April}^{-/}$mice). (f) Dot plots showing the total IgM, IgG1, IgG2b, IgG2c, IgG3 and IgA plasma antibody titers (n $=10 \mathrm{Ldll}^{-/} \mathrm{April}^{+/+}$ mice and $\mathrm{n}=12 \mathrm{Ldlr}^{-1}$ April ${ }^{--}$mice). All results show mean \pm s.e.m.. ${ }^{*} \mathrm{P}<0.05,{ }^{*} * \mathrm{P}<0.01$, (twotailed Mann-Whitney $U$ or two-tailed unpaired Student $t$ test), scale bar: $200 \mu \mathrm{m}$.

\section{Figure 2. APRIL protects from atherosclerosis via binding to heparan sulfate proteoglycan}

2 (HSPG2). (a) Dot plot showing the average amount of APRIL in total denatured protein lysates of human atherosclerotic plaque extracts from the Athero-Express clinical study ( $\mathrm{n}=199$ samples) (b) Representative photomicrographs of human carotid and coronary artery specimens stained with an anti-APRIL antibody and analyzed by confocal microscopy. Representative photomicrographs of different human coronary and carotid artery specimens with or without atherosclerosis stained 
(c, d) with anti-APRIL and anti-CD31 antibodies and (e) stained with anti-APRIL, anti-CD31 and anti-HSPG2 antibodies, and analyzed by confocal microscopy. (f, g, h) Apoe ${ }^{-/} H s p g 2^{w t}$ and Apoe $e^{-/}$ $H s p g 2^{d 3}$ mice that were treated with either a mouse anti-mouse APRIL antibody (clone 108) or an isotype $\operatorname{IgG} 1$ for 7 weeks and were fed an atherogenic diet for the last 6 weeks of the study. (f) Representative photomicrographs of H\&E-stained aortic root lesions and line graph of the total lesion area in the aortic origin expressed as $\mu \mathrm{m}^{2}(160 \mu \mathrm{m}: \mathrm{P}=0.037,240 \mu \mathrm{m}: \mathrm{P}=0.004,320 \mu \mathrm{m}$ : $\mathrm{P}=0.045)$, (g) dot plot showing the average lesion size in the aortic origin expressed as $\mu \mathrm{m}^{2} /$ section $\left(\right.$ Apoe $e^{-/} H s p g 2^{w t}$ treated with 108 vs Apoe ${ }^{-/-H s p g} 2^{w t}$ treated with isotype: $\mathrm{P}=0.026$, Apoe $e^{-/} H \operatorname{spg} 2^{w t}$ treated with isotype vs $A$ poe $e^{-/} H s p g 2^{d 3}$ treated with isotype: $\left.\mathrm{P}=0.028\right)$ and $(\mathbf{h})$ total plasma cholesterol. (f, $\mathbf{g}, \mathbf{h})$ All results show mean \pm s.e.m. of $\mathrm{n}=11$ Apoe $^{-/} H$ spg $2^{\text {wt }}$ treated with 108, $\mathrm{n}=10$ Apoe $^{-/} \mathrm{Hspg}^{\text {wt }}$ treated with isotype, $\mathrm{n}=12$ Apoe $^{-/-H s p g} 2^{d 3}$ treated with 108 and $\mathrm{n}=11$ Apoe ${ }^{-/} H s p g 2^{d 3}$ treated with isotype. ${ }^{*} \mathrm{P}<0.05$, $* * \mathrm{P}<0.01, * * * \mathrm{P}<0.001$, (1- Way ANOVA and Tukey's test, 2-Way ANOVA and Sidak's test). scale bars: (b) carotid 1 and 3; $100 \mu \mathrm{m}$, carotid 2; $20 \mu \mathrm{m}$ and coronary $50 \mu \mathrm{m}$, (c) $10 \mu \mathrm{m}$, (d) $5 \mu \mathrm{m}$, (e) $10 \mu \mathrm{m}$, (f) $200 \mu \mathrm{m}$.

Figure 3. Antibody targeting of APRIL at the BCMA/TACI binding site reduces

atherosclerosis in vivo. Apoe ${ }^{-/}$mice were treated biweekly for 10 weeks with a mixture consisting of either mouse anti-APRIL antibody (Apry-1-1) and Ctrl-Ig ( $\alpha$-APRIL group), or TACI-Ig and isotype IgG2b (TACI-Ig group), or isotype IgG2b and Ctrl-Ig (Ctrl group) and were fed an atherogenic diet for the last 8 weeks of the study. (a) Representative photomicrographs of H\&Estained aortic root lesions and dot plot of the average lesion size in the aortic origin expressed as $\mu_{\mathrm{m}}^{2} /$ section ( $\mathrm{n}=10$ Apoe $^{-/-}$; Ctrl, $\mathrm{n}=12$ Apoe $^{-/-}$; TACI-Ig, $\mathrm{n}=10$ Apoe $^{-/-} ; \alpha$-APRIL; P = 0.025).

Scale bar: $200 \mu \mathrm{m}$ (b) Representative photomicrographs of Sudan-VI stained aortas and dot plot of the quantification of en face atherosclerotic lesion size expressed as percentage of total aortic area ( $\mathrm{n}=9$ Apoe $^{-/} ;$Ctrl, $\mathrm{n}=12$ Apoe $^{--} ;$TACI-Ig, $\mathrm{n}=10$ Apoe ${ }^{-/} ; \alpha$-APRIL; P = 0.006). (c) HEK 293 wild-type cells were stained with Flag-ACRP-mAPRIL A88 (multimeric APRIL) that was 392 preincubated or not with mouse anti-APRIL antibody Apry-1-1 or heparin and analyzed by flow 393 cytometry. The results show that APRIL binds to HEK 293 wt cells in a heparin-inhibitable manner 394 as expected for binding to heparan sulfate proteoglycans, and that Apry-1-1 increases this binding. 395 Data are representative of two independent experiments performed in duplicates (error bars are 
smaller than symbols). All results show mean \pm s.e.m.. $* \mathrm{P}<0.05, * * \mathrm{P}<0.01$ (1- Way ANOVA and 397 Newman-Keuls test).

Figure 4. Levels of a non-canonical form of APRIL (nc-APRIL) in serum predict cardiovascular mortality in humans. (a) APRIL standard of c-APRIL specific ELISA was 401 depleted twice with beads coupled to a recombinant APRIL receptor (TACI-Ig) or to a control 402 receptor (TNFR2-Ig), or with beads coupled to an anti-APRIL monoclonal antibody (Aprily2) or 403 to an isotype-matched control (mIgG1), in the indicated combinations. Unbound fractions were 404 measured for APRIL using nc-APRIL specific (right) or c-APRIL specific ELISA (left). (b) 405 Recombinant flag-APRIL in native or unfolded states was depleted once with the indicated bead 406 combinations. Unbound fractions were analyzed by anti-flag Western blot. (c) Human serum from 407 a healthy individual was depleted twice with the indicated combinations of beads, then analyzed 408 for APRIL content with nc-APRIL specific (right) or c-APRIL specific ELISA (left). (d) Fc409 human APRIL (wt) (aa 98-233) and Fc-APRIL with C-term truncations of 1, 2, 3, or 4 amino acids 410 were transfected in HEK-293T cells, and S/N and cell extracts were analyzed by reducing WB. (e) 411 Fc-APRIL with or without C-term truncations were measured with a c-APRIL specific (left) and 412 a nc-APRIL specific ELISA (right) at $25 \mathrm{ng} / \mathrm{ml}$ and $125 \mathrm{ng} / \mathrm{ml}$ respectively. (f) S/N adjusted for 413 APRIL concentrations were tested for activity on BCMA:Fas reporter cells. For mock, same 414 volume as truncated APRIL was used. (g) Quantified c-APRIL was used as a standard in the c415 APRIL specific ELISA (left) and quantified purified nc-APRIL was used as a standard in the nc416 APRIL specific ELISA (middle). Using these standard curves, the concentration of c-APRIL and 417 nc-APRIL was measured by ELISA in sera of healthy individuals $(\mathrm{n}=8$, two-tailed paired Student $418 t$ test, $\mathrm{P}<0.001)$. Serum levels of nc-APRIL were associated with cardiovascular mortality in (h) 419 asymptomatic individuals included in the ICARAS study and (i) in symptomatic patients included 420 in the LURIC. Data are representative of $(\mathbf{a}, \mathbf{b}, \mathbf{c}, \mathbf{e})$ three and $(\mathbf{d}, \mathbf{g})$ two independent experiments. 421 (a, $, \mathbf{c}, \mathbf{e}, \mathbf{g})$ Results show mean \pm s.e.m. (h, i) see methods for the methodology of statistical 422 analysis. 


\section{METHODS}

\section{Mice, treatments and diets}

$426 \mathrm{Ldlr}^{-/-}$and Apoe $\mathrm{C}^{-/}$mice were bought from The Jackson Laboratories (USA). April/- mice were 427 provided by Genentech (USA). $\mathrm{Bcma}^{-/-}$mice were provided by Biogen (USA). $\mathrm{Ldlr}^{-/-}$April $\mathrm{pl}^{-/-}$mice 428 were generated by crossing $\mathrm{Ldlr}^{-/-}$and $\mathrm{April}^{-/}$mice. Hspg ${ }^{\mathrm{d} 3}$ sperm was purchased from the 429 Biocenter Oulu (University of Oulu) and mice were generated via in vitro fertilization of Apoe - $^{-/}$ 430 mice. All mice were on C57BL/6J background and were maintained either in the SPF facility of 431 the Medical University of Vienna (Austria) or of the University of Lausanne. Female Ldlr $^{-/}$April $^{-}$ 432 / and $\mathrm{Ldlr}^{-/} \mathrm{April}^{+/+}$littermate mice (13-15 weeks old) were fed an atherogenic diet $(0.2 \%$ 433 cholesterol, 21\% fat; E15721-347 bought from Ssniff, Germany) for 10 weeks. For bone marrow 434 transplant experiments, male $L d l r^{-/}$mice (10 weeks old) were irradiated (10.5 Gray) then 435 reconstituted by i.v. injection with $7 \times 10^{6}$ bone marrow cells isolated from $\mathrm{Bcma}^{+/+}$and $\mathrm{Bcma}^{-/-}$ 436 donors. All mice could recover for four weeks and then they were placed on atherogenic diet for 43710 weeks. Female Apoe $e^{-/-}$mice ( 8 weeks old) were injected biweekly for 10 weeks with $5 \mathrm{mg} / \mathrm{kg}$ 438 of a mixture consisting of either mouse anti-APRIL antibody (Apry-1-1; AG-27B-0001PF, 439 purchased from Adipogen, Liestal, Switzerland) and Ctrl-Ig, or TACI-Ig and isotype IgG2b 440 (LEAF; Biolegend), or isotype IgG2b and Ctrl-Ig (all reagents were provided by Merck KGaA, 441 Germany). In addition, all Apoe ${ }^{-/-}$mice were fed an atherogenic diet for the last 8 weeks of the 442 study. Female littermate Apoe ${ }^{-/-} H s p g 2^{\text {wt }}$ (data from Apoe ${ }^{-/-} H s p g 2^{\mathrm{wt} / \mathrm{wt}}$ and Apoe $e^{-/-} H s p g 2^{\mathrm{wt} / \mathrm{d} 3}$ mice 443 were pooled because no differences were observed between the two genotypes) and Apoe $e^{-/-} H \operatorname{spg} 2^{\mathrm{d} 3}$ 444 mice (8 weeks old) were injected biweekly for 7 weeks with $5 \mathrm{mg} / \mathrm{kg}$ of a either a blocking mouse 445 anti-mouse APRIL antibody (108; Extended Data fig. 5a-c; available from Adipogen under 446 Centotto-1; AG-20B-0083) or an isotype IgG1 (Ultra LEAF; Biolegend), and mice were fed an 447 atherogenic diet for the last 6 weeks of the study.

448 Multimeric human and mouse flag-ACRP30-APRIL fusion proteins (referred to as flag-APRIL) 449 were from Adipogen (human: AG-40B-0017-C010, mouse: AG-40B-0089-C010). Wild-type $450 \mathrm{C} 57 \mathrm{BL} / 6 \mathrm{~J}$ mice were injected intraperitoneally in Dulbecco's PBS (DPBS) with either $1 \mu \mathrm{g}$ of 451 mouse multimeric flag-APRIL (Adipogen) or a mixture of $1 \mu \mathrm{g}$ flag-APRIL and $10 \mu \mathrm{g}$ mouse anti452 APRIL antibody (Apry-1-1, AG-27B-0001PF, Adipogen). Blood was collected one, three, and six 453 hours later and flag-APRIL was quantified as described below. 
454 Mice were matched for sex and age in all studies. All experimental studies were approved by the 455 Animal Ethics Committee of the Medical University of Vienna (Austria) 66.009/0281$456 / \mathrm{WFV} / 3 \mathrm{~b} / 2014,66.009 / 0223-\mathrm{WF} / \mathrm{II} / 3 \mathrm{~b} / 2014$ and $66.009 / 0398-\mathrm{V} / 3 \mathrm{~b} / 2019$ or have been regulated 457 under the Animals (Scientific Procedures) Act 1986 Amendment Regulations 2012 following 458 ethical review by the University of Cambridge Animal Welfare and Ethical Review Body (PPL 459 PA4BDF775).

Anti-APRIL antibodies and biologicals

Anti-hAPRIL antibodies Mahya-1 (mouse IgG1, AG-20B-0078PF-C100), 110 (mouse IgG1) and His-tagged BAFF 60-mer (AG-40B-0112-C010) were provided by Adipogen. Aprily1, Aprily2, Aprily3, Aprily5, Aprily6, Aprily8, Aprily9 and Aprily10 (mouse IgG1) were custom-made by NanoTools (Teningen, Germany). Anti-EDA antibody EctoD1 (mIgG1) was as described ${ }^{34}$. The hybridoma for anti-rat SHH-5E1 (mouse IgG1) developed by T.M. Jessell and S. Brenner-Morton was obtained from the Developmental Studies Hybridoma Bank, maintained at the University of Iowa. Atacicept (TACI-Fc) was provided by Merck (KGaA). Etanercept (TNFR2-Fc) was purchased from the pharmacy of Lausanne University Hospital (CHUV). Bovine serum albumin was from Thermo Scientific (Cat\# 23209).

Atherosclerotic lesion size (staining Hematoxylin and Eosin), necrotic core content (staining 474 Hematoxylin and Eosin or DAPI) and collagen content (staining with Sirius Red) were evaluated 475 by computer-assisted image analysis using Adobe Photoshop Elements 6.0 and Fiji software in 476 aortic root cross paraffin-embedded ( $n=9 /$ mouse) or OCT-preserved sections ( $n=6 /$ mouse) with 50 477 or $80 \mu \mathrm{m}$ distance that were collected starting with the appearance of all 3 valve leaflets as described previously ${ }^{12}$.

480 Quantification of total cholesterol and triglycerides in mouse plasma

481 EDTA blood was collected from the vena cava at the time of sacrifice in MiniCollect purple cap 482 TUBE (Greiner Bio-One). Blood was centrifuged at $1000 \mathrm{~g}$ for $30 \mathrm{~min}$ at room temperature. 483 Plasma total cholesterol and triglycerides were measured in an ISO 15189 accredited medical 
laboratory on Beckman Coulter AU5400 (Beckman Coulter) or Roche Cobas 8000 (Roche)

485 instruments.

\section{Flow cytometry}

488 Flow cytometry analysis of splenic and peritoneal B cell subsets was performed as described 489 previously ${ }^{24,35}$ using directly conjugated antibodies on single cell suspensions of freshly isolated 490 spleens and peritoneal cells. Splenic T cells were identified using anti-CD3 PE (clone 145-2C11; 491 eBiosciences), anti-CD4 FITC (clone GK1.5; eBiosciences), anti-CD8 APC (clone 53-6.7; 492 eBiosciences). Peripheral blood from the vena cava was diluted with PBS $+2 \%$ dextran (Sigma) 493 and incubated for at least $30 \mathrm{~min}$ at $37^{\circ} \mathrm{C}$ to concentrate the RBCs at the bottom of the tube. The 494 upper clear phase was collected, and cells were incubated with blocking anti-CD16/32 antibody 495 (clone 93; eBiosciences). Peripheral monocytes were identified by staining with anti-CD11b-APC 496 (clone M1/70; eBiosciences), anti-Ly6C-FITC (clone HK1.4; Biolegend) and anti-Ly6G-PE 497 (clone 1A8; Biolegend) as described previously ${ }^{24}$.

498 HUVECs were stained in DPBS (Sigma) supplemented with 10\% FBS (Gibco) with $0.5 \mu \mathrm{g} / \mathrm{ml}$ of 499 either murine flag-tagged $\mathrm{APRIL}^{4}$ or amino-terminal flag-tagged bacterial alkaline phosphatase 500 (BAP) fusion protein (Sigma) for $30 \mathrm{~min}$ at $4^{\circ} \mathrm{C}$, followed by staining with $1 \mu \mathrm{g} / \mathrm{ml}$ of anti-flag $501 \mathrm{M} 2$ antibody (Sigma) for $20 \mathrm{~min}$ at $4^{\circ} \mathrm{C}$. Then cells were stained with $1 \mu \mathrm{g} / \mathrm{ml}$ of a biotinylated rat 502 anti-mouse IgG1 (cloneA85-1; BD Biosciences) for $20 \mathrm{~min}$ at $4^{\circ} \mathrm{C}$ and streptavidin-APC 503 (eBiosciences) for 20 minutes at $4^{\circ} \mathrm{C}$.

504 HEK 293 wild-type cells were stained for 20 min on ice with $50 \mu 1$ of flag-ACRP-mAPRIL A88 (DYKDDDDKGPGQVQLH-[aa 18-111 of mACRP30]-LQ-[aa 88-232 of mAPRIL]) in FACS buffer (PBS+ 5\% FCS) at $1000 \mathrm{ng} / \mathrm{ml}$ final and 5-fold dilutions, either alone or after preincubation

507 with Apry-1-1 at $25 \mu \mathrm{g} / \mathrm{ml}$, or after preincubation with liquemine (DrossaPharm, Basel, 508 Switzerland) at $10 \mathrm{IU} / \mathrm{ml}$ final concentration. Then cells were stained with biotinylated anti-flag 509 M2 (1:500; Sigma F9291) followed by PE-coupled streptavidin (1:500; eBiosciences).

510 HEK 293 wild-type cells were stained with 5\% rat serum in PBS+0.5\% BSA (buffer) for 15 min 511 on ice. After washing with buffer, cells were incubated with 1, or 3 or $6 \mu \mathrm{g} / \mathrm{ml}$ of Fc-human 512 APRIL-A88 for $30 \mathrm{~min}$ on ice. After washing cells were incubated with human native LDL 513 (generated as described previously ${ }^{36}$ ) at 25 or 75 or $225 \mu \mathrm{g} / \mathrm{ml}$ for $30 \mathrm{~min}$ on ice. Then, cells were 514 incubated with 4\% PFA for $20 \mathrm{~min}$ at room temperature. After washing with buffer, cells were 
515 stained with the monoclonal MB47 antibody (provided by Dr. Witztum's lab UCSD) at $0.5 \mu \mathrm{g} / \mathrm{ml}$ 516 for $20 \mathrm{~min}$ on ice, followed by an anti-mIgG2a-biot (rat; clone R19-15; BD) for $15 \mathrm{~min}$ on ice and 517 PE-coupled streptavidin for $15 \mathrm{~min}$ on ice (1:400; eBiosciences). Data were acquired on a FACS 518 Calibur (BD) or FACS Accuri C6 (BD) or LSRFortessa (BD) and were analysed using Flow Jo 519 software 7.6 (Tree Star).

\section{Total antibody quantification in plasma by ELISA}

522 Total IgM, IgG1, IgG2b, IgG2c, IgG3 and IgA antibodies in plasma were measured by ELISA. 523 Briefly, 96-well white round-bottomed MicroFluor microtiter plates (Thermo Lab systems) or 524 immunoGrade, 96-well, PS Standard plates (781724; Brand) were coated with either an anti-mouse 525 IgM (Sigma; M8644; at $2 \mu \mathrm{g} / \mathrm{ml}$ ) or anti-mouse IgG1 (Biolegend; RMG1-1; at $2 \mu \mathrm{g} / \mathrm{ml}$ ) or antimouse IgG2b (BD Biosciences; R9-91; at $3 \mu \mathrm{g} / \mathrm{ml}$ ) or anti-mouse IgG2c (STAR135; at $1 \mu \mathrm{g} / \mathrm{ml}$ ) 527 or anti-mouse IgG3 (BD Biosciences; R2-38; at $4 \mu \mathrm{g} / \mathrm{ml}$ ) or anti-mouse IgA (BD Biosciences; $528 \mathrm{C} 10-3$; at $3 \mu \mathrm{g} / \mathrm{ml}$ ) in PBS overnight and then washed 3 times with PBS and blocked with Tris529 buffered saline containing 1\% BSA (TBS/BSA) for 1 hour at room temperature. Then wells were 530 washed with either PBS (plates for IgM, IgG2b and IgG2c) or PBS supplemented with $0.05 \%$ 531 Tween (plates for IgG1, IgG3 and IgA), and diluted mouse plasma was added in TBS/BSA to the 532 wells and incubated overnight at $4^{\circ} \mathrm{C}$. Plates were washed, and bound Igs were detected with either 533 an anti-mouse IgM antibody conjugated to alkaline phosphatase (Sigma; A9688), or the 534 biotinylated forms of anti-mouse IgG1 (BD Biosciences; A85-1) or anti-mouse IgG2b (BD 535 Biosciences; R12-3), or anti-mouse IgG2c (JIR 115-065-208) or anti-mouse IgG3 (BD 536 Biosciences; R40-82) or anti-mouse IgA (BD Biosciences; C10-1). Wells were washed again as 537 before and neutravidin conjugated to alkaline phosphatase was added where appropriate. Then, 538 wells were washed again as before and rinsed once with distilled water, and $25 \mu 1$ of a $30 \%$ 539 LumiPhos Plus solution in $\mathrm{dH}_{2} \mathrm{O}$ (Lumigen Inc) was added. After 75 min, the light emission was 540 measured with a Synergy 2 luminometer (BIO-TEK) and expressed as RLU per $100 \mathrm{~ms}$.

541 For antibody isotyping, ELISA plates were coated with purified antibodies at $2 \mu \mathrm{g} / \mathrm{ml}$ in PBS, 542 blocked, and incubated with horse radish peroxidase-coupled anti-IgA (\#1040-05), anti-IgM 543 (\#1020-05), anti-IgG1 (\#1070-05), ant-IgG2a (\#1080-05), anti-IgG2b (\#1090-05) or anti-IgG3 544 (\#1100-05) (all from Southern Biotech) at 1:4000 in ELISA buffer for 1 hour at $37^{\circ} \mathrm{C}$ and developed 
with $o$-phenylenediamine (OPD) - $\mathrm{H}_{2} \mathrm{O}_{2}$ substrate (Sigma-Aldrich, P9187). Reaction was terminated

546 with acid and plates were read at $492 \mathrm{~nm}$.

\section{Flag-APRIL quantification by ELISA}

549 To quantify flag-APRIL in plasma, ELISA plates (maxi-sorp NUNC) were coated with $2 \mu \mathrm{g} / \mathrm{ml}$ in $55070 \mu \mathrm{l}$ final volume of an anti-flag antibody (Biolegend; clone L5) overnight at $4^{\circ} \mathrm{C}$. Thereafter, 551 wells were blocked with PBS $+1 \%$ BSA for 1 hour at room temperature. Plasma samples were 552 added to the wells and incubated for 2 hours at room temperature. Bound flag-APRIL was detected 553 with a mouse anti-APRIL biotinylated antibody (clone 2C8; Extended Data fig. 5 a, b, d) used at $5541 \mu \mathrm{g} / \mathrm{ml}$ and incubated for 1 hour at room temperature. Then streptavidin-HRP (R\&D) was added 555 to the samples for $30 \mathrm{~min}$ at room temperature. Finally, 3,3',5,5' tetramethylbenzidine was added 556 for $15 \mathrm{~min}$. Reaction was terminated with acid and optical density was measured at $450 \mathrm{~nm}$ in a 557 luminometer VICTOR X3 (PerkinElmer).

558 To quantify the interaction of APRIL with heparan sulfate proteoglycan 2 (HSPG2), ELISA plates 559 (maxi-sorp NUNC) were coated with $1 \mu \mathrm{g} / \mathrm{ml}$ of HSPGs from the basement membrane of 560 Engelbreth-Holm-Swarm mouse sarcoma (Sigma) overnight at $4^{\circ} \mathrm{C}$. Thereafter, wells were 561 blocked with PBS $+1 \%$ BSA for 1 hour at room temperature and mouse multimeric flag-APRIL 562 (AG-40B-0089, Adipogen) was added at $1 \mu \mathrm{g} / \mathrm{ml}$ for two hours at room temperature. Bound flag563 APRIL was detected with an anti-flag conjugated to FITC (Sigma, clone: M2). Fluorescence was 564 measured in a luminometer VICTOR X3 (PerkinElmer).

\section{Immunofluorescence analysis}

567 Primary HUVECs were cultured in EGM-2 Bullet kit Endothelial Cell Growth Medium without 568 heparin (Lonza) in chambered coverslips (Ibidi) until a confluent monolayer was formed. Then 569 cells were washed with PBS with $\mathrm{Ca}^{2+}$ once and fixed with 4\% paraformaldehyde for $20 \mathrm{~min}$. Then 570 cells were carefully washed three times with DPBS (Sigma) and were incubated with $50 \mathrm{mM}$ 571 ammonium chloride for $10 \mathrm{~min}$ at room temperature. After washing as above cells were incubated 572 with $0.5 \mu \mathrm{g} / \mathrm{ml}$ of either human or murine multimeric flag-APRIL (Adipogen). For competition 573 experiments, staining with flag-APRIL was also performed in presence of $5 \mathrm{IU} / \mathrm{ml}$ heparin 574 (National Veterinary Services LTD, UK). An anti-flag antibody (clone: M2; Sigma) conjugated to 575 FITC was used to detect flag-APRIL. 
576 Paraffin embedded sections of human coronary and carotid artery specimens with or without 577 atherosclerotic plaques obtained at necropsy and anonymized were provided by Dr. Patrick 578 Bruneval (Paris Transplant Group, France). Sections were rehydrated by incubation first in Xylene 579 (three times; each three minutes), then in ethanol (100\%, 96\%, 90\% and 70\%; each for three 580 minutes) and finally in $\mathrm{dH}_{2} \mathrm{O}$ for three minutes. Then antigen retrieval (Dako) was performed for 5811 hour in a water bath at $100^{\circ} \mathrm{C}$. Sections were then permeabilized in $0.1 \%$ Triton + citric acid for $58220 \mathrm{~min}$ and were blocked with 5\% goat and/or donkey serum diluted in assay buffer (PBS $+2.5 \%$ $583 \mathrm{BSA}+2 \mathrm{mM}$ EDTA $+0.01 \%$ sodium azide) for $30 \mathrm{~min}$. Sections were then stained with a mouse anti-human APRIL (Aprily-2), an anti-HSPG2 (clone: A7L6; Merck Millipore) and an anti-CD31 (clone: EPR3094; Abcam) in blocking buffer overnight at $4^{\circ} \mathrm{C}$. Next, sections were stained with a goat anti-rat AF488, goat anti-rabbit AF647 and goat anti-mouse AF555 or goat anti-mouse AF488, donkey anti-rat AF555 and goat and anti-rabbit AF647 (all from Life Technologies) where appropriate, in assay buffer for 3 hours at room temperature.

589 Paraffin embedded sections of mouse aortic root with atherosclerotic plaques rehydrated by 590 incubation first in Xylene (three times; each three min), then in ethanol (100\%, 96\%, 90\% and $59170 \%$; each for three min) and finally in $\mathrm{dH}_{2} \mathrm{O}$ for three min. Then antigen retrieval (Dako) was 592 performed for 1 hour in water-bath at $100^{\circ} \mathrm{C}$. Sections were blocked with $5 \%$ donkey serum or a 593 mixture of $5 \%$ mouse serum and $2.5 \mu \mathrm{g} / \mathrm{ml}$ of anti-mouse CD16/32 antibody (clone 93; Invitrogen) 594 diluted in assay buffer (PBS $+2.5 \%$ BSA $+2 \mathrm{mM}$ EDTA $+0.01 \%$ sodium azide) for $30 \mathrm{~min}$. 595 Sections were then stained with either a rat anti-mouse Mac-2 (M3/38; Biolegend), or a rabbit 596 polyclonal anti-ApoB (ab20737; Abcam), or a mouse anti-aSMC antibody conjugated to Cy-3 in 597 blocking buffer overnight at $4^{\circ} \mathrm{C}$. Next, sections were stained with either a donkey anti-rat AF488 598 or a donkey anti-rabbit AF555 (all from Life Technologies) in assay buffer for 3 hours at room 599 temperature.

600 For the LDL binding competition assay, cryosections (10 $\mu \mathrm{m}$ thickness) of a sham operated mouse 601 carotid artery from a model of neointima hyperplasia as described previously ${ }^{37}$ were fixed in 602 acetone for $20 \mathrm{~min}$ at $-20^{\circ} \mathrm{C}$ and then were incubated with $10 \mu \mathrm{g} / \mathrm{ml}$ of murine multimeric flag603 APRIL in assay buffer (PBS $+2.5 \%$ BSA $+2 \mathrm{mM}$ EDTA $+0.01 \%$ sodium azide) or only with 604 assay buffer overnight at $4^{\circ} \mathrm{C}$. After washing in DPBS (Sigma), sections were incubated with 100 $605 \mu \mathrm{g} / \mathrm{ml}$ of human native LDL (isolated from healthy donors) for two hours at room temperature. 606 Sections were then fixed in 4\% PFA for $15 \mathrm{~min}$ at room temperature and then blocked with 5\% 
607 donkey serum in assay buffer. Sections were then stained with a rabbit anti-ApoB antibody 608 (Abcam; ab20737) for 1.5 hours at room temperature and then with a donkey anti-rabbit conjugated 609 to AF555 (Life Technologies) for 1 hour at room temperature.

610 Mouse multimeric flag-APRIL was detected with an anti-flag PE (Biolegend; clone: L5) or a 611 mouse anti-mouse APRIL biotinylated antibody (clone: 2C8) and streptavidin PE (Biolegend) in

612 sections that were blocked with $5 \mu \mathrm{g} / \mathrm{ml}$ of anti-CD16/32 antibody (Thermo Fisher Scientific; 613 clone: 93). For competition experiments with heparin, flag-APRIL was mixed with $30 \mathrm{IU} / \mathrm{ml}$ 614 heparin (National Veterinary Services LTD, UK) prior to the addition on the section.

615 HSPG2 in murine carotid arteries was detected with an anti-HSPG2 antibody (clone: A7L6; Merck 616 Millipore) and donkey anti-rat AF555 (Life Technologies). Finally, all samples were stained with 617 Hoechst or DAPI solution for $8 \mathrm{~min}$ at room temperature. Epifluorescence or confocal microscopy 618 were performed using a Leica CTR6500 or Axio Imager M2 or Carl Zeiss LSM 700 (ZEISS) or 619 LSM780 (ZEISS) microscope and Zen software. The plugin JACoP in Fiji was used to calculate 620 the Pearson`s Coefficient. The antibodies were used at $1-6 \mu \mathrm{g} / \mathrm{ml}$ where appropriate.

\section{Coupling of proteins to Sepharose beads}

$6235 \mathrm{mg}$ of TACI-Fc or TNFR2-Fc or $2 \mathrm{mg}$ of Aprily1, Aprily2 ${ }^{4}$, Aprily3, Aprily5, Aprily6, Aprily8, 624 Aprily9 or Aprily10 or EctoD1 antibodies or mouse IgG1 5E1 anti-rat SHH were coupled to $1 \mathrm{ml}$ 625 of NHS-activated Sepharose beads (GE Healthcare, \#90-1004-00). Briefly, beads stored in 626 isopropanol were centrifuged for $5 \mathrm{~min}$ at $2400 \mathrm{~g}$ and washed three times with $1 \mathrm{ml}$ of ice-cold 1 $627 \mathrm{mM} \mathrm{HCl} .1 \mathrm{ml}$ of TACI-Fc or TNFR2-Fc at $5 \mathrm{mg} / \mathrm{ml}$ or Aprily or anti-rat SHH antibodies at 2 $628 \mathrm{mg} / \mathrm{ml}$ in $0.2 \mathrm{M} \mathrm{NaHCO}_{3}, 0.5 \mathrm{M} \mathrm{NaCl}, \mathrm{pH} 8.3$ were added to the beads and incubated for $30 \mathrm{~min}$ 629 at room temperature. Beads were then washed three times with $1 \mathrm{ml}$ of ethanolamine buffer $(0.5$ $630 \mathrm{M}$ ethanolamine, $0.5 \mathrm{M} \mathrm{NaCl}, \mathrm{pH} 8.3)$ and then three times with $1 \mathrm{ml}$ of acetate buffer $(0.1 \mathrm{M}$ 631 sodium acetate, $0.5 \mathrm{M} \mathrm{NaCl}, \mathrm{pH}$ 4) and again $3 \mathrm{ml}$ of ethanolamine buffer. Beads were incubated 632 for $30 \mathrm{~min}$ at room temperature in ethanolamine buffer, then washed three times with acetate 633 buffer, then ethanolamine buffer, then acetate buffer and finally PBS. Beads were stored in $1 \mathrm{ml}$ 634 of PBS $0.05 \%$ azide at $4{ }^{\circ} \mathrm{C}$.

635

636 Production and quantification of Flag-tagged or Fc-tagged APRIL 
637 Flag-hAPRIL, Flag-mAPRIL, Flag-mAPRIL (+Ala112) or Fc-hAPRIL with deletion or 638 truncations at the C-terminus were transiently transfected in $293 \mathrm{~T}$ cells using PEI ${ }^{38}$ in serum-free 639 OptiMEM medium in $10 \mathrm{~cm}$ plates. After seven days, the supernatants of Fc-tagged constructs 640 were collected, and the cells were washed in PBS and lysed in $200 \mu 1$ of SDS containing lysis 641 buffer plus DTT and boiled for $5 \mathrm{~min}$ at $95^{\circ} \mathrm{C}$ to be loaded on a SDS-PAGE. Also, seven days after 642 the transfection, the supernatants of Flag-tagged APRIL constructs were affinity-purified on 643 TACI-Fc-Sepharose (see section "Coupling of proteins to Sepharose beads"), eluted with $50 \mathrm{mM}$ 644 of Na-citrate $\mathrm{pH} 2.7$ and immediately neutralized with Tris- $\mathrm{HCl} \mathrm{pH}$ 9. Buffer was exchanged for 645 PBS using a $30 \mathrm{kDa}$ cut off centrifugal device (Millipore). Purified proteins were quantified by 646 absorbance at $280 \mathrm{~nm}$ using $1 \mathrm{mg} / \mathrm{ml}$ extinction coefficients of 0.857 and 1.092 for Flag-hAPRIL 647 and Flag-mAPRIL respectively. The concentration of Flag-hAPRIL was also determined by 648 densitometric quantification using the Fiji software ${ }^{39}$ of Coomassie-blue-stained SDS-PAGE gels 649 using His-BAFF and bovine serum albumin (BSA) as standards. cAPRIL was produced by 650 affinity-purification of conditioned supernatants containing Flag-hAPRIL on TACI-Fc-Sepharose 651 beads, followed by depletion on Aprily2-Sepharose beads. Conversely, ncAPRIL was affinity 652 purified on Aprily2-Sepharose beads followed by depletion on TACI-Fc-Sepharose beads. 653 Denatured Flag-hAPRIL was prepared by mixing $1 \mu \mathrm{g}$ of purified Flag-hAPRIL with $1 \mu \mathrm{l}$ of 654 denaturation buffer from PNGase F kit (Biolabs, P0704S lot: 0431703) and $8 \mu 1$ of $\mathrm{H}_{2} \mathrm{O}$ and heated 655 for $10 \mathrm{~min}$ at $100^{\circ} \mathrm{C}$. Then the mix was neutralized with $2 \mu 1$ of $10 \% \mathrm{NP}-40$ and $2 \mu 1$ of $10 \mathrm{x}$ glyco656 buffer 2 from the same kit.

658 Size exclusion chromatography

$659100 \mathrm{ng}$ of Adipogen APRIL (h) ELISA kit standard which was depleted either on TACI-Fc- or 660 Aprily2-Sepharose beads and their eluates were size-fractionated at a flow rate of $0.7 \mathrm{ml} / \mathrm{min}$ on a 661 Superdex S200 Increase HR 10/30 column (GE Healthcare) equilibrated in PBS, $10 \mu \mathrm{g} / \mathrm{ml} \mathrm{BSA \text {, }}$ 662 with online absorbance monitoring at $280 \mathrm{~nm}$ and $1 \mathrm{ml}$ fraction collection. Fractions were tested 663 in Adipogen and Invitrogen ELISA kits. The column was calibrated with $100 \mu 1$ of a mixture of 664 the following proteins, each at $1.4 \mathrm{mg} / \mathrm{ml}$, except ferritin at $0.14 \mathrm{mg} / \mathrm{ml}$, with sizes of: 669 665 (thyroglobulin), 440 (ferritin), 158 (aldolase), 13.7 (ribonuclease A), all from GE Healthcare), 67 666 (bovine serum albumin), 43 (ovalbumin), 29 (carbonic anhydrase), and $6.5 \mathrm{kDa}$ (aprotinin) (all 667 from Sigma-Aldrich). 


\section{SDS-PAGE}

670 SDS-PAGE and western blot (using Aprily2 at $0.5 \mu \mathrm{g} / \mathrm{ml}$ ) were performed under reducing 671 conditions according to standard procedures and revealed by WesternBright ECL spray 672 (Advansta). Coomassie blue staining was performed with a semidry iD Stain System 673 (Eurogentech).

\section{HEK 293T, Jurkat BCMA:Fas-2309 cl13 and U937 cells}

676 HEK 293T and histiocytic lymphoma U937 cells were obtained form late Dr. Jürg Tschopp 677 (University of Lausanne). HEK 293T cells were cultured in DMEM plus 10\% fetal calf serum. 678 Jurkat BCMA:Fas-2309 cl13 cells were cultured in RPMI plus 10\% fetal calf serum as reported 679 previously ${ }^{40}$. U937 cells and U937 cells deficient for BAFF were as described ${ }^{41}$. U937 cells 680 deficient for APRIL or deficient for BAFF and APRIL were generated by lentiviral transduction 681 of a CRISPR/Cas9-expression vector carrying a hAPRIL gRNA as described, except that the 682 following annealed oligonucleotides were used for cloning (5'683 CACCGAGGATATGGTGTCCGAATCC-3' and 5' - AAACGGATTCGGACACCATATCCTC$\left.6843^{\prime}\right)^{41}$. U937 cells were cultured in RPMI supplemented with $10 \%$ fetal calf serum.

\section{Human Umbilical Vein Endothelial Cell (HUVEC) culture}

687 Primary HUVECs were provided by Dr. Marion Gröger (Medical University of Vienna; Austria) 688 or Dr. Sanjay Sinha's group (University of Cambridge; UK). Cells were cultured in either EGM-

6892 Bullet kit Endothelial Cell Growth Medium without heparin (Lonza) or 90\% IMDM-Medium 690 supplemented with 10\% FBS, 1\% Glutamin, 1\% Pen-Strep and 10ml LSGS (Gibco). Cells were 691 used up to the $5^{\text {th }}$ passage.

692

\section{Human umbilical artery smooth muscle cells}

694 Human Umbilical artery smooth muscle cells were a gift of Dr. Peter Petzelbauer's lab (Medical 695 University of Vienna). Cells were cultured in Smooth Muscle Cell Growth Medium 2 ( Promocell). 696 For gene expression analysis, cells were cultured in 24-well plate (ThermoFisher) until 80-90\% 697 confluency and then were stimulated with either human TNF (eBiosciences) at 100ng/ml or native 
human LDL at $50 \mu \mathrm{g} / \mathrm{ml}$ or $\mathrm{CuOx}-\mathrm{LDL}$ at $50 \mu \mathrm{g} / \mathrm{ml}$ for 4 hours. Native human LDL and CuOxLDL were generated as described previously ${ }^{36}$.

\section{Cytotoxicity assay}

702

Cytotoxicity assays using BCMA:Fas cells were performed as described ${ }^{42}$. Briefly, flat-bottomed

96 well plates with 3 to $4 \times 10^{4}$ reporter cells per well in a final volume of $100 \mu 1$ of RPMI plus $10 \%$ of fetal calf serum were used in the presence of the indicated concentrations of flag-hAPRIL or Flag-mAPRIL, and 100 ng/ml of TACI-Fc, Apry-1-1 or mAb 108. After an overnight incubation at $37^{\circ} \mathrm{C}, 5 \% \mathrm{CO}_{2}$, cell viability was monitored with a colorimetric (PMS/MTS) test.

\section{Total RNA extraction, cDNA synthesis and Real-time PCR analysis}

Total RNA was extracted from cells with the peqGold total RNA kit (Peqlab) and cDNA was synthesized using the High-capacity cDNA reverse transcription kit (Applied Biosystems). Quantitative Real-time SYBR green based PCR (Peqlab) was performed with the KAPA SYBR green FAST BioRad icycler kit (Peqlab) on a BioRad CFX96 Real-time system. 36 B4 and 18S were used as reference genes. Data were analysed using the ddCT method.

\section{Primer list:} mouse Bcma forward: 5- ATCTTCTTGGGGCTGACCTT-3 mouse Bcma reverse: 5- CTTTGAGGCTGGTCCTTCAG -3 $36 B 4$ forward: 5-AGGGCGACCTGGAAGTCC-3 36B4 reverse: 5-CCCACAATGAAGCATTTTGGA-3 human Tnfsfl3 forward: 5- ATGGGTCAGGTGGTGTCTCG-3 human Tnfsf13 reverse: 5-TCCCCTTGGTGTAAATGGAAGA-3 human il-6 forward: 5- CAGGAGAAGATTCCAAAGAT-3 human il-6 reverse: 5- CTCTTGTTACATGTCTCCTT-3 human $18 S$ forward: 5- GTAACCCGTTGAACCCCATT-3 human $18 S$ reverse: 5- CCATCCAATCGGTAGTAGCG-3

\section{RNA sequencing and data analysis}

Aortas were isolated from C57BL/6 males. For ex vivo samples, tissues were immediately transferred to RNAlater followed by isolation of ascending aorta (AA) and descending thoracic aorta (DT) segments before manual removal of the adventitial and endothelial cell layers. The cleaned medial layer from 3-5 animals was then lysed in Trizol (Thermo-Fisher), RNA isolated and cleaned on a RNeasy column (Qiagen). In vitro cultured VSMC samples were isolated from enzymatically dispersed VSMCs that had been cultured for 4-5 passages in DMEM supplemented 
733 with $10 \%$ fetal calf serum, glutamine and penicillin. Sequencing libraries were generated from 550

734 ng quality-assessed total RNA (RNA integrity number [RIN] 7.8-9) using the TruSeq Stranded

735 mRNA Library Prep Kit (Illumina) and sequenced using HiSeq (Illumina).

736 Data analysis: Raw sequencing reads were quality controlled using FastQC v0.11.3

737 (https://www.bioinformatics.babraham.ac.uk/projects/fastqc/) and trimmed using the Trim Galore

738 v0.4.1 wrapper (https://www.bioinformatics.babraham.ac.uk/projects/trim_galore/). Reads were

739 then aligned to the GRCm38 mouse reference genome using Tophat v2.0.12 (Trapnell et al 2009).

740 Reads with a minimum map quality of 20 were imported into Seqmonk 1.45 .4

741 (http://www.bioinformatics.babraham.ac.uk/projects/seqmonk) for quantitation using the RNA-

742 seq quantitation pipeline, and visualisation. Data is available form GEO, GSE117963: from

743 VSMCs from the aortic arch and descending thoracic aorta and GSE17858 (from mouse

744 primary VSMCs that were stored in Trizol after isolation or had been cultured for 4-5 passages

745 until the analysis

747 Surface Plasmon Resonance

748 For the Biacore measurements, a Biacore X100 system was used. Biotinylated heparin at a 749 concentration of $1.5 \mu \mathrm{g} / \mathrm{ml}$ (Sigma-Aldrich B9806-10MG) was coupled to a Streptavidin Sensor 750 Chip SA (Cytiva BR100032) as the ligand, reaching a response of 152.2 RU. All measurements 751 were performed in PBS as general buffer. The different purified proteins (analytes) were tested in 752 single-cycle Kinetics/Affinity assay, preceded by a priming and a startup cycle with buffer. Protein 753 solutions were prepared as a $3 \mathrm{x}$ dilution series in PBS going down from $1000 \mathrm{nM}$ $754(1000 / 333 / 111 / 37 / 12.3 \mathrm{nM})$, with $70 \mathrm{sec}$ contact time, $600 \mathrm{sec}$ disscociation time, and $30 \mathrm{sec}$ 755 regeneration contact time. The chip was regenerated using a $500 \mathrm{mM} \mathrm{NaCl}, 25 \mathrm{mM} \mathrm{NaOH}$ 756 solution. Results were analyzed using the Biacore X100 Evaluation software version 2.0.1 Plus

757 Package. Stable response was measured just before injection of the next higher concentration (150 758 sec after injection stop, time window $15 \mathrm{sec}$ ). $\mathrm{K}_{\mathrm{D}-\mathrm{v}}$ alues were calculated using the Steady State 759 affinity model. Values of the stable response at different concentrations were exported and plotted 760 as a binding curve using GraphPad Prism version 8.4.0 for Mac. 
HUVECs: HUVECs were cultivated in $10 \mathrm{~cm}$ dishes in 90\% IMDM-Medium supplemented with 10\% FBS, 1\% Glutamine, 1\% Pen-Strep and 10ml LSGS (Gibco) until they reached 90\% confluency. Then media was removed, and cells were stimulated (in duplicates) with $0.5 \mu \mathrm{g} / \mathrm{ml}$ of either mouse flag-tagged APRIL ${ }^{4}$ or amino-terminal flag-tagged BAP protein (Sigma) as control bait for $30 \mathrm{~min}$ at $37^{\circ} \mathrm{C}$. At the end of the stimulation cells were washed three times with DPBS (Sigma) and on-plate cell lysis was performed with immunoprecipitation buffer (50 mM Tris, 150 $\mathrm{mM} \mathrm{NaCl}, 1 \%$ NP-40, 5 mM EDTA, 5 mM EGTA complemented with $5 \mathrm{mM}$ PMSF and protease inhibitor cocktail (Sigma)) for 20 min at $4{ }^{\circ} \mathrm{C}$. Lysates were cleared of non-lysed particles by centrifugation and protein concentration was determined by bicinchoninic acid (BCA) assay (Pierce). $750 \mu \mathrm{g}$ of each lysate were incubated with $20 \mu \mathrm{l}$ of washed anti-flag M2 bead gel (Sigma) and incubated for 4 hours at $4^{\circ} \mathrm{C}$ with gentle rotation. Supernatants were removed, and beads were washed 3 times with TBS and proteins were eluted twice with $100 \mathrm{mM}$ glycine $\mathrm{pH} 3.0$ for $5 \mathrm{~min}$ at RT. Eluates were neutralized by addition of TBS pH 7.4. After denaturation with NP-40 and incubation at $95^{\circ} \mathrm{C}$ for $10 \mathrm{~min}, 1000$ units of PNGase F (New England Biolabs) were added and incubated at $37^{\circ} \mathrm{C}$ for 6 hours. Deglycosylated proteins were subjected to tryptic digestion using the filter-aided sample preparation (FASP) protocol ${ }^{43,44}$. In brief, proteins were reduced with DTT and loaded onto $30 \mathrm{kDa}$ molecular weight cut-off filter columns and washed with $8 \mathrm{M}$ urea in 100 $\mathrm{mM}$ Tris. Reduced cysteine side chains were alkylated with $55 \mathrm{mM}$ iodoacetamide for $30 \mathrm{~min}$ at $\mathrm{RT}$ in the dark. Excessive reagent was removed by additional washing steps with $8 \mathrm{M}$ urea in 100 $\mathrm{mM}$ Tris. The buffer was exchanged again by washing to $50 \mathrm{mM}$ triethylammonium bicarbonate and $1 \mu \mathrm{g}$ of sequencing grade trypsin (Promega) was added to each filter. The digest was allowed to proceed for 16 hours at $37^{\circ} \mathrm{C}$. The resulting peptides were washed of the filters and desalted using the stop-and-go extraction (STAGE) protocol ${ }^{45}$. Desalted peptides were reconstituted in 5 $786 \%$ formic acid for LC-MSMS analysis.

787 Human APRIL: $10 \mu \mathrm{g}(\sim 10 \mu \mathrm{l})$ of purified canonical or non-canonical APRIL was resuspended in $78850 \mu \mathrm{L} 8 \mathrm{M}$ urea in $100 \mathrm{mM}$ TEAB buffer, $\mathrm{pH} 8$ and proteins reduced with a final concentration of $78910 \mathrm{mM}$ DTT and incubated at $56^{\circ} \mathrm{C}$ for 1 hour. After cooling down to room temperature, reduced 790 cysteines were alkylated with iodoacetamide at a final concentration of $55 \mathrm{mM}$ for $30 \mathrm{~min}$ in the 791 dark. Prior to tryptic digestion, urea concentration was diluted with $100 \mathrm{mM}$ TEAB buffer $\mathrm{pH} 8$ to $7921.5 \mathrm{M}$ and samples were digested with $1 \mu \mathrm{g}$ of trypsin overnight at $37^{\circ} \mathrm{C}$. Peptides were acidified 793 to a final concentration of 1\% TFA and cleaned up by solid phase extraction using C18 SPE 
columns (SUM SS18V, NEST group, USA) according to the manufacturer's instructions. Peptides were eluted using two times $50 \mu 190 \%$ Acetonitrile, 0.4\% formic acid, organic solvent removed in a vacuum concentrator and dried samples reconstituted in $20 \mu 1$ of $0.1 \%$ TFA.

\section{D-RP Liquid Chromatography Mass Spectrometry}

HUVECs: Liquid chromatography mass spectrometry was performed on a Q Exactive ${ }^{\mathrm{TM}}$ Hybrid Quadrupole-Orbitrap (ThermoFisher Scientific, Waltham, MA) coupled to an Agilent 1200 HPLC nanoflow system (Agilent Biotechnologies, Palo Alto, CA) via nanoelectrospray ion source using a liquid junction (Proxeon, Odense, Denmark). Tryptic peptides were loaded onto a trap column (Zorbax 300SB-C18 $5 \mu \mathrm{m}, 5 \times 0.3 \mathrm{~mm}$, Agilent Biotechnologies) at a flow rate of $45 \mu \mathrm{L} / \mathrm{min}$ using $0.1 \%$ TFA as loading buffer. After loading, the trap column was switched in-line with a $75 \mu \mathrm{m}$ inner diameter, $20 \mathrm{~cm}$ analytical column (packed in-house with ReproSil-Pur $120 \mathrm{C} 18-\mathrm{AQ}, 3 \mu \mathrm{m}$, Dr. Maisch, Ammerbuch-Entringen, Germany). Mobile-phase A consisted of $0.4 \%$ formic acid in water and Mobile-phase B of $90 \%$ acetonitrile in water plus $0.4 \%$ formic acid. The flow rate was set to $250 \mathrm{~nL} / \mathrm{min}$ and a $60 \mathrm{~min}$ gradient applied (4\% to $24 \%$ solvent B within $30 \mathrm{~min}, 24 \%$ to $36 \%$ solvent B within 4 min and, 36\% to $100 \%$ solvent B within $1 \mathrm{~min}, 100 \%$ solvent B for 4 min before equilibrating at 4\% solvent B for $21 \mathrm{~min}$ ). For the MS/MS experiment, the Q Exactive ${ }^{\mathrm{TM}} \mathrm{MS}$ was operated in a Top10 DDA mode with a MS1 scan range of 350 to $1,650 \mathrm{~m} / \mathrm{z}$ at a resolution of 70,000 (at $\mathrm{m} / \mathrm{z}$ of 200 ). Automatic gain control (AGC) was set to a target of $3 \times 10 \mathrm{E} 6$ and a maximum injection time of $100 \mathrm{~ms}$. MS2-spectra were acquired at a resolution of 17,500 (at $\mathrm{m} / \mathrm{z}$ of 200) with AGC settings of $1 \times 10 \mathrm{E} 5$ and a maximum injection time of $120 \mathrm{~ms}$. Precursor isolation width was set to $1.6 \mathrm{Da}$ and the HCD normalized collision energy to $28 \%$. The threshold for selecting MS2 precursor ions was set to an underfill ratio of $\sim 12 \%$. Dynamic exclusion for selected ions was $60 \mathrm{~s}$. A single lock mass at m/z 445.120024 was employed for internal mass calibration ${ }^{46}$. All samples were analyzed in technical duplicates. XCalibur version 4.1.31.9 Tune 2.9.2926 were used to operate the Q Exactive MS instrument.

Human APRIL: Mass spectrometry was performed on an Orbitrap Fusion ${ }^{\mathrm{TM}}$ Lumos $^{\mathrm{TM}}$ Tribrid $^{\mathrm{TM}}$ mass spectrometer (Thermo Fisher Scientific, San Jose, CA) coupled to a Dionex U3000 RSLC nano UHPLC system (Thermo Fisher Scientific, San Jose, CA) via nanoflex source interface applying a hybrid approach consisting of an inclusion list triggered data dependent acquisition (DDA) experiment followed by a parallel reaction monitoring (PRM) experiment. A preceding 
825 DDA discovery shotgun LC-MS experiment was carried out to generate a scheduled mass list for 82699 selected human Fc-APRIL derived high confidence (1\%FDR) peptide sequences using 827 Proteome Discoverer 2.4. Approximately equal amounts of either canonical and non-canonical 828 APRIL tryptic peptides were loaded onto a trap column (Acclaim ${ }^{\text {TM }}$ PepMap ${ }^{\text {TM }} 100$ C18, $3 \mu \mathrm{m}, 5$

$829 \times 0.3 \mathrm{~mm}$, Fisher Scientific, San Jose, CA) at a flow rate of $10 \mu \mathrm{L} / \mathrm{min}$ using $0.1 \%$ TFA as loading 830 buffer. After loading, the trap column was switched in-line with a $50 \mathrm{~cm}, 75 \mu \mathrm{m}$ inner diameter 831 analytical column (Acclaim ${ }^{\mathrm{TM}}$ PepMap $^{\mathrm{TM}} 100$ C18, $2 \mu \mathrm{m}$, Fisher Scientific, San Jose, CA) 832 thermostatted at $50^{\circ} \mathrm{C}$. Mobile-phase A consisted of $0.4 \%$ formic acid in water and mobile-phase 833 B of $0.4 \%$ formic acid in a mix of $90 \%$ acetonitrile and $10 \%$ water. The flow rate was set to 230 $834 \mathrm{~nL} / \mathrm{min}$ and a $90 \mathrm{~min}$ gradient applied (4 to $24 \%$ solvent B within $82 \mathrm{~min}, 24$ to $36 \%$ solvent B 835 within $8 \mathrm{~min}$ and, 36 to $100 \%$ solvent B within $1 \mathrm{~min}, 100 \%$ solvent B for 6 min before re836 equilibrating at $4 \%$ solvent $\mathrm{B}$ for $18 \mathrm{~min}$ ). For the MS/MS (DDA) experiment, the MS was 837 operated in a $3 \mathrm{sec}$ TopN dependent scan cycle mode with a MS1 scan range of 375 to $1,650 \mathrm{~m} / \mathrm{z}$ 838 at a resolution of 120,000 (at $\mathrm{m} / \mathrm{z}$ of 200). Automatic gain control (AGC) was set to a target value 839 of $2 \times 10 \mathrm{E} 5$ and a maximum injection time of $80 \mathrm{msec}$. MS2 scans were acquired at a resolution 840 of 15,000 (at $\mathrm{m} / \mathrm{z}$ of 200) with an AGC setting of $5 \times 10 \mathrm{E} 4$ and a maximum injection time of 100 841 msec. Precursor isolation width was set to 1.6 Da and HCD normalized collision energy to $30 \%$. 842 Additional parameters were: MIPS enabled for peptide selection, intensity threshold for selecting 843 precursor ions set to $1 \times 5 \mathrm{E} 4$, charge state inclusion of 2-6 and dynamic exclusion for selected ions 844 set to 60 seconds and a targeted mass list filter (scheduled mass list of $99 \mathrm{~m} / \mathrm{z}$ values). A single 845 lock mass at m/z 445.120024 was employed (1). Settings for PRM were quadrupole isolation 846 window $\mathrm{m} / \mathrm{z}$ of $0.8, \mathrm{HCD}$ fragmentation using 30\% NCE, Orbitrap detection at a resolution of 84715,000 (at m/z of 200) and a defined first mass of $120 \mathrm{~m} / \mathrm{z}$. Automatic gain control (AGC) was set 848 to a target of $5 \times 10 \mathrm{E} 4$ and a maximum injection time of $50 \mathrm{msec}$. XCalibur version 4.3.73.11 and 849 Tune 3.3.2782.28 were used to operate the instrument.

\section{Mass spectrometry data analysis}

852 HUVECs: Raw files were searched against a human database (containing 42265 entries, 853 downloaded from swissprot on $30^{\text {th }}$ Dec. 2016) using Mascot version 2.3.02 (Matrix Science, 854 London, UK) and Phenyx (GeneBio, Geneva, Switzerland) as search engines. Common 855 contaminating proteins such as porcine trypsin, were appended to the database. Mass tolerances 
were set to $4 \mathrm{ppm}$ and $0.025 \mathrm{Da}$ for precursor and fragment ions, respectively. Cleavage specificity

857 was set to tryptic, however, one missed cleavage was allowed. Carbamidomethylation of cysteines

858 was set as a static modification and oxidation of methionines was considered as a dynamic 859 modification. A target-decoy search strategy was employed to ensure a false discovery rate of $1 \%$ 860 on the protein level.

861 Human APRIL: Acquired raw data files were processed using Proteome Discoverer 2.4.1.15 SP1 862 for DDA experimental data or Skyline version 20.1.0.155 for PRM experimental data. Data base 863 search within PD 2.4 was done using the Sequest HT algorithm and Percolator validation software 864 node (V3.04) to remove false positives with strict filtering at a false discovery rate (FDR) of 1\% 865 on PSM, peptide and protein level. Searches were performed with full tryptic digestion against the 866 human SwissProt database V2017.06 including a common contamination list with up to two miscleavage sites. Oxidation (+15.9949Da) of methionine was set as variable modification, whilst carbamidomethylation $(+57.0214 \mathrm{Da})$ of cysteine residues was set as fixed modification. Data was searched with mass tolerances of $\pm 10 \mathrm{ppm}$ and $0.025 \mathrm{Da}$ on the precursor and fragment ions, respectively. Results were filtered to include peptide spectrum matches (PSMs) with Sequest HT cross-correlation factor (Xcorr) scores of $\geq 1$ and high peptide confidence. For relative quantitative

872 comparison of 26 selected APRIL tryptic peptide sequences, Skyline analysis was performed for 873 canonical and non-canonical Fc-APRIL. The PD result file was utilized to build up a reference 874 spectral library for Skyline analysis. Product ion chromatograms were extracted using the 875 following Skyline settings: Spectrum library ion match tolerance of $0.1 \mathrm{~m} / \mathrm{z}$; method match 876 tolerance of $0.025 \mathrm{~m} / \mathrm{z}$; MS/MS filtering using targeted acquisition method at resolving power of 87715,000 at $\mathrm{m} / \mathrm{z}$ of 200 . High-selectivity extraction was used for all matching scans. Integrated peak 878 abundance values for selected peptides were exported (Supplemental table 1).

\section{Human blood collection from healthy individuals}

881 Human blood was collected from fasted healthy volunteers via venipuncture of the antecubital 882 vein using $21 \mathrm{G}$ needles. Blood samples were collected into $9 \mathrm{ml}$ serum or sodium citrate (3.8\%) 883 containing collection tubes (VACUETTE® tubes, Greiner Bio-One) and centrifuged within 20 $884 \mathrm{~min}$ of venipuncture twice for $10 \mathrm{~min}$ at 2,000 $\mathrm{g}$ at room temperature. All plasma and serum 885 samples were aliquoted in $1.5 \mathrm{ml}$ or $2 \mathrm{ml}$ microtubes and were stored at $-80^{\circ} \mathrm{C}$ until further 
analysis. Human blood collection was conducted under the approval of the Ethics Committee of

887 the Medical University of Vienna, Austria (EK Nr: 1845/2015).

\section{Human APRIL quantification}

890 Canonical APRIL (c-APRIL) in human serum was quantified with the APRIL (human) ELISA kit 891 (Adipogen, AG-45B-0012-KI01; referred to as ELISA 1 in the main text) and non-canonical 892 APRIL (nc-APRIL) with the APRIL Human ELISA kit (Invitrogen, BMS2008; referred to as 893 ELISA 2 in the main text), according to manufacturer's instructions. For ELISA validation, 100 $894 \mu \mathrm{l}$ of normal human serum, or $100 \mu \mathrm{l}$ of Invitrogen APRIL standard at $12.5 \mathrm{ng} / \mathrm{ml}$ were depleted 895 overnight at $4^{\circ} \mathrm{C}$ with $20 \mu \mathrm{l}$ of a $50 \%$ slurry of Sepharose beads coupled to the indicated 896 combinations of Aprily2, TACI-Ig or control reagents, with agitation. Beads were spun, and supernatants were depleted again with fresh beads. APRIL in supernatants was measured with the Invitrogen ELISA $(80 \mu 1)$ or with the Adipogen ELISA (10 $\mu 1$ for sera, $2 \mu 1$ for standard). For native and unfolded APRIL, $50 \mu \mathrm{l}$ at $5 \mu \mathrm{g} / \mathrm{ml}$ were depleted overnight at $4^{\circ} \mathrm{C}$ with $30 \mu 1$ of a $50 \%$ slurry of the indicated bead combinations, then beads were spun down and $15 \mu 1$ of supernatant was analysed by Western blot according to standard procedures, revealed with Aprily2 at 0.5

$902 \mu \mathrm{g} / \mathrm{ml}$, followed by horseradish peroxidase-coupled anti-mouse secondary antibody and ECL. 903 Total APRIL in total denatured protein extracts from human atherosclerotic plaques $(\mathrm{n}=199)$ from 904 the Athero-Express ${ }^{15}$ was quantified with the APRIL Human ELISA kit (Invitrogen, BMS2008).

906 Patients from the LURIC prospective clinical study (The Ludwigshafen Risk and 907 Cardiovascular Health study) ${ }^{32}$, the ICARAS (Inflammation and Carotid Artery-Risk for 908 Atherosclerosis Study) ${ }^{\mathbf{3 1}}$ and French registry of Acute ST elevation or non-ST-elevation 909 Myocardial Infarction clinical study (FAST-MI) ${ }^{33}$.

910 ICARAS study: In this single-center study, 1268 consecutive patients who underwent duplex

911 ultrasound investigations of the extracranial carotid arteries were prospectively enrolled between 912 March 2002 and March 2003. Of these, 203 patients (16\%) were lost to clinical follow-up and for 913280 patients (22\%) no serum sample for the measurement of APRIL levels was available, leaving 914785 patients for the final analysis. The 483 patients who had to be excluded from analysis did not 915 differ significantly from the subjects who were included with respect to baseline and demographic 916 parameters (age, sex, frequency of risk factors for atherosclerosis, and cardiovascular 
917 comorbidities; data not shown). The study cohort comprised 486 male patients (62.1\%); the 918 median age was 69.0 (IQR 61 to 76). Demographic data and clinical characteristics of the 785

919 patients are given in Supplemental table 2. Study design, inclusion and exclusion criteria have

920 been published previously ${ }^{31,47}$. In brief, patients with atherosclerotic carotid artery disease, as 921 defined by the presence of non-stenotic plaques or atherosclerotic carotid narrowing of any degree, 922 who were neurologically asymptomatic at the time of screening, were enrolled. The indications 923 for performing carotid ultrasound investigation included carotid bruits, cardiovascular risk factors 924 and known atherosclerotic diseases of other vessel areas. Patients with a myocardial infarction 925 (MI), stroke, coronary intervention or peripheral vascular surgery during the preceding 6 months, 926 were excluded from the study. The rationale behind this was the assumption that acute 927 cardiovascular events may affect laboratory measures and rather reflect the severity of an acute 928 situation than chronic atherosclerosis. The study complied with the Declaration of Helsinki and 929 was approved by the review board and the institutional ethics committee of the Medical University 930 of Vienna. All patients gave their written informed consent.

931 LURIC study: The detailed study design, inclusion and exclusion criteria have been published 932 previously ${ }^{32}$. We analyzed 1,514 samples that were randomly selected. Demographic data and 933 clinical characteristics of the 1,514 patients are given in Supplemental table 3.

934 FAST-MI study: The detailed study design, inclusion and exclusion criteria have been published 935 previously ${ }^{33}$. We analyzed 974 samples.

\section{Clinical and laboratory data for the ICARAS clinical study}

938 Every patient completed a detailed study questionnaire assessing the patient's medical history, 939 current medication, biometric data, and family history. Physical examination was assessed by a 940 trained physician with special attention to patients' cardiovascular risk factors and comorbidities. 941 All demographic and vital parameters were ascertained by two independent observers. Antecubital 942 venous blood samples were drawn and analyzed directly without freezing according to local 943 laboratory standard procedure. In addition, a secondary serum sample of each patient was drawn 944 at baseline visit and directly frozen at $-80^{\circ} \mathrm{C}$ according to local standard procedures. Color-coded 945 duplex sonography examinations of carotid arteries at baseline visits were performed on an 946 Acuson128 XP10 with a 7.5-MHZ linear array probe (Acuson, Malvern, PA, USA). Treating 947 physicians and ultrasonographers were blinded for all laboratory values. Definitions of risk factors 
948 and comorbidities were published previously ${ }^{31,47}$. Cardiovascular and all-cause mortality were

949 assessed by searching the national death register for the specific cause of death (according to the

950 International Statistical Classification of Diseases and Related Health Problems, 10th Revision).

951 Only the specific cause of death (e.g. stroke) was used to categorize death as either all-cause or

952 cardiovascular death. In $43 \%$ of deaths, the underlying cause was assessed by autopsy. All

953 demographic and vital parameters were ascertained by two independent observers.

955 Statistical analyses

956 Statistical analyses were performed using Graph Pad Prism 8 (Graph Pad Software). Experimental

957 groups were compared using two tailed Student's unpaired or paired $t$ or two tailed Mann-Whitney

$958 U$ test as appropriate. To analyse multiple group data, 1-Way ANOVA test followed by Newman-

959 Keuls or Tukey's test, or 2-Way ANOVA test followed by Sidak's test were used. Data are

960 presented as mean \pm s.e.m.. A P value of $<0.05$ was considered significant. ICARAS clinical study:

961 Serum levels of APRIL or nc-APRIL were categorized in tertiles or quartiles (where indicated) to

962 obtain clinically useful measures for the effect sizes. Continuous data are presented as median and

963 interquartile range (range from the 25 th to the 75 th percentile). Discrete data are given as counts

964 and percentages. ANOVA (analysis of variance) and the $\chi^{2}$ test were used for comparisons

965 between tertiles or quartiles, as appropriate. The log-rank test was used for comparison between

966 groups. Event-free survival probabilities were estimated using the Kaplan-Meier method.

967 Univariable and multivariable Cox proportional hazards models were applied to assess the

968 association between serum levels of APRIL or nc-APRIL and the occurrence of either all-cause or

969 cardiovascular death, including the following variables: age (years), sex (male/female), history of

970 myocardial infarction (binary), history of stroke (binary), peripheral arterial disease (binary), body

971 mass index $(\mathrm{kg} / \mathrm{m} 2)$, hypertension (binary), diabetes mellitus (binary), serum creatinine $(\mathrm{mg} / \mathrm{dL})$,

972 glycohemoglobin A1 (\%), levels of triglycerides (mg/dL), total cholesterol levels (mg/dL), low

973 density lipoprotein cholesterol levels (mg/dL), high-sensitivity C-reactive protein (mg/dL),

974 ICAM-1 (ng/ml), VCAM-1 (ng/ml) and statin treatment (binary). The selection of the variables

975 was defined a priori and is based on current guidelines for cardiovascular risk prediction. All of

976 the variables listed above were included in every multivariable Cox proportional hazard model

977 used for this study. Results of the Cox models are presented as hazard ratios (HR; 95\% confidence

978 interval $[\mathrm{CI}]$ ). We assessed the overall model fit using Cox-Snell residuals. We also tested the 
proportional hazard assumption for all covariates using Schoenfeld residuals (overall test) and the 980 scaled Schoenfeld residuals (variable-by-variable testing). A 2-sided $P$ value of $<0.05$ was 981 considered significant. All calculations were performed with SPSS (version 20.0, SPSS Inc) for 982 Windows. LURIC clinical study: Survival analysis was performed considering the following 983 variables as potential risk factors: Serum levels of nc-APRIL, age (years), sex (male/female), body 984 mass index, history of myocardial infarction (no, one, more than one), history of stroke (binary), 985 peripheral arterial disease (binary), body mass index $(\mathrm{kg} / \mathrm{m} 2)$, hypertension (binary), Type II 986 diabetes mellitus (binary), peripheral vascular disease (binary), isolated systolic hypertension $987(>=140 /<90)$, C-reactive protein $(\mathrm{mg} / \mathrm{dL})>0.01$ (binary), glycosylated hemoglobin $(\%)$, serum 988 creatinine $(\mathrm{mg} / \mathrm{dL})$, levels of triglycerides $(\mathrm{mg} / \mathrm{dL})$, total cholesterol levels $(\mathrm{mg} / \mathrm{dL})$. Serum levels 989 of nc-APRIL were categorized in quartiles for descriptive purposes and for Kaplan-Meier curves. 990 Baseline characteristics for all variables are provided for the complete data set and stratified by the nc-APRIL quartiles. Metric variables are presented as mean $\pm 95 \%$ confidence intervals. For 992 discrete variables counts and percentages are given. ANOVA (analysis of variance) and the $\chi 2$ test 993 were used for comparisons between quartiles to provide a quick overview of potential confounding 994 of risk factors with nc-APRIL. Multivariable Cox proportional hazards models were applied to 995 assess the association between the above listed risk factors and the occurrence of either all-cause 996 or cardiovascular death. Due to very strong right-skewness the laboratory parameters serum 997 creatinine, triglycerides and cholesterol as well as nc-APRIL were log-transformed. Again, no 998 model selection was performed, and the set of variables was defined a priori based on current 999 guidelines for cardiovascular risk prediction. Results of the Cox models are presented as hazard 1000 ratios (HR; 95\% confidence interval [CI]). The proportional hazard assumption was tested for all 1001 covariates using Schoenfeld residuals (overall test) and the scaled Schoenfeld residuals (variable1002 by-variable testing). A 2 -sided $P$ value of $<0.05$ was considered significant. All calculations were 1003 performed with $\mathrm{R}$ version 3.6 .0 (https://www.R-project.org/). Survival analysis was 1004 performed using the R packages survival (https://CRAN.R-project.org/package=surviva1) 1005 and survminer (https://CRAN.R-project.org/package=survminer). FAST-MI clinical 1006 study: The primary endpoint was all-cause death during 2 years of follow-up after the index 1007 myocardial infarction. A multivariable Cox proportional-hazards model was used to assess the 1008 independent prognostic value of variables with the primary endpoint. The multivariable model 1009 comprised age, sex, previous or current smoking, previous myocardial infarction, family history 
1010 of coronary disease, history of hypertension, diabetes, renal failure, heart rate at admission, heart

1011 failure, Killip class, left ventricular ejection fraction, hospital management (including reperfusion

1012 therapy, statins, beta blockers, clopidogrel, diuretics, digitalis, heparin), troponin I and log CRP

1013 levels.

1014

1015

\section{METHODS REFERENCES:}

1016 34. Kowalczyk-Quintas, C., et al. Generation and characterization of function-blocking anti-

1017

1018

1019

1020

1021

1022

1023

1024

1025

1026

1027

1028

1029

1030

1031

1032

1033

1034

1035

1036

1037

1038

1039

1040

1041

1042

1043

1044

1045

1046

1047

1048

1049

1050

1051 ectodysplasin A (EDA) monoclonal antibodies that induce ectodermal dysplasia. J Biol Chem 289, 4273-4285 (2014).

35. Tsiantoulas, D., et al. Increased Plasma IgE Accelerate Atherosclerosis in Secreted IgM Deficiency. Circ Res (2016).

36. Chou, M.Y., et al. Oxidation-specific epitopes are dominant targets of innate natural antibodies in mice and humans. J Clin Invest 119, 1335-1349 (2009).

37. Kijani, S., Vazquez, A.M., Levin, M., Boren, J. \& Fogelstrand, P. Intimal hyperplasia induced by vascular intervention causes lipoprotein retention and accelerated atherosclerosis. Physiol Rep 5(2017).

38. Tom, R., Bisson, L. \& Durocher, Y. Transfection of HEK293-EBNA1 Cells in Suspension with Linear PEI for Production of Recombinant Proteins. CSH Protoc 2008, pdb prot4977 (2008).

39. Schindelin, J., et al. Fiji: an open-source platform for biological-image analysis. Nat Methods 9, 676-682 (2012).

40. Bossen, C., et al. TACI, unlike BAFF-R, is solely activated by oligomeric BAFF and APRIL to support survival of activated B cells and plasmablasts. Blood 111, 1004-1012 (2008).

41. Kowalczyk-Quintas, C., et al. Inhibition of Membrane-Bound BAFF by the Anti-BAFF Antibody Belimumab. Front Immunol 9, 2698 (2018).

42. Schneider, P., Willen, L. \& Smulski, C.R. Tools and techniques to study ligand-receptor interactions and receptor activation by TNF superfamily members. Methods in enzymology 545, 103-125 (2014).

43. Manza, L.L., Stamer, S.L., Ham, A.-J.L., Codreanu, S.G. \& Liebler, D.C. Sample preparation and digestion for proteomic analyses using spin filters. Proteomics 5, 17421745 (2005).

44. Wisniewski, J.R., Zougman, A., Nagaraj, N. \& Mann, M. Universal sample preparation method for proteome analysis. Nat Meth 6, 359-362 (2009).

45. Rappsilber, J., Ishihama, Y. \& Mann, M. Stop and Go Extraction Tips for Matrix-Assisted Laser Desorption/Ionization, Nanoelectrospray, and LC/MS Sample Pretreatment in Proteomics. Anal Chem 75, 663-670 (2003).

46. Olsen, J.V., et al. Parts per Million Mass Accuracy on an Orbitrap Mass Spectrometer via Lock Mass Injection into a C-trap. Mol Cell Proteomics 4, 2010-2021 (2005).

47. Mayer, F.J., et al. Combined Effects of Inflammatory Status and Carotid Atherosclerosis: A 12-Year Follow-Up Study. Stroke 47, 2952-2958 (2016). 


\section{DATA AVAILABILITY}

1054 The RNA sequencing datasets (from vascular smooth muscle cells) are available in the Gene 1055 Expression Omnibus with accession codes GSE117963 and GSE (TO BE COMPLETED

1056 BEFORE PUBLICATION). All other relevant data are available from the corresponding authors 1057 upon reasonable request. Source data of Figures 1, 2, 3, 4 and Extended Data figures 1, 2, 5, 6, 7 1058 and 8 are included within the paper. Supplemental Information is available for this paper.

\section{CODE AVAILABILITY}

1061 For the clinical studies, the calculations were performed with SPSS (version 20.0, SPSS Inc) for

1062 Windows, R version 3.6.0 (https://www.R-project.org/), survival analysis was performed using the $1063 \mathrm{R}$ packages survival (https://CRAN.R-project.org/package=survival) and survminer 1064 (https://CRAN.R-project.org/package=survminer). For analysis of mass-spectometry data, 1065 acquired raw data files were processed using Proteome Discoverer 2.4.1.15 SP1 for DDA 1066 experimental data or Skyline version 20.1.0.155 for PRM experimental data or using Mascot 1067 version 2.3.02 (Matrix Science, London, UK) and Phenyx (GeneBio, Geneva, Switzerland) as 1068 search engines. RNA-Seq data were quality controlled using FastQC v0.11.3 1069 (https://www.bioinformatics.babraham.ac.uk/projects/fastqc/) and trimmed using the Trim Galore 1070 v0.4.1 wrapper (https://www.bioinformatics.babraham.ac.uk/projects/trim_galore/). Reads were 1071 aligned to the GRCm38 mouse reference genome using Tophat v2.0.12 (Trapnell et al 2009). 1072 Reads with a minimum map quality of 20 were imported into Seqmonk 1.45 .4 1073 (http://www.bioinformatics.babraham.ac.uk/projects/seqmonk).

1075 ACKNOWLEDGMENTS-FUNDING: We are particularly thankful to Ms. Astrid Fabry and Ms. 1076 Tamara Wenko for their help with the in vivo experimental studies and to Mr. Christoph Friedl for 1077 his help with confocal microscopy. This work was supported by grants of the Austrian Science 1078 Fund (SFB F54), the European Union (FP7 VIA) and the Leducq Foundation (TNE-20CVD03) to 1079 CJB, and by grants of the European Research Area Network on Cardiovascular Diseases (I4647), 1080 the British Heart Foundation (RCAG/917) to DT. DT is also supported by the Austrian Science 1081 Fund (I4963). PS is supported by the Swiss National Science Foundation (31003A_176256, 1082 310030E_197000). ZM is supported by the British Heart Foundation (RCAM/104, RCAM-659, 1083 RRCAM.163), the British Heart Foundation Center for Research Excellence (RE/18/1/34212), the 
1084 NIHR Cambridge Biomedical Research Centre (RG85315), the European Union (FP7 VIA; 1085 RCAG/430) and the European Research Council (ERC). TH is supported by a NWO Veni grant 1086 (91619012).

AUTHOR CONTRIBUTIONS: D.T. conceived and designed the study, performed most of the experiments, analyzed and interpreted data, and wrote the manuscript, M.E. and P.S. generated materials, performed experiments to characterize nc-APRIL and interpreted data, G.O., L.E., S.K., L.W., T.A., T.H., M.K., M.O.K., L.G. F.P, J.E.M., P.F., aided in mouse studies and provided technical assistance with the experiments, M.C. aided in immunofluorescence analyses. D.S. aided

1093 in mouse studies, J.L and H.F.J, provided the RNA-Seq data of murine VSMCs. A.M and J.W. 1094 performed the mass-spectrometry analysis and analyzed the data, F.J.M. and F.F. performed 1095 statistical analysis of the ICARAS and LURIC clinical data respectively, O.D. and J.B. provided reagents and technical expertise with the experiments, and critically revised the manuscript, M.H. was involved in the analysis of human samples, T.S and N.D. provided the samples of FAST-MI 1098 clinical study and performed the statistical analysis of the data, H.S. W.M. and Z.M. provided 1099 the samples of the LURIC clinical study and measured nc-APRIL levels. G.P. provided materials,

1100 H.H. provided materials and critically revised the manuscript, Z.M. and P.S. contributed to study 1101 design, interpreted data and critically revised the manuscript, C.J.B. designed the study, 1102 interpreted data and wrote the manuscript.

1104 COMPETING INTERESTS: DT, CJB, PS and ME are named inventors on a patent application 1105 (EP20217536.0; pending) to exploit c-APRIL and nc-APRIL for diagnostic and therapeutic 1106 purposes in cardiovascular disease that has been filed by the Medical University of Vienna 1107 (Austria) and CeMM Research Center for Molecular Medicine of the Austrian Academy of 1108 Sciences (Austria). OD is employee of Adipogen Life Sciences, which provided some reagents used 1109 in this study.

\section{Correspondence and requests for materials should be addressed to:}

1112 Dr. Dimitrios Tsiantoulas: dimitris.tsiantoulas@meduniwien.ac.at

1113 or Dr. Christoph J. Binder: christoph.binder@meduniwien.ac.at 
1116 Extended Data Figure 1. APRIL deficiency does not alter the smooth muscle cell content, collagen deposition and the numbers of circulating monocytes, $B$ and $T$ lymphocytes in atherosclerotic lesions of $\mathrm{Ldlr}^{-/-}$mice. $\mathrm{Ldlr}^{-/} \mathrm{April}^{+/+}$or $\mathrm{Ldlr}^{-/} \mathrm{April} \mathrm{F}^{-/}$mice were fed an 1119 atherogenic diet for 10 weeks. (a) Whole body weight, plasma triglyceride levels and en face lesion 1120 size ( $\mathrm{n}=10 \mathrm{Ldlr}^{-/}$April ${ }^{+/+}$mice and $\mathrm{n}=12 \mathrm{Ldlr}^{-/-} \mathrm{April}^{-/-}$mice$)$. Representative photomicrographs 1121 of (b) DAPI, (c) $\alpha$-SMA and (d) SPR2 stained lesions in the aortic origin and dot plots showing 1122 the averaged $(\mathbf{b})$ acellular $\left(\mathrm{n}=9 \mathrm{Ldlr}^{-/} \mathrm{April}^{+/+}\right.$mice and $\mathrm{n}=12 \mathrm{Ldlr}^{-/}$April $^{-/}$mice, $\left.\mathrm{P}=0.036\right),(\mathbf{c})$ $1123 \alpha$-SMA ( $=9 \mathrm{Ldlr}^{-/} \mathrm{April}^{+/+}$mice and $\mathrm{n}=10 \mathrm{Ldlr}^{-/-} \mathrm{April}^{-/-}$mice$)$and (d) collagen positive area 1124 normalized to total lesion size $\left(\mathrm{n}=10 \mathrm{Ldlr}^{-/-} \mathrm{April}^{+/+}\right.$mice and $\mathrm{n}=12 \mathrm{Ldlr}^{-/} \mathrm{April}^{-/}$mice $)$. 1125 Representative flow cytometry dot plots showing the (e) absolute numbers of splenic $\mathrm{CD}^{+}, \mathrm{CD}^{+}$ 1126 (defined as $\mathrm{CD}^{+} \mathrm{CD} 4^{+} \mathrm{CD} 8^{-}$) and $\mathrm{CD} 8^{+} \mathrm{T}$ cells (defined as $\mathrm{CD} 3{ }^{+} \mathrm{CD}^{+} \mathrm{CD} 4^{-}$), (f) frequencies of 1127 peritoneal B-1a (defined as B220 low $\mathrm{CD} 11 \mathrm{~b}^{\text {int }} \mathrm{CD}^{+}$), B-1b (defined as B220 ${ }^{\text {low }} \mathrm{CD}_{11} \mathrm{~b}^{\text {int }} \mathrm{CD}^{-}$),

$1128 \mathrm{CD}^{2} 3^{+} \mathrm{B}-2$ (defined as B220 ${ }^{\text {high }} \mathrm{CD} 11 \mathrm{~b}^{-} \mathrm{CD}^{-} \mathrm{CD} 23^{+}$) cells and (g) the frequencies of circulating 1129 Ly6C ${ }^{\text {high }}$, Ly6C $C^{\text {int }}$ and Ly6C $C^{\text {low }}$ monocytes in peripheral blood. All results show mean (two-tailed 1130 unpaired Student $t$ test). Scale bars: $200 \mu \mathrm{m}$

1132 Extended Data Figure 2. BCMA is dispensable for atherosclerosis development. Lethally 1133 irradiated $\mathrm{Ldlr}^{-/-}$mice that were injected with bone marrow from $\mathrm{Bcma}^{+/+}$(hem- $\mathrm{Bcma}^{+/+}$; light 1134 orange) or $\mathrm{BCma}^{-/}$donors (hem- $\mathrm{BCma}^{-/}$; dark orange) and were fed an atherogenic diet for 10 1135 weeks. (a) Dot plot shows of Bcma mRNA in the spleen ( $\mathrm{n}=11$ hem- $\mathrm{Bcma}^{+/+}$and $\mathrm{n}=13$ hem$1136 \mathrm{Bcma}^{-/}$mice), (b) representative photomicrographs of H\&E-stained aortic root lesions and dot plot 1137 of the average lesion size in the aortic origin expressed as $\mu \mathrm{m}^{2} / \mathrm{section}\left(\mathrm{n}=11 \mathrm{hem}-\mathrm{Bcma}^{+/+}\right.$and $1138 \mathrm{n}=12$ hem-Bcma ${ }^{-/}$mice), (c) Whole body weight, plasma triglyceride levels and en face lesion 1139 size $\left(\mathrm{n}=11\right.$ hem- $B c m a^{+/+}$and $\mathrm{n}=13 \mathrm{hem}-B c m a^{-/-}$mice $)$. (d) Total plasma cholesterol $(\mathrm{n}=11$

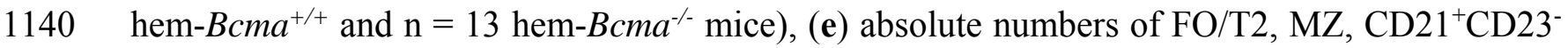
$1141 \quad(\mathrm{P}=0.028), \mathrm{T} 1(\mathrm{P}=0.023)$, newly formed $(\mathrm{NF})(\mathrm{P}=0.031)$ and B-1 B cells cells $(\mathrm{n}=11$ hem$1142 \mathrm{Bcma}^{+/+}$and $\mathrm{n}=13$ hem-Bcma ${ }^{-/}$mice), (f) absolute numbers of $\mathrm{CD}^{+}, \mathrm{CD}^{+}, \mathrm{CD}^{+} \mathrm{T}$ cells $(\mathrm{n}=$ $114311 \mathrm{hem}-\mathrm{Bcma}^{+/+}$and $\mathrm{n}=13 \mathrm{hem}-\mathrm{Bcma}^{-/-}$mice $),(\mathrm{g})$ frequencies of peritoneal B-1a $(\mathrm{P}=0.003)$, $1144 \mathrm{~B}-1 \mathrm{~b}(\mathrm{P}=0.021), \mathrm{CD} 23^{+} \mathrm{B}-2$ cells $(\mathrm{P}=0.0003)$ and $(\mathbf{h})$ total $\operatorname{IgM}(\mathrm{P}=0.002), \operatorname{IgG} 1, \operatorname{IgG} 2 \mathrm{~b}(\mathrm{P}=$ 
1145 0.002), $\operatorname{IgG} 2 \mathrm{c}(\mathrm{P}=0.001), \operatorname{IgG} 3(\mathrm{P}=0.032)$ and $\operatorname{IgA}$ plasma antibody titers $\left(\mathrm{n}=11\right.$ hem- $\mathrm{Bcma}^{+/+}$ 1146 and $\mathrm{n}=13$ hem- $B c m a^{-/}$mice). All results show mean. $* \mathrm{P}<0.05, * * \mathrm{P}<0.01, * * * \mathrm{P}<0.001, * * * * \mathrm{P}$

$1147<0.0001$ (two-tailed Mann-Whitney $U$ or two-tailed unpaired Student $t$ test). Scale bar: $200 \mu \mathrm{m}$.

Extended Data Figure 3. APRIL is produced by mouse and human vascular smooth muscle cells (VSMCs). (a) Tnfsf13 gene expression in human tissues in the Genotype-Tissue Expression

1151 (GTEx) project ${ }^{14}$. The GTEx project was supported by the Common Fund of the Office of the 1152 Director of the National Institutes of Health, and by NCI, NHGRI, NHLBI, NIDA, NIMH, and 1153 NINDS. The data described in this manuscript were obtained from the GTEx Portal on 01/21/21 1154 and dbGaP accession number phs000424.v8.p2, results show median (aorta: median $=55.05$, $1155 \mathrm{n}=432$; coronary artery: median $=40.7, \mathrm{n}=240)$. $(\mathbf{b}, \mathbf{c})(\mathbf{b})$ Dot plot of bulk RNA-seq analysis of 1156 VSMCs from the aortic arch (AA) and descending thoracic aorta (DT) (n = 3-5 mice) 1157 (GSE117963) and (c) from mouse primary VSMCs that were stored in Trizol after isolation or had 1158 been cultured for 4-5 passages until the analysis (GSE TO BE COMPLETED BEFORE 1159 PUBLICATION). Tnfsf13, Myosin-11 (Myh11) and ki67 gene expression are depicted. (d) Dot 1160 plots showing the Tnfsf13 and $I L-6$ gene expression by human umbilical artery smooth muscle 1161 cells that were stimulated in quadruplicates with recombinant human TNF or native human LDL 1162 or human OxLDL (TNF stimulation is representative of three independent experiments; $\mathrm{P}=0.003$ ). 1163 Results show mean \pm s.e.m. **P $<0.01$ (1- Way ANOVA and Tukey's test).

1165 Extended Data Figure 4. APRIL binds heparan sulfate proteoglycan 2 (HSPG2). (a) 1166 Representative photomicrographs (left) and quantification analysis (right) of HUVECs incubated 1167 with either human or mouse flag-APRIL in the presence or absence of heparin and stained with 1168 the anti-flag M2 antibody conjugated to FITC and analyzed by confocal microscopy. (b) Flow 1169 cytometry analysis of HUVECs incubated with flag-APRIL or flag-tagged bacterial alkaline 1170 phosphatase (flag-BAP) and stained with the anti-flag M2 antibody. (c) Identification of protein 1171 binding partners of APRIL in HUVEC culture by performing a pull-down assay with agarose beads 1172 coupled to the anti-flag M2 antibody followed by a mass-spectrometry analysis. (d) APRIL 1173 binding to coated HSPGs from mouse basement membrane quantified by ELISA determine in 1174 triplicates $(* * * * \mathrm{P}<0.0001)$. Data shown are representative of $(\mathbf{a}, \mathbf{b}, \mathbf{d})$ at least two independent 
1175 experiments. Photomicrographs of mouse carotid artery sections incubated (e) with mouse 1176 multimeric flag-APRIL and stained with either an anti-flag antibody conjugated to PE or with an 1177 anti-mouse APRIL biotinylated antibody (2C8), (scale bar $75 \mu \mathrm{m}$, data are derived from two 1178 independent experiments), (f) with mouse multimeric flag-APRIL in presence or absence of 1179 heparin and were stained with an anti-APRIL biotinylated antibody (2C8) or with an anti-HSPG2 1180 or only secondary antibody, (scale bar $75 \mu \mathrm{m}$, data are derived from one experiment). (g) 1181 Quantitative Surface Plasmon Resonance (Biacore) analysis of the affinity of soluble human Fc1182 APRIL (total), human canonical Fc-APRIL (human Fc-c-APRIL), human non-canonical Fc1183 APRIL (human Fc-nc-APRIL), mouse canonical Fc-APRIL (mouse Fc-c-APRIL), mouse non1184 canonical Fc-APRIL (mouse Fc-nc-APRIL) and negative controls EDAR-Fc and human Fas-Fc, 1185 to biotinylated heparin coupled to streptavidin Sensor Chip A ( $\mathrm{n}=3$ independent experiments). All 1186 results show mean \pm s.e.m.. $* * * * \mathrm{P}<0.0001$, (two-tailed unpaired Student $t$ test). IntDen: Integrated 1187 density.

1189 Extended Data Figure 5. Anti-APRIL antibodies 108, 2 C8 and Apry-1-1 are specific for mouse APRIL. (a) Coomassie blue analyses of anti-mAPRIL mAb 108 and 2C8 under reducing 1191 conditions. (b) Isotyping of the Fc portions of anti-mAPRIL 108, Apry-1-1 and 2C8. Purified 1192 antibodies coated on an ELISA plate were revealed with peroxidase-conjugated antibodies against 1193 different isotypes. (c) Inhibitory activity of 108 and Apry-1-1 compared to that of TACI-Fc on 1194 human and mouse APRIL. Flag-human APRIL and two splice variants of Flag mouse APRIL (1195 /+Ala112) were titrated on BCMA:Fas reporter cells in the presence of a fixed, non-saturating 1196 concentration of 108, Apry-1-1 or TACI-Fc. The data show that 108 and Apry-1-1 inhibit both 1197 splice variants of mAPRIL at roughly stoichiometric ratios, but do not cross-react with human 1198 APRIL. (d) ELISA for 2C8 binding to mouse APRIL. Binding of 2C8 to plates coated with human 1199 Fc-mouse APRIL was evaluated with a peroxidase-coupled anti-mouse antibody. (a, b) Data are 1200 representative of two independent experiments.

1202 Extended Data Figure 6. APRIL competes the binding of LDL to proteoglycans. (a) 1203 Representative photomicrographs (left) and quantification (right) of anti-ApoB antibody binding 1204 to murine carotid artery sections incubated with human native LDL in presence or absence of 
1205 mouse multimeric flag-APRIL analyzed by both confocal and epifluorescence microscopy (w/o 1206 APRIL: $\mathrm{n}=7$ and with APRIL: $\mathrm{n}=9, \mathrm{P}=0.0004)$. (b) A line graph showing the amount of bound 1207 human LDL (triplicates; quantified by flow cytometry) on the surface of HEK293 wild type cells 1208 in presence of different amounts of human recombinant APRIL. (c) Representative 1209 photomicrographs of ApoB-stained lesions in the aortic origin and dot plot showing the ApoB1210 positive area normalized to DAPI positive lesion area of $\mathrm{Ldlr}^{-/} \mathrm{April}^{+/+}$or $\mathrm{Ldll}^{-/} \mathrm{April}^{-/}$mice that 1211 were fed an atherogenic diet for 10 weeks $\left(\mathrm{n}=8 \mathrm{Ldlr}^{-} \mathrm{April}^{+/+}\right.$mice and $\mathrm{n}=12 \mathrm{Ldlr}^{-1} \mathrm{April}^{-/-}$mice, $1212 \mathrm{P}=0.035$ ). Data shown are (a) pooled from four independent experiments with seven to nine 1213 sections per group, (b) representative of three independent experiments. All results show mean \pm 1214 s.e.m.. $* \mathrm{P}<0.05,{ }^{* * *} \mathrm{P}<0.001$, (two-tailed unpaired Student $t$ test), scale bars: (a) $20 \mu \mathrm{m}$ and (c) $1215200 \mu \mathrm{m}$.

Extended Data Figure 7. Treatment with the blocking anti-APRIL antibody Apry1-1 does 1218 not alter B cell responses and plasma lipid levels in Apoe $^{-/}$mice. Apoe $e^{-/-}$mice were treated 1219 biweekly for 10 weeks with a mixture of either mouse anti-APRIL antibody (Apry-1-1) and Ctrl1220 Ig ( $\alpha$-APRIL group), or TACI-Ig and isotype IgG2b (TACI-Ig group), or isotype IgG2b and Ctrl$1221 \operatorname{Ig}$ (Ctrl group) and were fed an atherogenic diet for the last 8 weeks of the study. Dot plots showing 1222 the numbers of (a) total splenic B cells, (b) follicular (FO) B cells, (c) marginal zone (MZ) B cells, 1223 frequencies of (d) peritoneal B-1a, (e) peritoneal B-1b and (f) total IgM antibody levels in plasma. 1224 (g) Wild-type mice were injected intraperitoneally with either $1 \mu \mathrm{g}$ of mouse multimeric flag1225 APRIL or a mixture of $1 \mu \mathrm{g}$ flag-APRIL and $10 \mu \mathrm{g}$ anti-mouse APRIL antibody (Apry-1-1). The 1226 amount of flag-APRIL in plasma was measured by ELISA one, three and six hours after the 1227 injection ( $\mathrm{n}=4$ mice APRIL-flag, $\mathrm{n}=5$ mice APRIL-flag+ $\alpha$-APRIL (Apry1-1)). (h) Whole body 1228 weight, plasma triglyceride and cholesterol levels. (a, b, $, \mathbf{c}, \mathbf{d}, \mathbf{e}, \mathbf{f}, \mathbf{h})$ All results show mean \pm 1229 s.e.m. of $\mathrm{n}=10$ Apoe $^{-/} ;$Ctrl, $\mathrm{n}=12$ Apoe $^{-/}$; TACI-Ig, $\mathrm{n}=10$ Apoe A- $^{-\alpha} \alpha$-APRIL). $* * * \mathrm{P}<0.001$, $* * * * \mathrm{P}<0.0001$ (1- Way ANOVA and Newman-Keuls test).

1232 Extended Data Figure 8. (a-h) Epitope mapping of anti-human APRIL antibodies. (a) The 1233 epitopes recognized by Aprily1, 2, 3, 5 and 10 were mapped by Western Blot of truncated APRIL 1234 proteins. (b, c, d) Aprily5 and Aprily1 or 2 recognize distinct epitopes, (e, f) while Aprily3 and 10 
1235 recognize epitopes distinct from those of Aprily1, Aprily2 and Aprily5. (g) Expression of all 1236 constructs was validated by Western Blot with anti-Fc antibody. (h, i) Human serum was depleted 1237 of APRIL using the anti-human APRIL antibodies: Aprily1, Aprily2, Aprily3, Aprily5, Aprily6, 1238 Aprily8, Aprily9, Aprily10, Mahya-1, 110.6 or the biological atacicept (TACI-Ig: a recombinant 1239 fusion protein of the receptor TACI and the Fc region of Ig, that binds to APRIL) or the negative 1240 control EctoD1 and then analyzed with (h) a c-APRIL specific (ELISA 1) or (i) a nc-APRIL 1241 specific ELISA (ELISA 2) Data are derived from one experiment in this format. (j-n) Native 1242 canonical and non-canonical APRIL differ in size. (j) Flag-human APRIL (from c-APRIL 1243 ELISA 1 standards) was depleted on TACI-Fc (or TNFR2-Fc as control) and/or on Aprily2 (or 1244 mIgG1 as control). APRIL was then detected by c-APRIL specific (top) or nc-APRIL specific 1245 (bottom) ELISA. (k, l) Flag-human APRIL (from Adipogen ELISA standards) was depleted on 1246 immobilized TACI-Fc or on Aprily2, and the flow through was then size-fractionated by size 1247 exclusion chromatography (SEC) and detected in fractions by (k) c-APRIL specific (ELISA 1) or 1248 (I) nc-APRIL specific (ELISA 2) ELISA. TACI-Fc and Aprily2 beads used for depletion were then 1249 acid-eluted. $(\mathbf{m}, \mathbf{n})$ The neutralized eluate was size-fractionated, and APRIL in fractions were 1250 detected with (m) c-APRIL specific or (n) nc-APRIL specific ELISA. These results indicate that 1251 Flag-c-APRIL has the size of a 3-mer, while nc-APRIL is much larger. $(\mathbf{o}, \mathbf{p})$ Canonical and non1252 canonical APRIL are produced by the same Tnfsf 13 gene locus. The Tnfsfl3 gene (which 1253 encodes APRIL) was inactivated in human macrophage cell line U937 by CRISPR/Cas9 1254 technology. As a control the Tnfsfl $3 b$ gene (which encodes BAFF) was also deleted. APRIL in 1255 supernatants was measured with (o) a c-APRIL specific and (p) a nc-APRIL specific ELISA. (105, 1256110,301 and 302 depict different clones).

1258 Extended Data Figure 9. LC-MS-based Parallel Reaction Monitoring (PRM) analysis of 1259 tryptic digest of purified human canonical or non-canonical Fc-APRIL. Raw data was 1260 analyzed using Skyline software and extracted product ion chromatograms (XICs) are shown 1261 either in form of peaks (upper panel) or total sum of integrated product ion areas (lower panel) for 1262 the three selected peptides (a) EEQYNSTYR (Fc part), (b) LNLSPHGTFLGFVK (tryptic C1263 terminus APRIL) and (c) LNLSPHGTFLGFVKL (miscleaved tryptic C-terminus APRIL). MS2 1264 fragment ion spectra for the selected peptide precursor ions are illustrated in the lower right panel. 1265 While the peptide shown in (a) is representative for comparable injection amounts of canonical 
1266 versus non-canonical Fc-APRIL, the C-terminal miscleaved full tryptic peptide shown in (c) is 1267 undetectable in non-canonical APRIL. Relative abundances are given in arbitrary units. Right 1268 panel illustrates the FASTA sequence of Fc-APRIL with selected tryptic peptide sequences 1269 highlighted in blue or red. Note the different scales in panels $(\mathbf{b})\left(10^{9}\right)$ and $(\mathbf{c})\left(10^{6}\right)$. (d) Structure 1270 of human c-APRIL highlighting the importance of the C-terminus for the folding of the different 1271 forms (canonical and non-canonical) of APRIL. The representation based on protein data 1272 bank accession number 1XU1 highlights the last two C-terminal amino acids (Lys232, 1273 Leu233). The N-terminal amino acid of the TNF homology domain (His98), and 1274 Asp142 are also shown. All of these residues are conserved in mouse APRIL and human 1275 APRIL, although the sequence surrounding Asp142 is different in mouse and human. 1276 The C-terminal carboxylic group of Leu233 is very close to His 98 of the same monomer

1277 (3.6 $\AA, 4.1 \AA$ and $3.4 \AA$ in the three monomers) and also very close to His 98 of the 1278 neighbouring monomer (4.3 $\AA, 3.8 \AA$ and $3.8 \AA$ ). Thus, H98 and the carboxylic group 1279 or Leu233 seem to form a ring of 6 salt bridges at the top surface of APRIL. In addition, 1280 Lys232 contacts Asp142 (4.3 $\AA, 4.3 \AA$ and 5.7 $\AA$ in the three mouse APRIL monomers, 1281 and is at only $3.2 \AA$ of Asp142 in human APRIL (pdb accession number 4ZCH).

1283 Extended Data Table 1. Human clinical studies. (a) Univariate and multivariate Cox 1284 Regression analyses of the ICARAS study (nc-APRIL). $1^{\text {st }}$ Tertile includes patients with nc1285 APRIL levels lower than $4.22 \mathrm{ng} / \mathrm{ml}, 2^{\text {nd }}$ tertile patients with nc-APRIL levels between 4.23 to $12866.47 \mathrm{ng} / \mathrm{ml}$, the $3^{\text {rd }}$ tertile patients with nc-APRIL levels above $6.47 \mathrm{ng} / \mathrm{ml}$. Adjusted for age, sex, 1287 body mass index, smoking, hypertension, low-density lipoprotein cholesterol levels, triglyceride 1288 levels, statin treatment, glycohemoglobin A1 level, diabetes mellitus, history of myocardial 1289 infarction, history of peripheral artery disease, history of stroke, and serum creatinine, intercellular 1290 adhesion molecule-1, vascular cell adhesion molecule-1, and high-sensitivity C-reactive protein. 1291 The third tertile serves as the reference category, $(\mathrm{n}=785)$. (b) Univariate and multivariate Cox 1292 Regression analyses of the ICARAS study (c-APRIL). $1^{\text {st }}$ Tertile includes patients with APRIL 1293 levels lower than $1.67 \mathrm{ng} / \mathrm{ml}, 2^{\text {nd }}$ tertile patients with APRIL levels between 1.67 to $2.54 \mathrm{ng} / \mathrm{ml}$, 1294 the $3^{\text {rd }}$ tertile patients with APRIL levels above $2.54 \mathrm{ng} / \mathrm{ml}$. Adjusted for age, sex, body mass index, 
1295 smoking, hypertension, low-density lipoprotein cholesterol levels, triglyceride levels, statin 1296 treatment, glycohemoglobin A1 level, diabetes mellitus, history of myocardial infarction, history 1297 of peripheral artery disease, history of stroke, and serum creatinine, intercellular adhesion 1298 molecule-1, vascular cell adhesion molecule-1, and high-sensitivity C-reactive protein. The third 1299 tertile serves as the reference category $(\mathrm{n}=730)$. (c) Multivariate Cox Regression analyses for 1300 cardiovascular mortality in the LURIC study (nc-APRIL). Adjusted for age (years), sex

1301 (male/female), C-reactive protein (mg/dL), triglycerides ( $\mathrm{mg} / \mathrm{dL}$ ), total cholesterol levels $(\mathrm{mg} / \mathrm{dL}$ ), 1302 history of myocardial infarction (binary), history of stroke (binary), peripheral arterial disease 1303 (binary), body mass index ( $\mathrm{kg} / \mathrm{m} 2)$, hypertension (binary), diabetes mellitus (binary), serum 1304 creatinine $(\mathrm{mg} / \mathrm{dL})$, hemoglobin $1 \mathrm{AC}$ (percent) $(\mathrm{n}=1,514)$. (d) Multivariate Cox Regression 1305 analyses French registry of Acute ST elevation or non-ST-elevation Myocardial Infarction clinical 1306 study (FAST-MI). Circulating levels of nc-APRIL in patients at the admission for acute 1307 myocardial infarction are associated with cardiovascular outcomes at follow-up. The probability 1308 of death during 2 years of follow-up as a function of baseline circulating plasma APRIL levels 1309 ( $\mathrm{n}=974)$. Results are expressed as hazard ratios (HR) with 95\% confidence intervals (CIs).

\section{REFERENCES (altogether as ENDNOTE library):}

1311 1. World Health Organization. Global status report on noncommunicable diseases 2014. xvii, 1312280 pages (World Health Organization,, Geneva, Switzerland, 2014).

1313 2. World Health Organization, Noncommunicable diseases country profiles 2018, ISBN: 978 1314

1315

1316

1317

1318

1319

1320

1321

1322

1323

1324

1325

1326

1327

1328

1329

1330

1331

1332 924151462 0. (2018).

3. Gistera, A. \& Hansson, G.K. The immunology of atherosclerosis. Nat Rev Nephrol 13, 368-380 (2017).

4. Ingold, K., et al. Identification of proteoglycans as the APRIL-specific binding partners. $J$ Exp Med 201, 1375-1383 (2005).

5. Vincent, F.B., Morand, E.F., Schneider, P. \& Mackay, F. The BAFF/APRIL system in SLE pathogenesis. Nat Rev Rheumatol 10, 365-373 (2014).

6. Castigli, E., et al. Impaired IgA class switching in APRIL-deficient mice. Proc Natl Acad Sci U S A 101, 3903-3908 (2004).

7. Huard, B., et al. APRIL secreted by neutrophils binds to heparan sulfate proteoglycans to create plasma cell niches in human mucosa. J Clin Invest 118, 2887-2895 (2008).

8. McCarron, M.J., Park, P.W. \& Fooksman, D.R. CD138 mediates selection of mature plasma cells by regulating their survival. Blood 129, 2749-2759 (2017).

9. Hymowitz, S.G., et al. Structures of APRIL-receptor complexes: like BCMA, TACI employs only a single cysteine-rich domain for high affinity ligand binding. $J$ Biol Chem 280, 7218-7227 (2005).

10. Sandberg, W.J., et al. The tumour necrosis factor superfamily ligand APRIL (TNFSF13) is released upon platelet activation and expressed in atherosclerosis. Thromb Haemost 102, 704-710 (2009). 
1333 11. Mackay, F. \& Schneider, P. Cracking the BAFF code. Nat Rev Immunol 9, 491-502 (2009).

1334 12. Tsiantoulas, D., et al. B Cell-Activating Factor Neutralization Aggravates Atherosclerosis.

1335 Circulation 138, 2263-2273 (2018).

1336 13. Patel, D.R., et al. Engineering an APRIL-specific B cell maturation antigen. J Biol Chem

1337

1338 279, 16727-16735 (2004).

1339

14. Consortium, G.T., et al. Genetic effects on gene expression across human tissues. Nature 550, 204-213 (2017).

1340

1341

1342

1343

1344

1345

1346

1347

1348

1349

1350

1351

1352

1353

1354

1355

1356

1357

1358

1359

1360

1361

1362

1363

1364

1365

1366

1367

1368

1369

1370

1371

1372

1373

1374

1375

1376

1377

1378

15. Hellings, W.E., Moll, F.L., de Kleijn, D.P. \& Pasterkamp, G. 10-years experience with the Athero-Express study. Cardiovasc Diagn Ther 2, 63-73 (2012).

16. Lord, M.S., et al. The multifaceted roles of perlecan in fibrosis. Matrix Biol 68-69, 150166 (2018).

17. Vikramadithyan, R.K., et al. Atherosclerosis in perlecan heterozygous mice. J Lipid Res 45, 1806-1812 (2004).

18. Tran-Lundmark, K., et al. Heparan sulfate in perlecan promotes mouse atherosclerosis: roles in lipid permeability, lipid retention, and smooth muscle cell proliferation. Circ Res 103, 43-52 (2008).

19. Skalen, K., et al. Subendothelial retention of atherogenic lipoproteins in early atherosclerosis. Nature 417, 750-754 (2002).

20. Sarrazin, S., Lamanna, W.C. \& Esko, J.D. Heparan sulfate proteoglycans. Cold Spring Harb Perspect Biol 3(2011).

21. Parish, C.R. The role of heparan sulphate in inflammation. Nat Rev Immunol 6, 633-643 (2006).

22. Bernelot Moens, S.J., et al. Impact of the B Cell Growth Factor APRIL on the Qualitative and Immunological Characteristics of Atherosclerotic Plaques. PLoS One 11, e0164690 (2016).

23. Haselmayer, P., Vigolo, M., Nys, J., Schneider, P. \& Hess, H. A mouse model of systemic lupus erythematosus responds better to soluble TACI than to soluble BAFFR, correlating with depletion of plasma cells. Eur J Immunol 47, 1075-1085 (2017).

24. Tsiantoulas, D., et al. BAFF Neutralization Aggravates Atherosclerosis. Circulation (2018).

25. Kyaw, T., et al. B1a B lymphocytes are atheroprotective by secreting natural IgM that increases IgM deposits and reduces necrotic cores in atherosclerotic lesions. Circ Res 109, 830-840 (2011).

26. Gruber, S., et al. Sialic Acid-Binding Immunoglobulin-like Lectin G Promotes Atherosclerosis and Liver Inflammation by Suppressing the Protective Functions of B-1 Cells. Cell Rep (2016).

27. Rosenfeld, S.M., et al. B-1b Cells Secrete Atheroprotective IgM and Attenuate Atherosclerosis. Circ Res 117, e28-39 (2015).

28. Lewis, M.J., et al. Immunoglobulin $\mathrm{M}$ is required for protection against atherosclerosis in low-density lipoprotein receptor-deficient mice. Circulation 120, 417-426 (2009).

29. Tsiantoulas, D., et al. Increased Plasma IgE Accelerate Atherosclerosis in Secreted IgM Deficiency. Circ Res 120, 78-84 (2017).

30. Dishman, A.F., et al. Evolution of fold switching in a metamorphic protein. Science 371, 86-90 (2021).

31. Schillinger, M., et al. Inflammation and Carotid Artery--Risk for Atherosclerosis Study (ICARAS). Circulation 111, 2203-2209 (2005). 
32. Winkelmann, B.R., et al. Rationale and design of the LURIC study--a resource for functional genomics, pharmacogenomics and long-term prognosis of cardiovascular disease. Pharmacogenomics 2, S1-73 (2001).

33. Puymirat, E., et al. Acute Myocardial Infarction: Changes in Patient Characteristics, Management, and 6-Month Outcomes Over a Period of 20 Years in the FAST-MI Program (French Registry of Acute ST-Elevation or Non-ST-Elevation Myocardial Infarction) 1995 to 2015. Circulation 136, 1908-1919 (2017).

34. Kowalczyk-Quintas, C., et al. Generation and characterization of function-blocking antiectodysplasin A (EDA) monoclonal antibodies that induce ectodermal dysplasia. J Biol Chem 289, 4273-4285 (2014).

35. Tsiantoulas, D., et al. Increased Plasma IgE Accelerate Atherosclerosis in Secreted IgM Deficiency. Circ Res (2016).

36. Chou, M.Y., et al. Oxidation-specific epitopes are dominant targets of innate natural antibodies in mice and humans. J Clin Invest 119, 1335-1349 (2009).

37. Kijani, S., Vazquez, A.M., Levin, M., Boren, J. \& Fogelstrand, P. Intimal hyperplasia induced by vascular intervention causes lipoprotein retention and accelerated atherosclerosis. Physiol Rep 5(2017).

38. Tom, R., Bisson, L. \& Durocher, Y. Transfection of HEK293-EBNA1 Cells in Suspension with Linear PEI for Production of Recombinant Proteins. CSH Protoc 2008, pdb prot4977 (2008).

39. Schindelin, J., et al. Fiji: an open-source platform for biological-image analysis. Nat Methods 9, 676-682 (2012).

40. Bossen, C., et al. TACI, unlike BAFF-R, is solely activated by oligomeric BAFF and APRIL to support survival of activated B cells and plasmablasts. Blood 111, 1004-1012 (2008).

41. Kowalczyk-Quintas, C., et al. Inhibition of Membrane-Bound BAFF by the Anti-BAFF Antibody Belimumab. Front Immunol 9, 2698 (2018).

42. Schneider, P., Willen, L. \& Smulski, C.R. Tools and techniques to study ligand-receptor interactions and receptor activation by TNF superfamily members. Methods in enzymology 545, 103-125 (2014).

43. Manza, L.L., Stamer, S.L., Ham, A.-J.L., Codreanu, S.G. \& Liebler, D.C. Sample preparation and digestion for proteomic analyses using spin filters. Proteomics 5, 17421745 (2005).

44. Wisniewski, J.R., Zougman, A., Nagaraj, N. \& Mann, M. Universal sample preparation method for proteome analysis. Nat Meth 6, 359-362 (2009).

45. Rappsilber, J., Ishihama, Y. \& Mann, M. Stop and Go Extraction Tips for Matrix-Assisted Laser Desorption/Ionization, Nanoelectrospray, and LC/MS Sample Pretreatment in Proteomics. Anal Chem 75, 663-670 (2003).

46. Olsen, J.V., et al. Parts per Million Mass Accuracy on an Orbitrap Mass Spectrometer via Lock Mass Injection into a C-trap. Mol Cell Proteomics 4, 2010-2021 (2005).

47. Mayer, F.J., et al. Combined Effects of Inflammatory Status and Carotid Atherosclerosis: A 12-Year Follow-Up Study. Stroke 47, 2952-2958 (2016). 


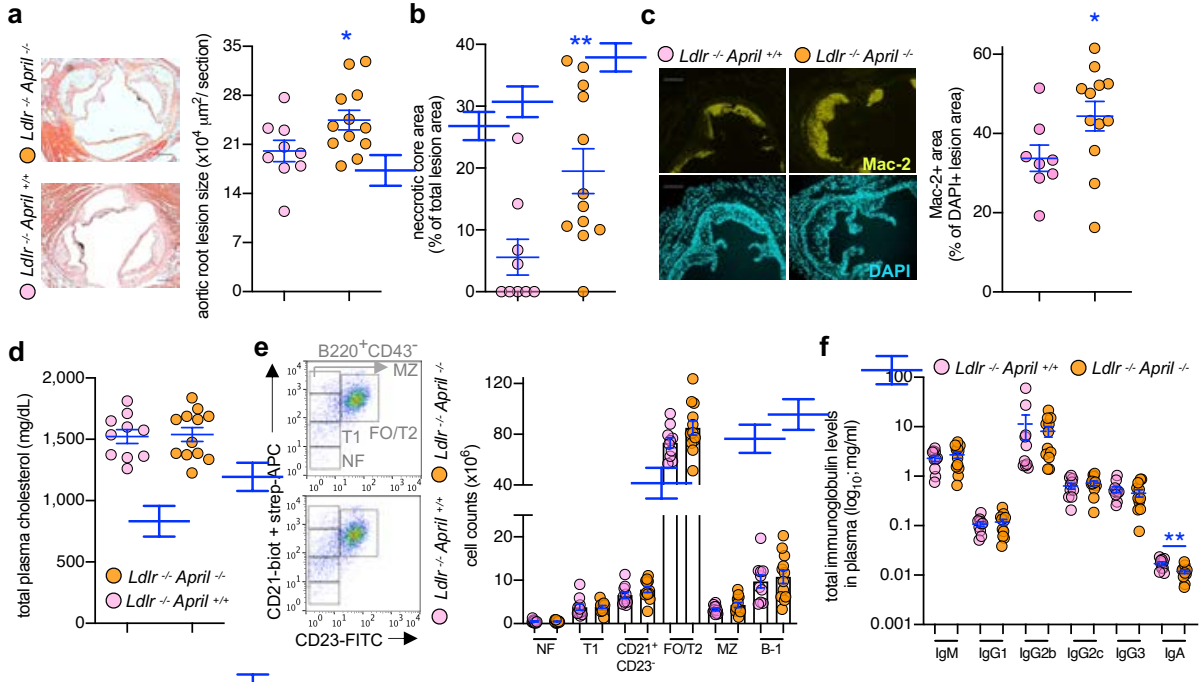

Figure 1 
a

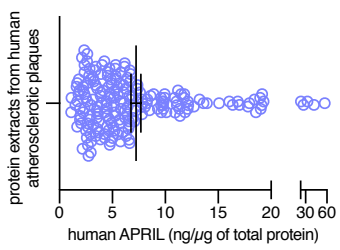

c

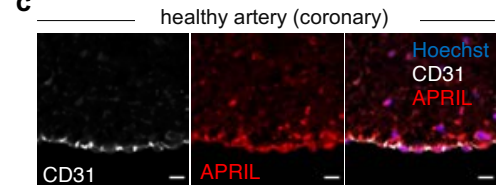
d.

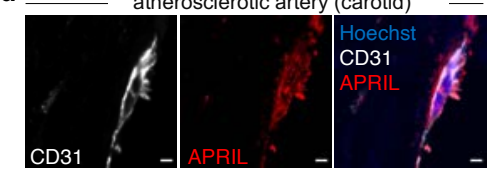

b

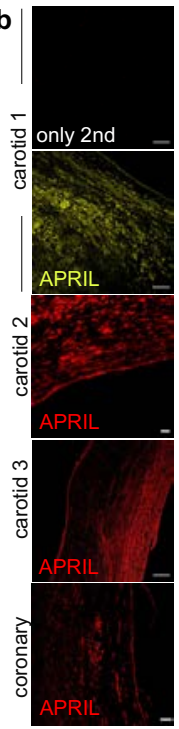

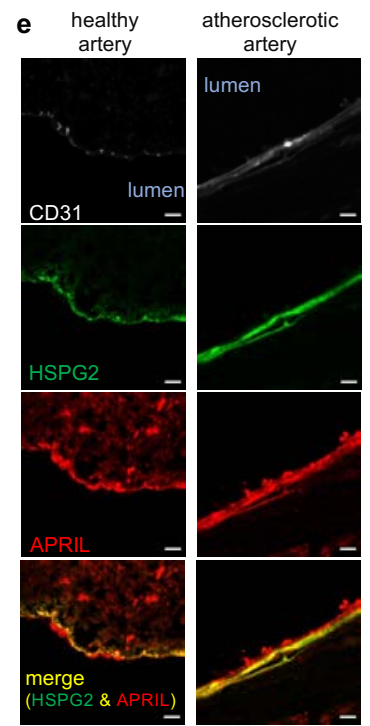

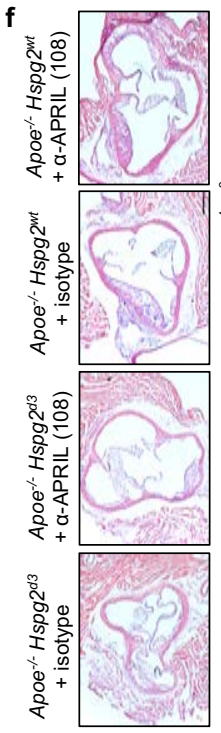

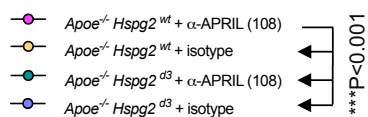

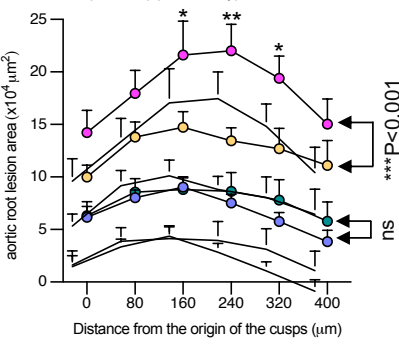

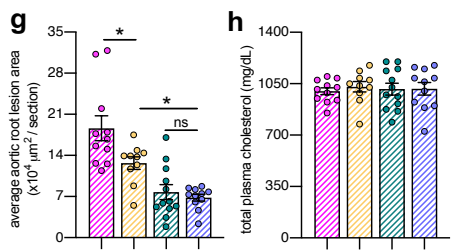

Figure 2 


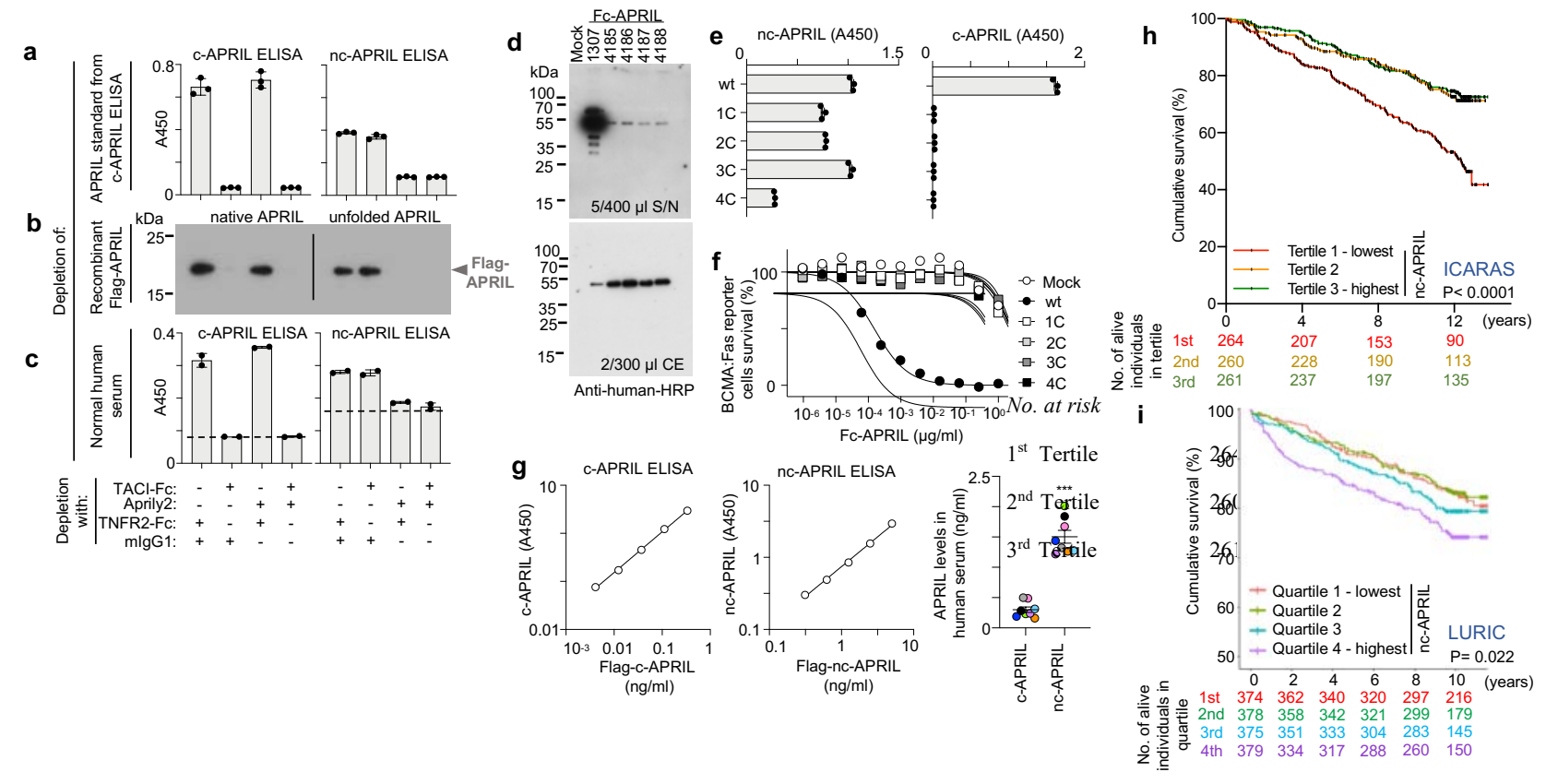

Figure 4 
a

\begin{tabular}{|c|c|c|c|}
\hline $\begin{array}{l}\text { experimental } \\
\text { groups }\end{array}$ & $\begin{array}{l}\text { whole body } \\
\text { weight }(\mathrm{g})\end{array}$ & $\begin{array}{c}\text { plasma } \\
\text { triglycerides } \\
\text { (mg/dL) }\end{array}$ & $\begin{array}{l}\text { en face lesion size } \\
\text { ( } \% \text { of total area) }\end{array}$ \\
\hline Ldlr $r^{\prime-}$ Aprill $^{+/+}$ & $22.98 \pm 0.74$ & $665.0 \pm 53.61$ & $1.89 \pm 0.19$ \\
\hline Ldllr $r^{-}$Aprit ${ }^{-}$ & $23.28 \pm 0.40$ & $596.9 \pm 43.06$ & $1.67 \pm 0.20$ \\
\hline
\end{tabular}
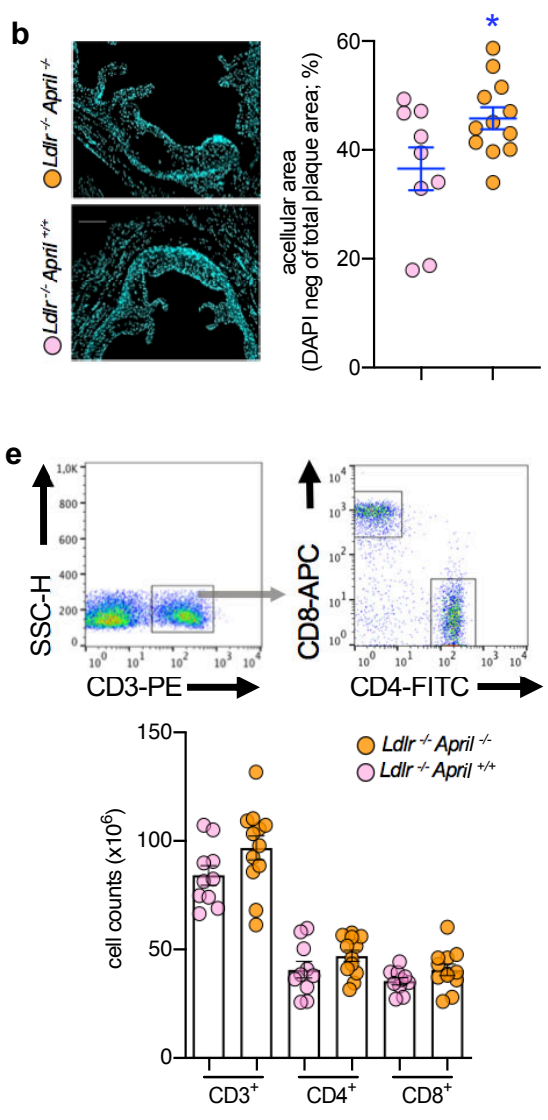
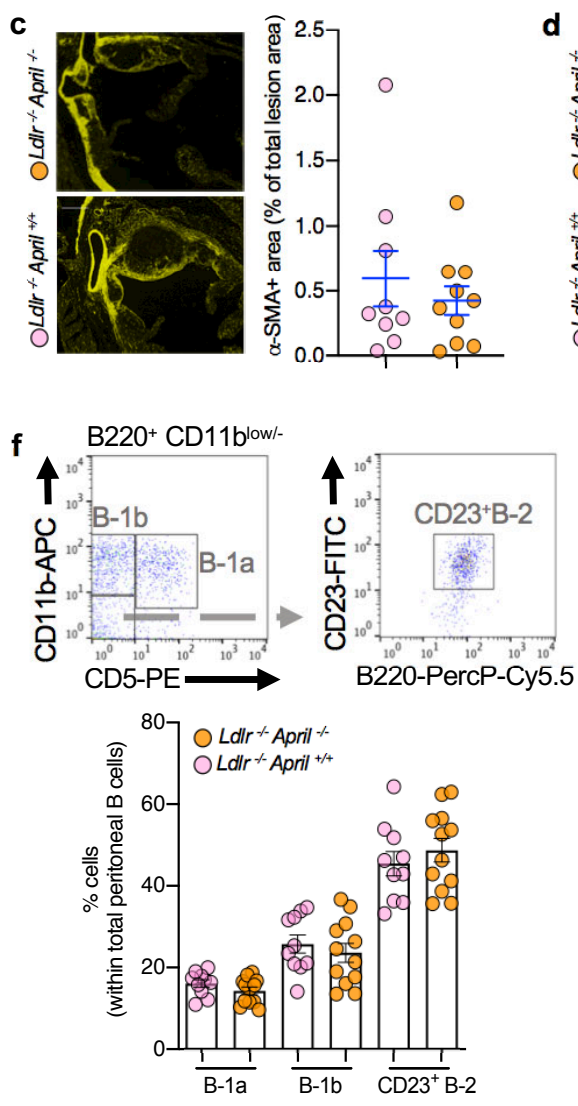

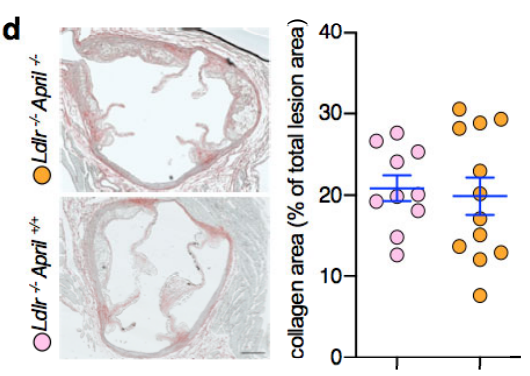

g CD11b+ B220-Ly6C+Ly6G-
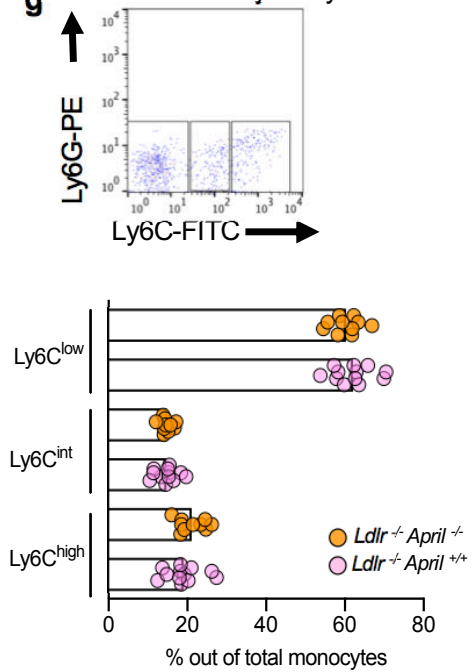

Extended Data Figure 1 

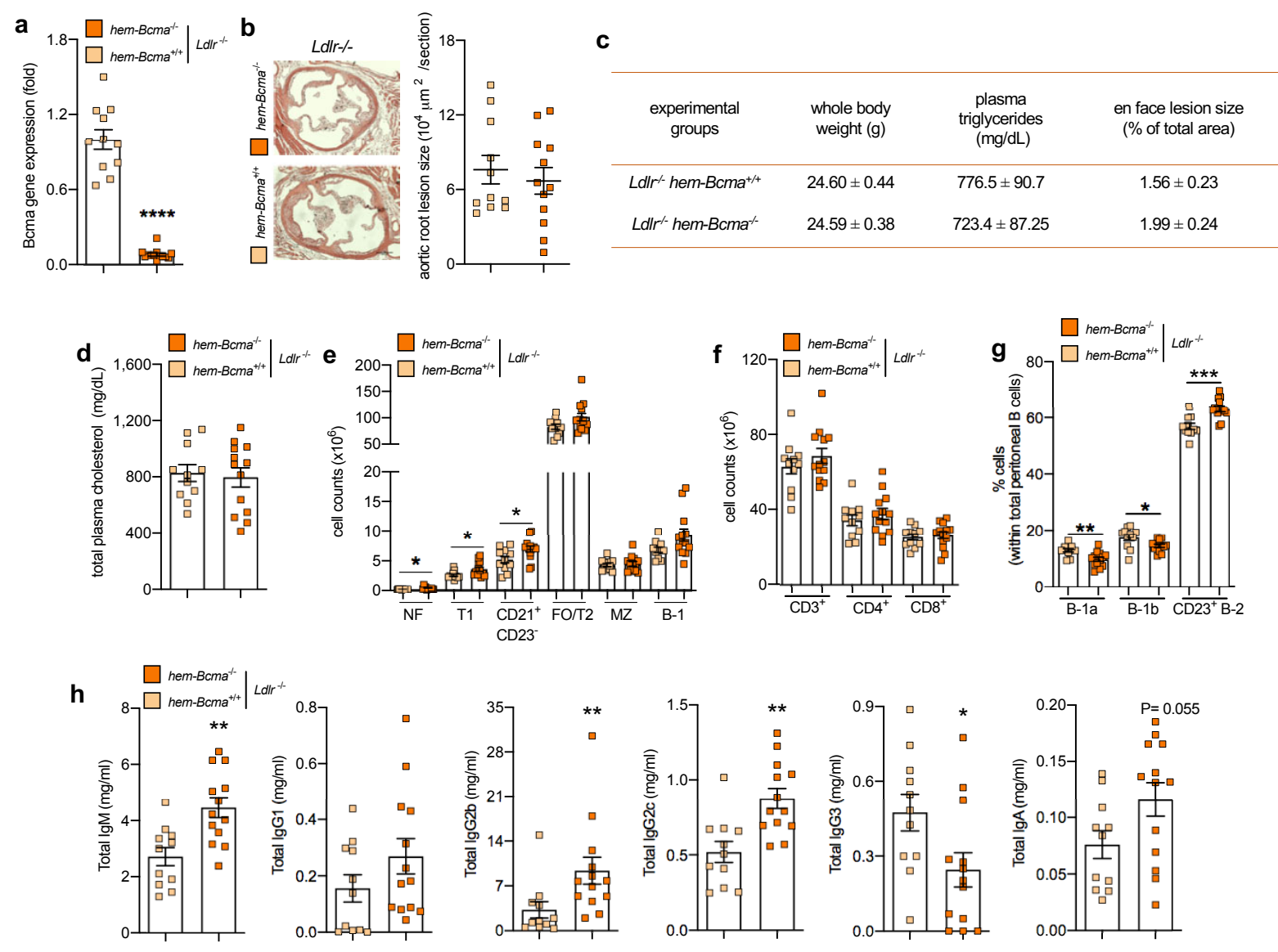

Extended Data Figure 2 


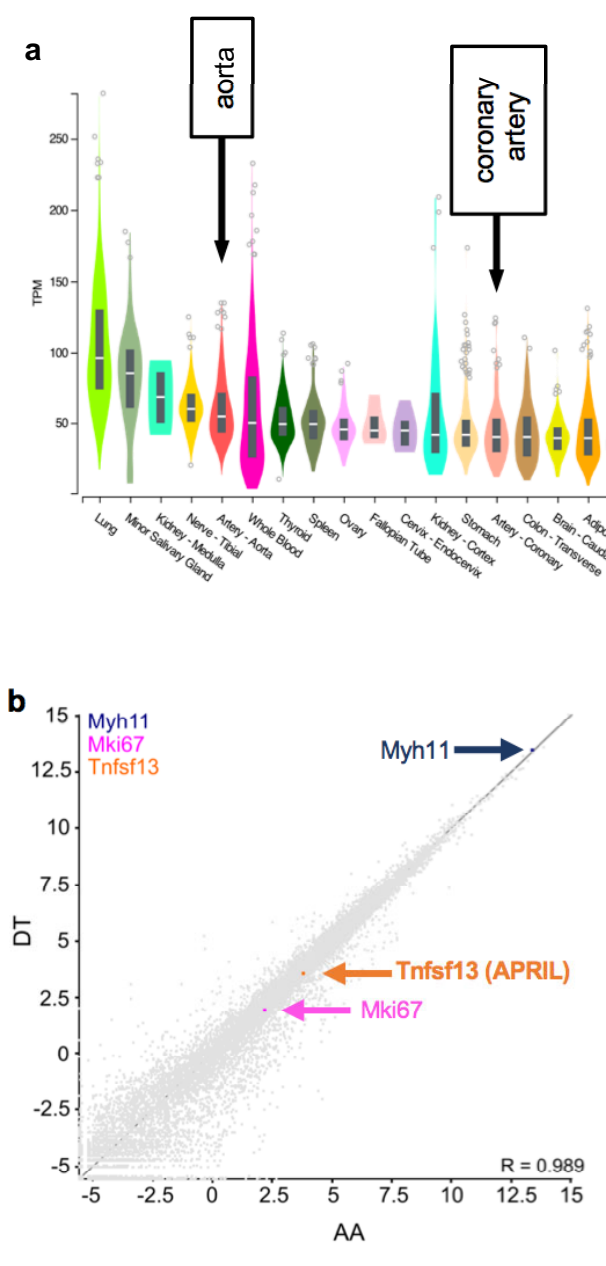

Gene expression for TNFSF13

(ENSG00000161955.16)
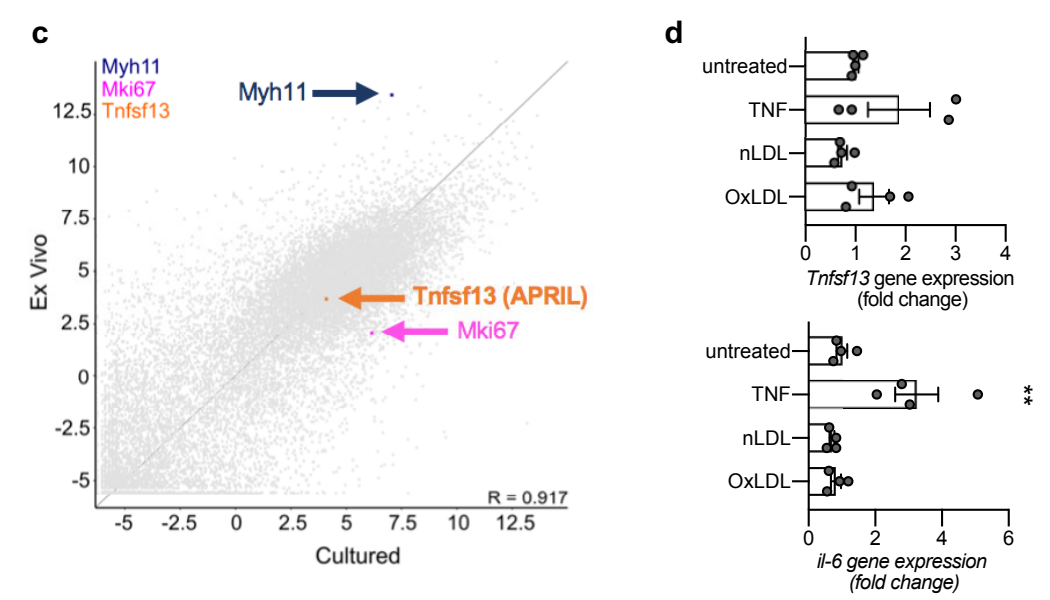

\section{Extended Data Figure 3}



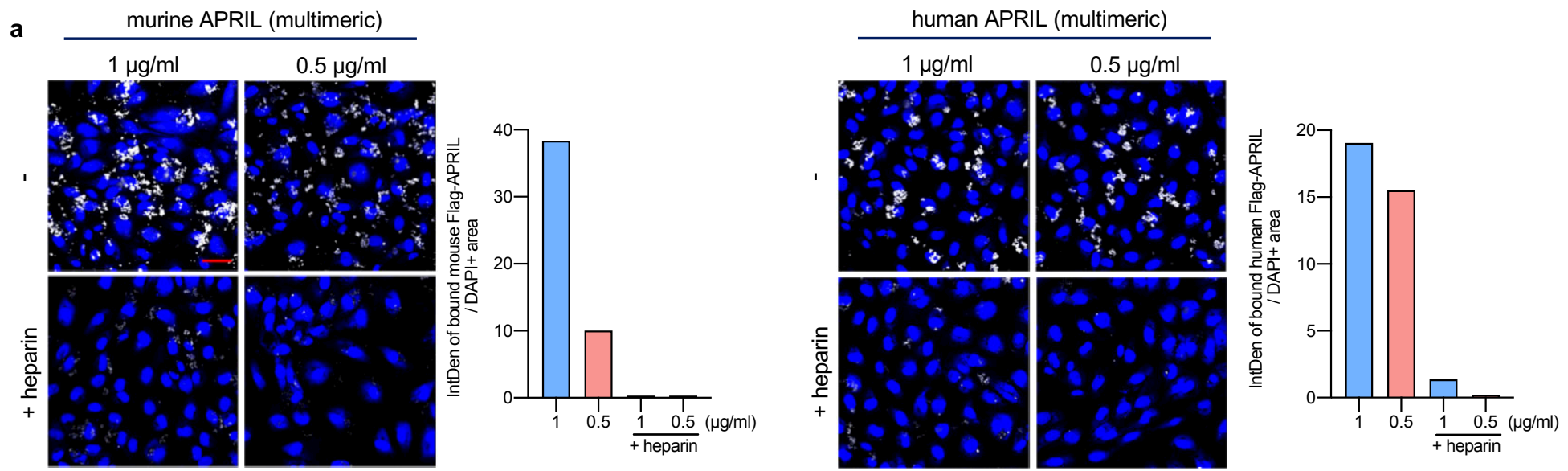

b

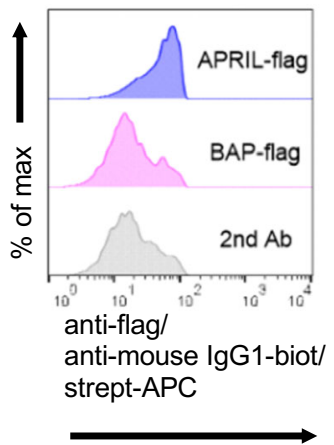

C Proteins that were exclusively identified in the APRIL pulldown compared to control by MASCOT, and filtered with GO terms "extracellular region" (GO:0005576) and "extracellular space" (GO:0005615)

\begin{tabular}{cccccc}
\hline ACLY & CTNNB1 & HSPH1 & LGALS9 & RAB10 & SERPINE1 \\
ACTBL2 & CTSC & IGLC2 & MARCKSL1 & RAB1A & SFN \\
ACTR1B & DDX5 & KRT12 & MIF & RAB1B & SLPI \\
ATP5L & DNAJA2 & KRT24 & PAFAH1B2 & RAB5A & TMED9 \\
BAX & DNAJB4 & KRT26 & PPA1 & RAB8A & TNFSF12 \\
BPIFB1 & EIF2S3 & KRT33A & PRCP & REEP5 & TUBB2A \\
CAPN1 & FAM213A & KRT71 & PRR4 & RHOA & TYK2 \\
CILP & GDI2 & KRT73 & PRSS3 & RPL35A & \\
CNN2 & HBD & KRT86 & PSMD12 & SERPINB3 & \\
COPA & HSPG2 & LGALS7 & PSME2 & SERPINB9 & \\
\hline
\end{tabular}

e
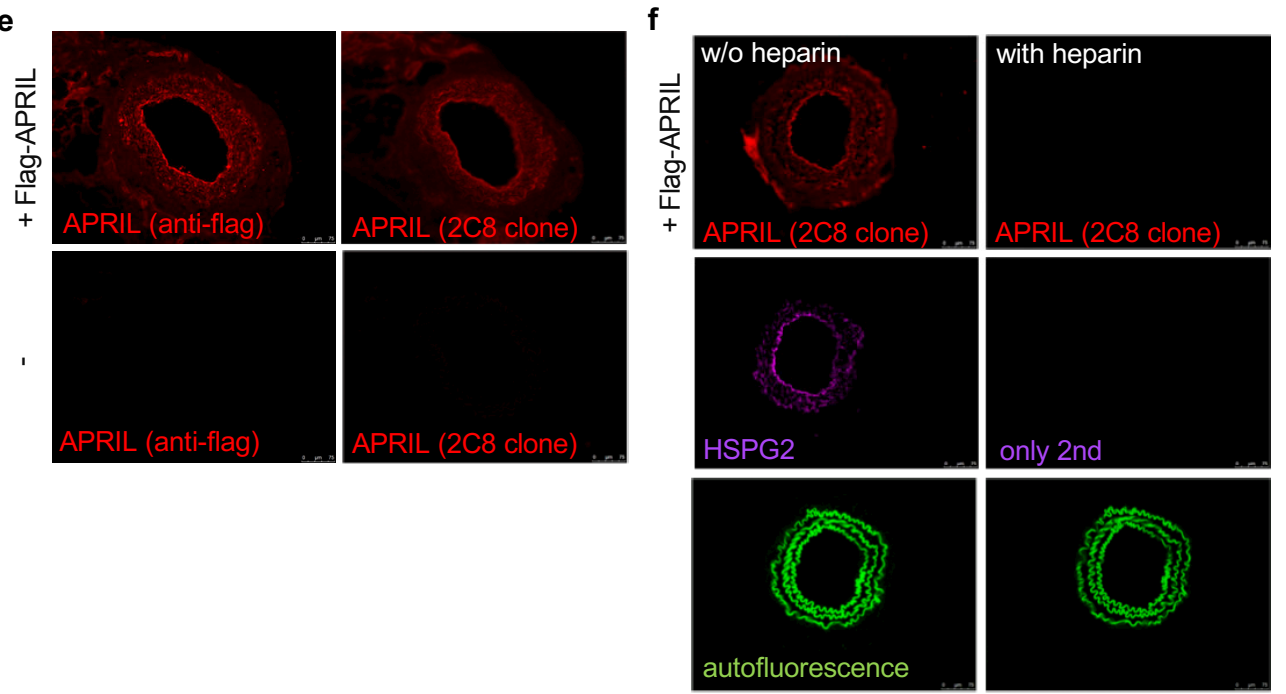

d

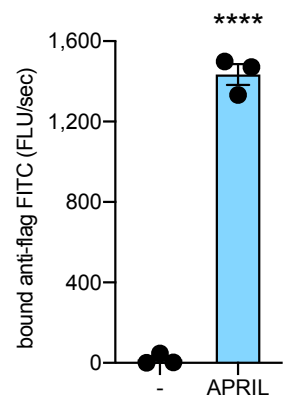

g

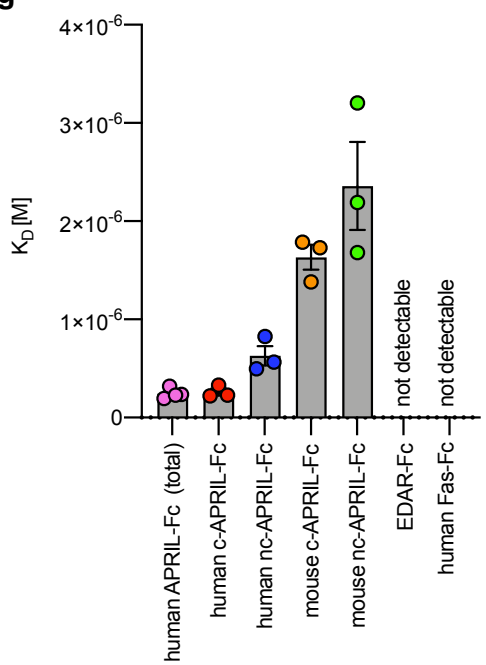

\section{Extended Data Figure 4}


a

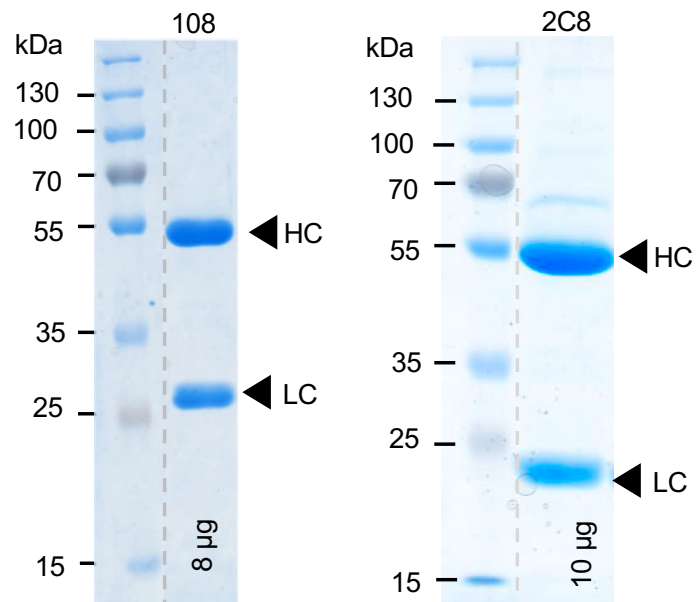

b

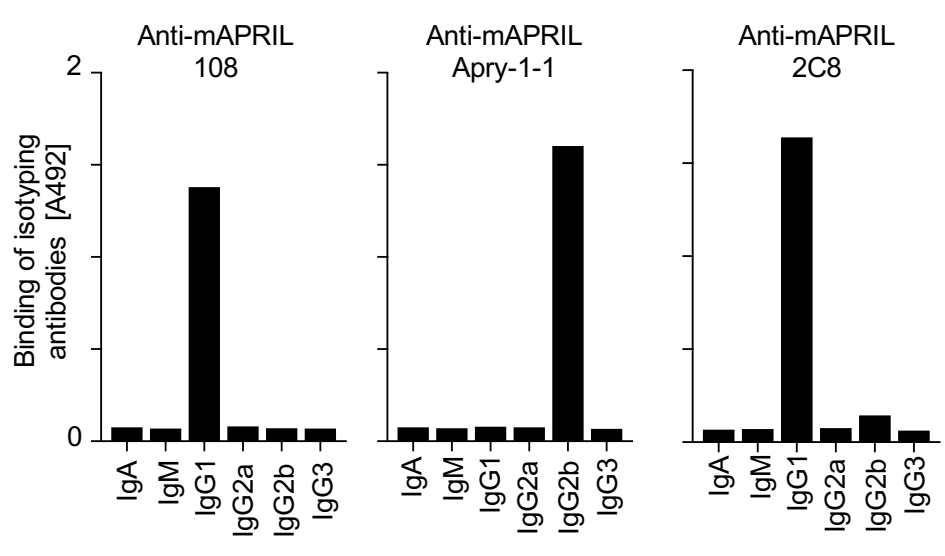

c Inhibition
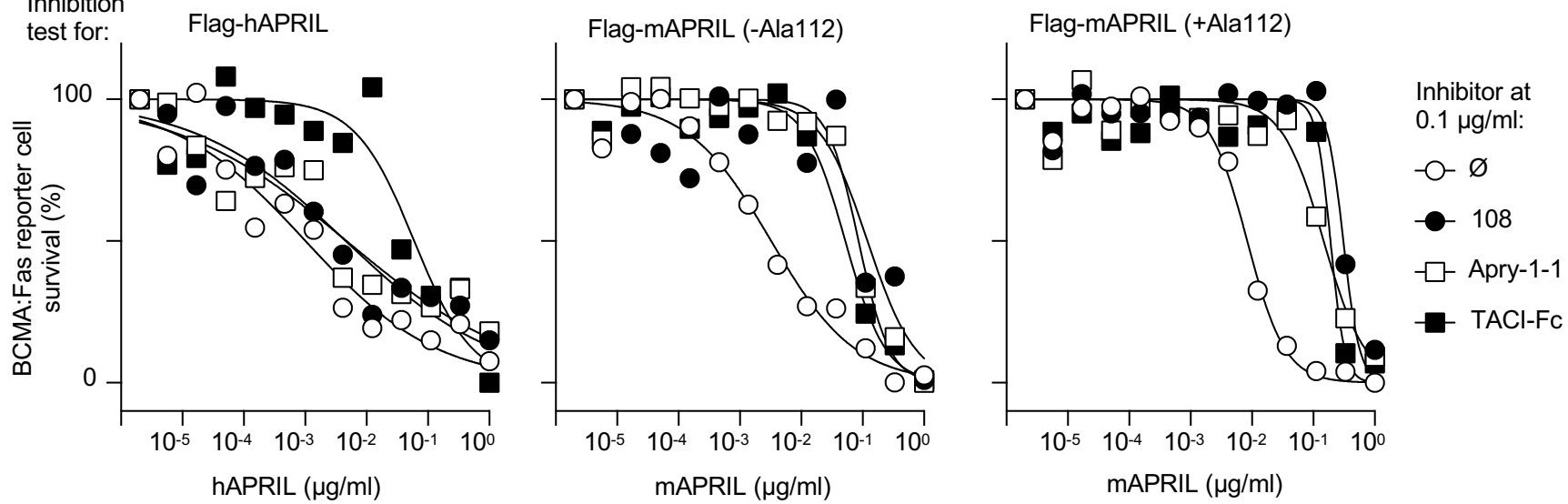

d

Binding of 2C8 to mAPRIL

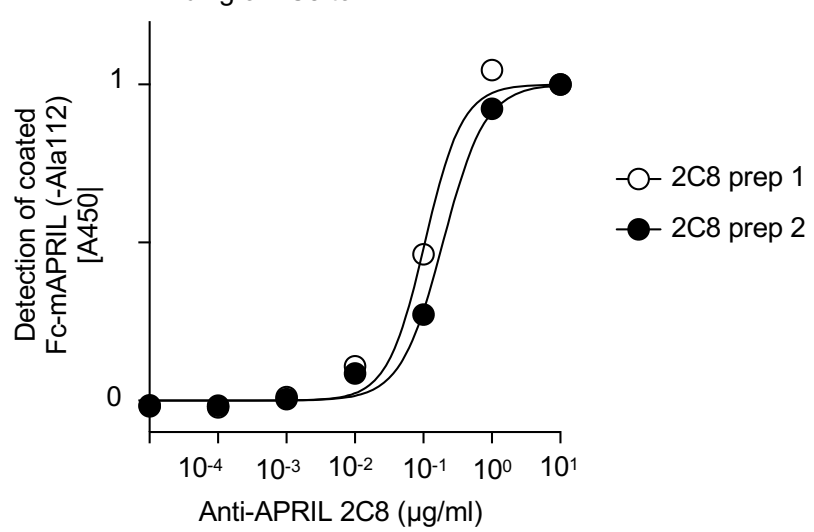

Extended Data Figure 5 
a

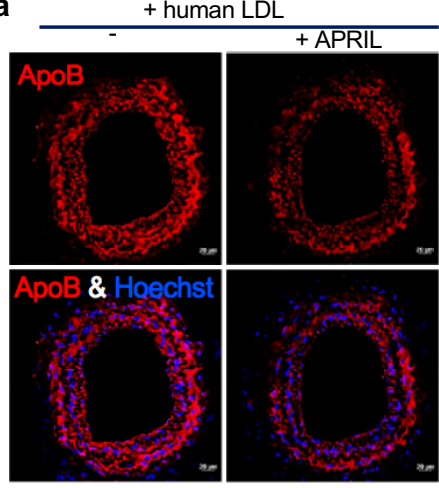

b

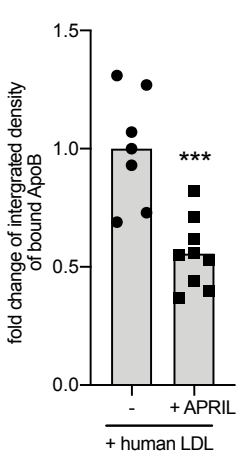

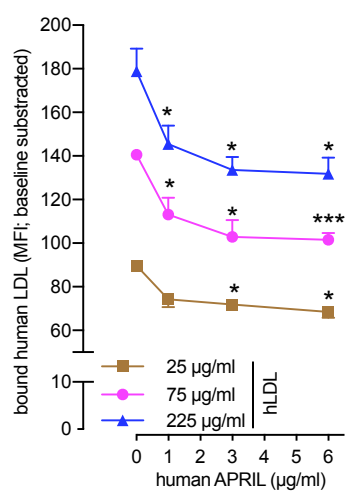

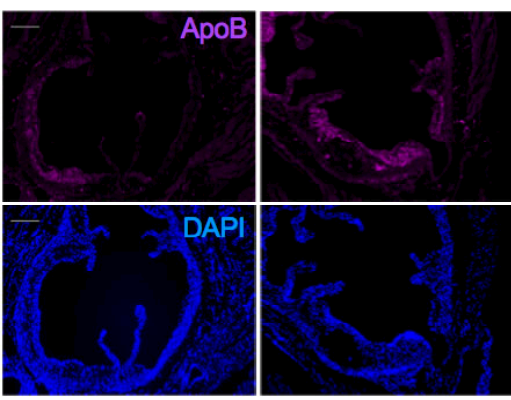

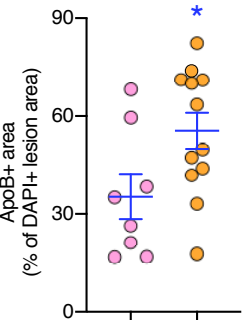

\section{Extended Data Figure 6}


a

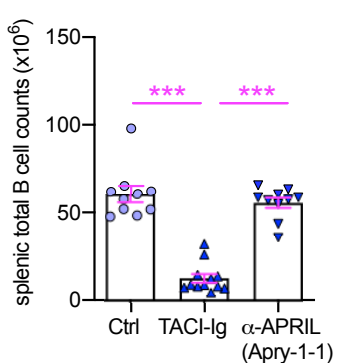

d

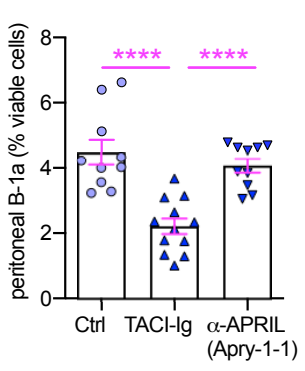

b
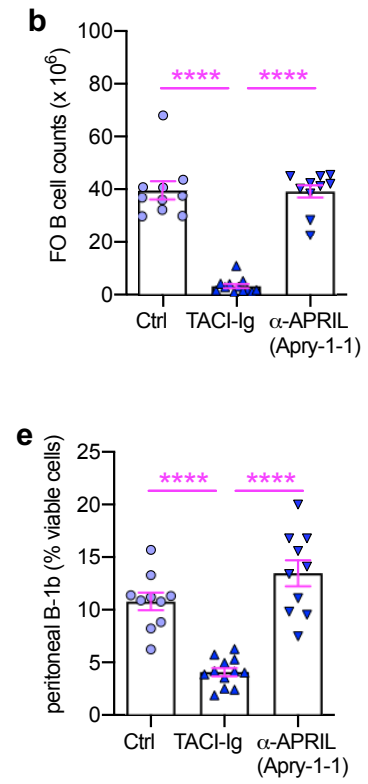
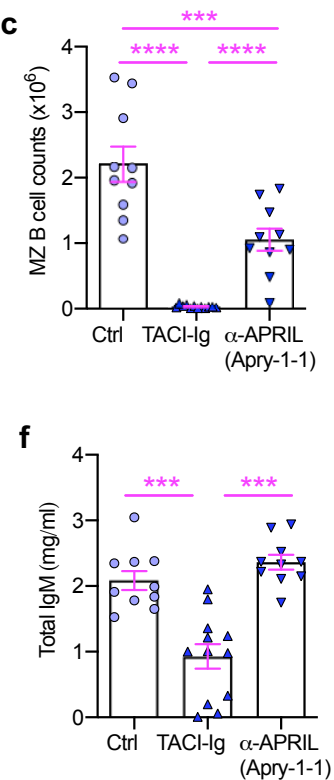

APRIL-flag + $\alpha$-APRILAb (Apry-1-1)

g $\rightarrow$ APRIL-flag

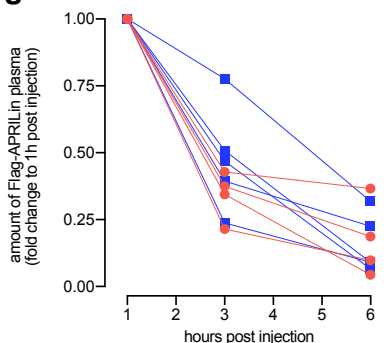

h

\begin{tabular}{cccc}
\hline $\begin{array}{c}\text { experimental } \\
\text { groups }\end{array}$ & $\begin{array}{c}\text { whole body } \\
\text { weight }(\mathrm{g})\end{array}$ & $\begin{array}{c}\text { plasma } \\
\text { triglycerides } \\
(\mathrm{mg} / \mathrm{dL})\end{array}$ & $\begin{array}{c}\text { plasma } \\
\text { cholesterol } \\
(\mathrm{mg} / \mathrm{dL})\end{array}$ \\
\hline $\begin{array}{c}\text { Apoe } \\
\text { Apoe }+ \text { Ctrl } \\
(\text { Apry-1-1) }\end{array}$ & $22.77 \pm 0.51$ & $178.8 \pm 14.80$ & $1606 \pm 83$ \\
$\begin{array}{c}\text { Apoe } \\
\text { Ap }+ \text { TACl-lg }\end{array}$ & $22.90 \pm 0.36$ & $155.5 \pm 15.16$ & $1513 \pm 86$ \\
\hline
\end{tabular}

Extended Data Figure 7 

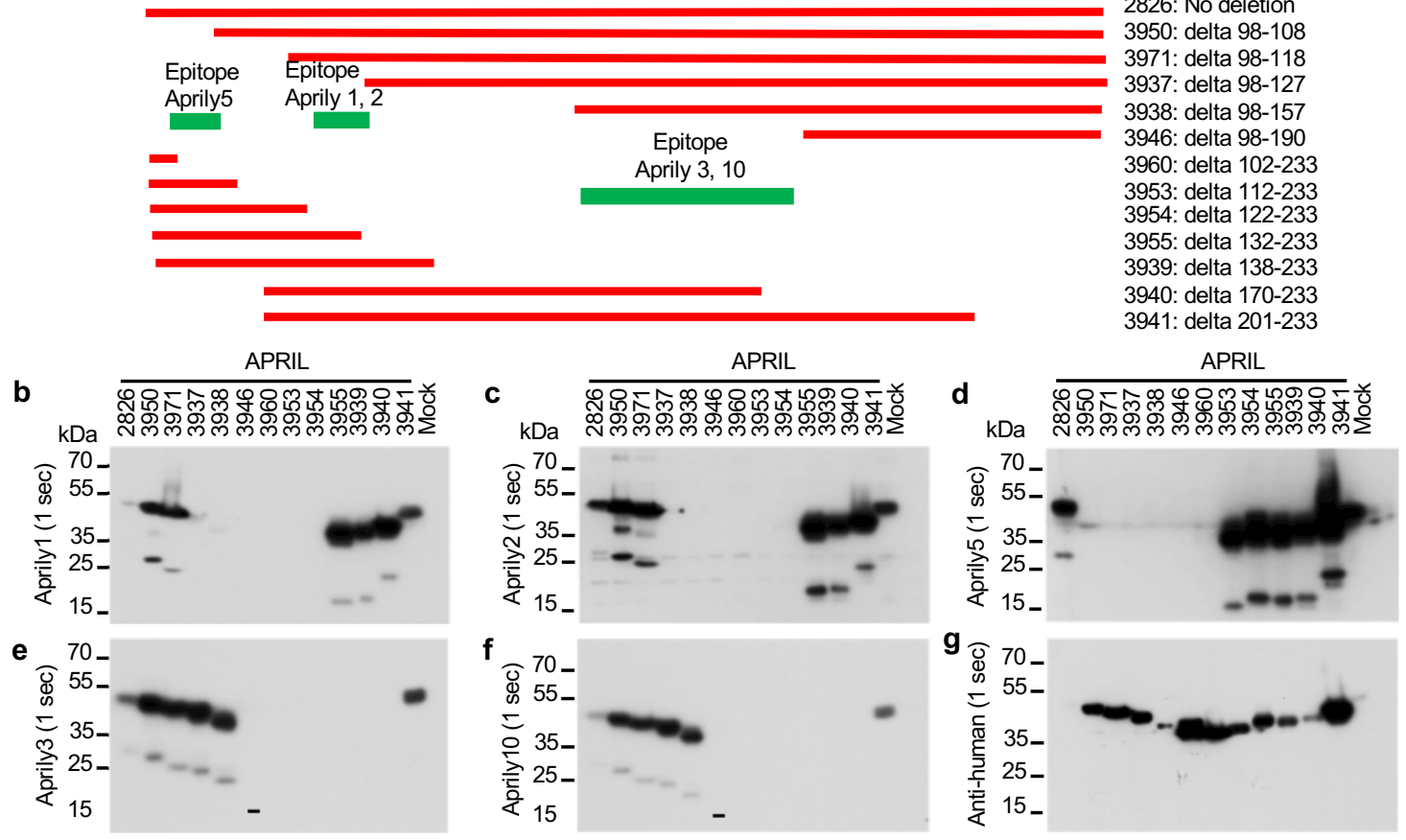

h hAPRIL level in depleted healthy sera

i hAPRIL level in depleted healthy sera

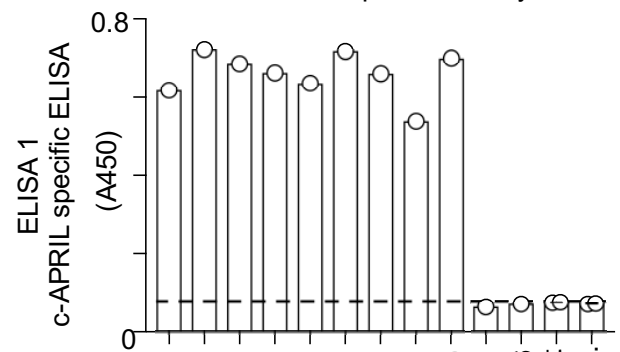

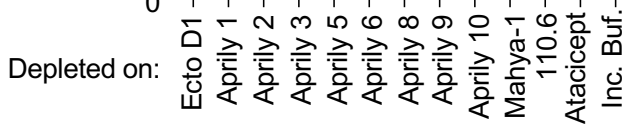

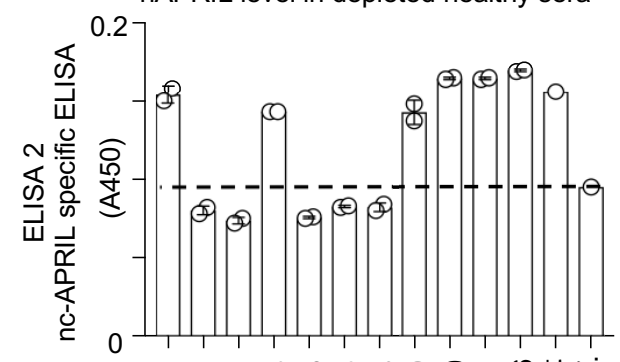

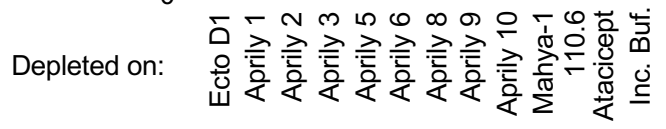
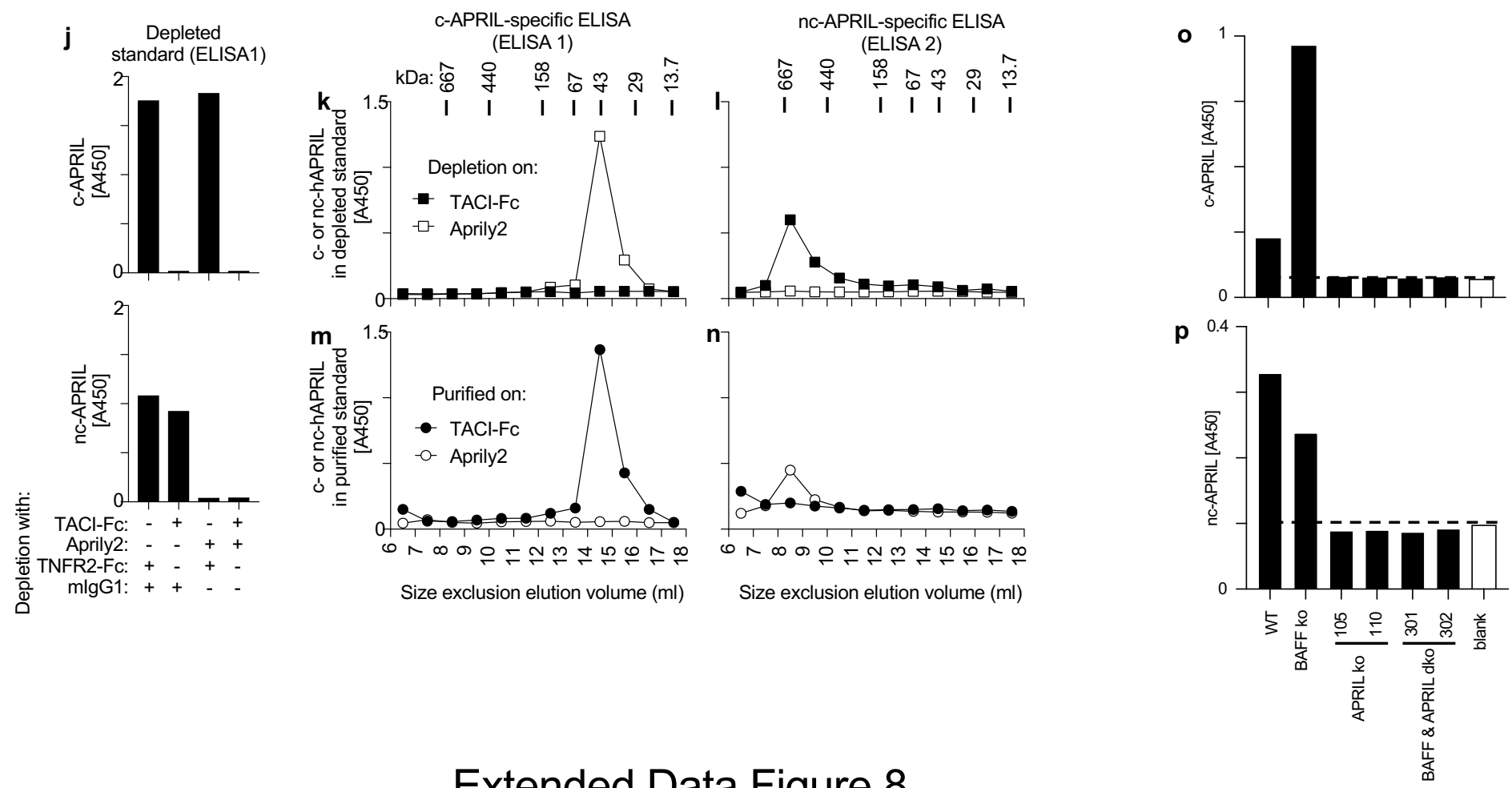

\section{Extended Data Figure 8}



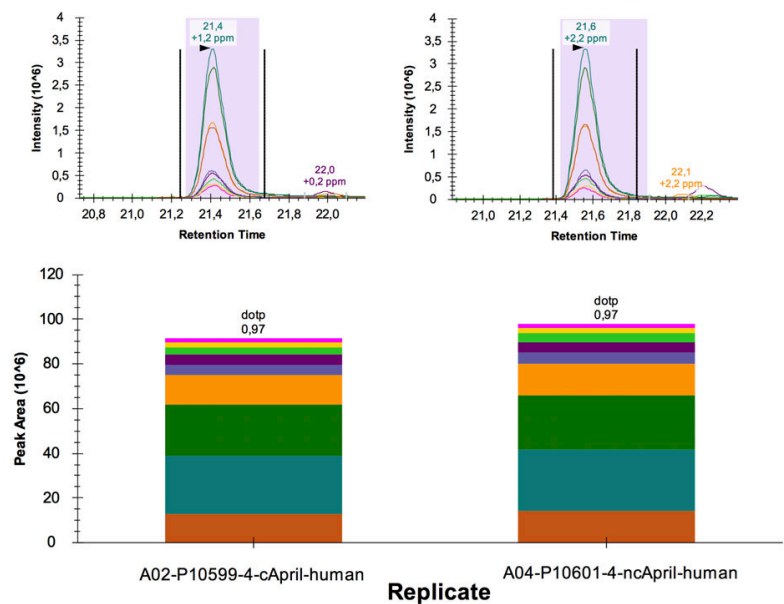

b
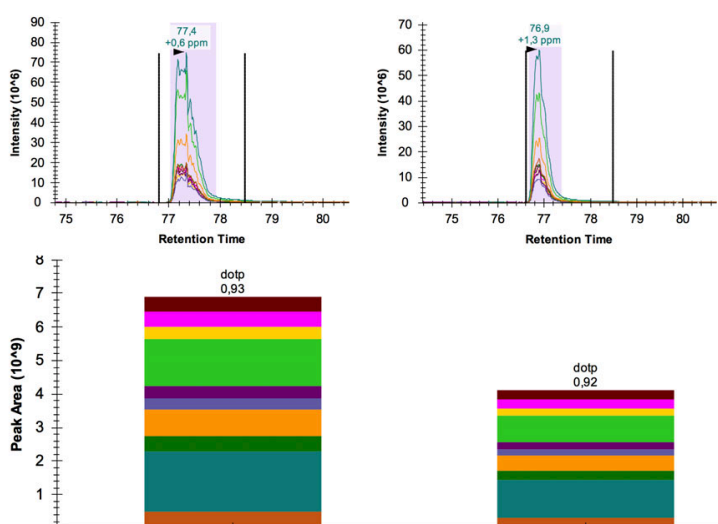

A02-P10599-4-cApril-huma
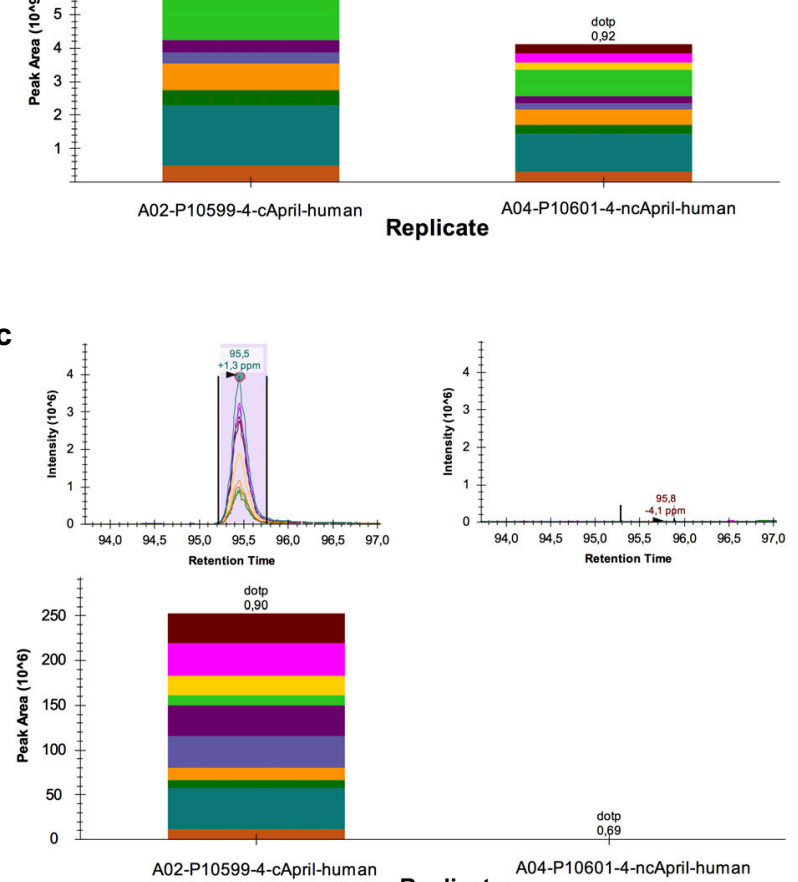

A02-P10599-4-cApril-huma
LDKTHTCPPCPAPELLGGPSVFLFPPKPKDTLMISRTPEVTCVVVDVSHEDP EVKFNWYVDGVEVHNAKTKPREEOYNSTYRVVSVLTVLHODWLNGKEYKCKV SNKALPAPIEKTISKAKGQPREPQVYTLPPSRDELTKNQVSLTCLVKGFYPS DIAVEWESNGOPENNYKTTPPVLDSDGSFFLYSKLTVDKSRWOOGNVFSCSV MHEALHNHYTQKSLSLSPGKRSPQPQPKPQPKPEPEGSLEVLFOGPGSLQHS VLHLVPINATSKDDSDVTEVMWOPALRRGRGLQAQGYGVRIQDAGVYLLYSQ VLFQDVTFTMGQVVSREGQGRQETLFRCIRSMPSHPDRAYNSCYSAGVFHLH QGDILSVIIPRARAKLNLSPHGTFLGFVKL

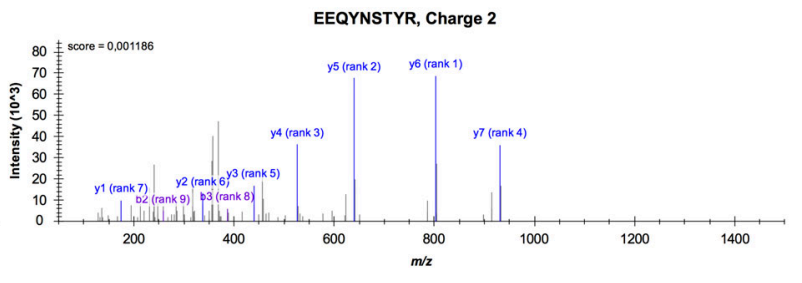

LDKTHTCPPCPAPELLGGPSVFLFPPKPKDTLMISRTPEVTCVVVDVSHEDP EVKFNWYVDGVEVHNAKTKPREEQYNSTYRVVSVLTVLHQDWLNGKEYKCKV SNKALPAPIEKTISKAKGOPREPOVYTLPPSRDELTKNOVSLTCLVKGFYPS DIAVEWESNGQPENNYKTTPPVLDSDGSFFLYSKLTVDKSRWQQGNVFSCSV MHEALHNHYTQKSLSLSPGKRSPQPQPKPQPKPEPEGSLEVLFQGPGSLQHS VLHLVPINATSKDDSDVTEVMWOPALRRGRGLOAOGYGVRIODAGVYLLYSO VLFQDVTFTMGQVVSREGQGRQETLFRCIRSMPSHPDRAYNSCYSAGVFHLH QGDILSVIIPRARAKLNLSPHGTFLGFVKL

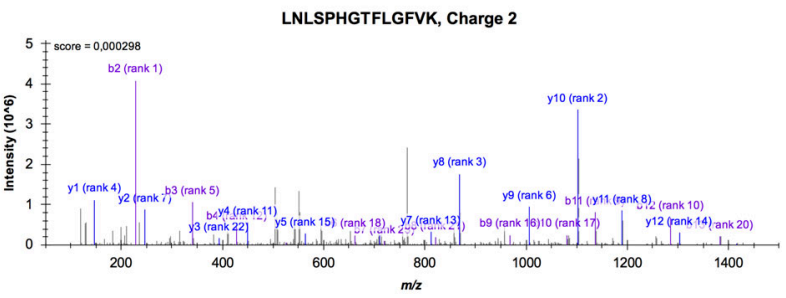

LDKTHTCPPCPAPELLGGPSVFLFPPKPKDTLMISRTPEVTCVVVDVSHEDP EVKFNWYVDGVEVHNAKTKPREEOYNSTYRVVSVLTVLHODWLNGKEYKCKV SNKALPAPIEKTISKAKGQPREPQVYTLPPSRDELTKNQVSLTCLVKGFYPS DIAVEWESNGOPENNYKTTPPVLDSDGSFFLYSKLTVDKSRWOOGNVFSCSV MHEALHNHYTQKSLSLSPGKRSPQPQPKPQPKPEPEGSLEVLFQGPGSLOHS VLHLVPINATSKDDSDVTEVMWOPALRRGRGLOAOGYGVRIODAGVYLLYSO VLFQDVTFTMGQVVSREGQGRQETLFRCIRSMPSHPDRAYNSCYSAGVFHLH QGDILSVIIPRARAKLNLSPHGTFLGFVKL

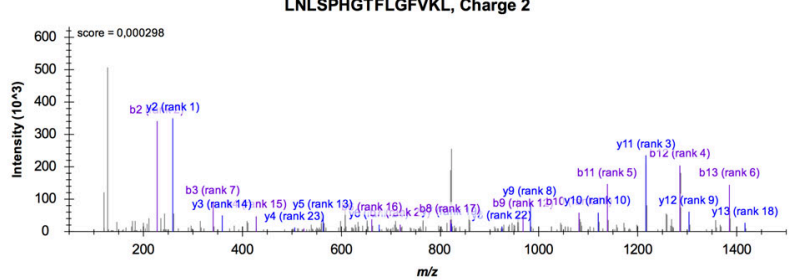

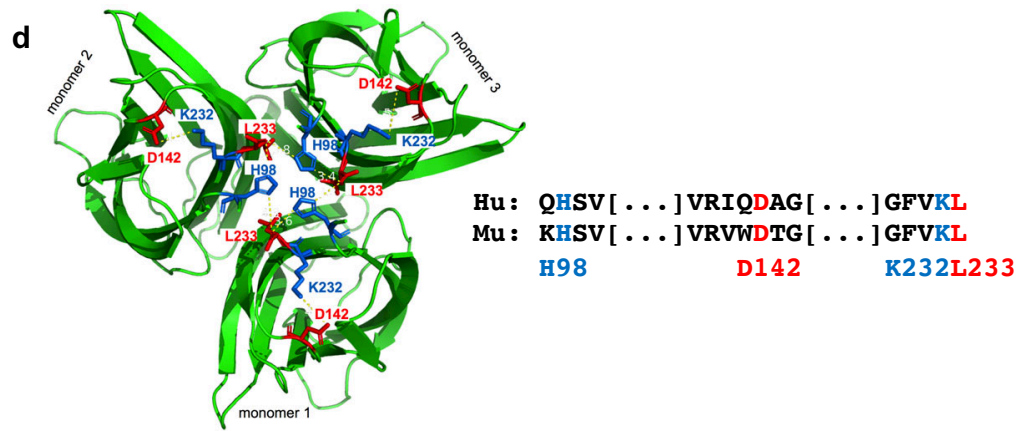


a

\begin{tabular}{|c|c|c|c|c|c|c|}
\hline \multirow[b]{2}{*}{ Variable } & \multicolumn{3}{|c|}{ Univariate } & \multicolumn{3}{|c|}{ Multivariate } \\
\hline & $\begin{array}{c}\text { Hazard } \\
\text { ratio }\end{array}$ & $\mathrm{Cl}$ & $\begin{array}{c}\mathrm{P}- \\
\text { value }\end{array}$ & $\begin{array}{c}\text { Hazard } \\
\text { ratio }\end{array}$ & $\mathrm{Cl}$ & $\begin{array}{c}\mathrm{P}- \\
\text { value }\end{array}$ \\
\hline \multicolumn{7}{|c|}{ All-Cause Mortality } \\
\hline $\begin{array}{c}3^{\text {rd }} \text { Tertile* } \\
(>6.47 \mathrm{ng} / \mathrm{ml})\end{array}$ & - & - & - & - & - & - \\
\hline $\begin{array}{c}2^{\text {nd }} \text { Tertile } \\
(4.23-6.47 \\
\text { ng/ml) }\end{array}$ & 1.17 & $\begin{array}{l}0.90- \\
1.52\end{array}$ & 0.25 & 1.31 & $\begin{array}{c}0.97- \\
1.77\end{array}$ & 0.07 \\
\hline $\begin{array}{c}1^{\text {st }} \text { Tertile } \\
(<4.22 \mathrm{ng} / \mathrm{ml})\end{array}$ & 1.99 & $\begin{array}{l}1.56- \\
2.54\end{array}$ & $<0.01$ & 1.95 & $\begin{array}{l}1.48- \\
2.56\end{array}$ & $<0.01$ \\
\hline \multicolumn{7}{|c|}{ Cardiovascular Mortality } \\
\hline
\end{tabular}

\begin{tabular}{|c|c|c|c|c|c|c|}
\hline $\begin{array}{c}3^{\text {rd }} \text { Tertile* } \\
(>6.47 \mathrm{ng} / \mathrm{ml})\end{array}$ & - & - & - & - & - & - \\
\hline $\begin{array}{c}2^{\text {nd }} \text { Tertile } \\
(4.23-6.47 \\
\mathrm{ng} / \mathrm{ml})\end{array}$ & 1.08 & $\begin{array}{c}0.76- \\
1.52\end{array}$ & 0.68 & 1.28 & $\begin{array}{l}0.86- \\
1.91\end{array}$ & 0.22 \\
\hline $\begin{array}{c}\text { 1st Tertile } \\
(<4.22 \mathrm{ng} / \mathrm{ml})\end{array}$ & 2.27 & $\begin{array}{l}1.67- \\
3.07\end{array}$ & $<0.01$ & 2.20 & $\begin{array}{l}1.56- \\
3.12\end{array}$ & $<0.01$ \\
\hline
\end{tabular}

b

ICARAS (c-APRIL)

\begin{tabular}{|c|c|c|c|c|}
\hline \multirow[b]{2}{*}{ Variable } & \multicolumn{2}{|c|}{ Univariate } & \multicolumn{2}{|c|}{ Multivariate } \\
\hline & Hazard ratio & $\begin{array}{c}\mathrm{P}- \\
\text { value }\end{array}$ & Hazard ratio & $\begin{array}{c}\mathrm{P}- \\
\text { value }\end{array}$ \\
\hline \multicolumn{5}{|c|}{ All-Cause Mortality } \\
\hline \multicolumn{5}{|l|}{$\begin{array}{c}\text { 3rd Tertile* }^{\text {rd }} \\
(>2.54 \mathrm{ng} / \mathrm{ml})\end{array}$} \\
\hline $\begin{array}{c}2^{\text {nd }} \text { Tertile } \\
(1.67-2.54 \mathrm{ng} / \mathrm{ml})\end{array}$ & 1.03 & 0.82 & 0.94 & 0.67 \\
\hline $\begin{array}{c}1^{\text {st }} \text { Tertile } \\
(<1.67 \mathrm{ng} / \mathrm{ml})\end{array}$ & 1.07 & 0.63 & 1.13 & 0.41 \\
\hline \multicolumn{5}{|c|}{ Cardiovascular Mortality } \\
\hline \multicolumn{5}{|l|}{$\begin{array}{c}3^{\text {rd }} \text { Tertile* } \\
(>2.54 \mathrm{ng} / \mathrm{ml})\end{array}$} \\
\hline $\begin{array}{c}2^{\text {nd }} \text { Tertile } \\
(1.67-2.54 \\
\text { ng/ml) }\end{array}$ & 0.89 & 0.38 & 0.78 & 0.21 \\
\hline $\begin{array}{c}1^{\text {st }} \text { Tertile } \\
(<1.67 \mathrm{ng} / \mathrm{ml})\end{array}$ & 1.0 & 0.89 & 1.19 & 0.35 \\
\hline
\end{tabular}

LURIC (nc-APRIL)

b

\begin{tabular}{|c|c|c|c|c|}
\hline Parameter & Hazard ratio & Lower .95 & Upper .95 & $P$ values \\
\hline Log nc-APRIL & 1.14 & 1.02 & 1.27 & 0.022 \\
\hline age & 1.06 & 1.04 & 1.07 & 0.000 \\
\hline sex & 0.70 & 0.53 & 0.92 & 0.011 \\
\hline CRP & 1.38 & 0.95 & 2.01 & 0.087 \\
\hline Triglycerides (log) & 0.84 & 0.63 & 1.12 & 0.230 \\
\hline Total cholesterol (log) & 1.26 & 0.86 & 1.85 & 0.240 \\
\hline $\begin{array}{l}\text { Myocardial infarction (no vs } \\
\text { one) }\end{array}$ & 1.06 & 0.82 & 1.37 & 0.666 \\
\hline $\begin{array}{l}\text { Myocardial infarction (no vs } \\
\text { >one) }\end{array}$ & 1.93 & 1.33 & 2.81 & 0.001 \\
\hline Stroke & 1.61 & 1.17 & 2.22 & 0.003 \\
\hline Periph. Vasc. Disease & 1.83 & 1.33 & 2.50 & 0.000 \\
\hline BMI & 0.98 & 0.95 & 1.02 & 0.331 \\
\hline $\begin{array}{l}\text { Isolated systolic hypertension } \\
(>=140 /<90)\end{array}$ & 0.83 & 0.65 & 1.06 & 0.140 \\
\hline Type II diabetes & 1.25 & 0.89 & 1.76 & 0.189 \\
\hline Creatinine (log) & 1.86 & 1.19 & 2.90 & 0.007 \\
\hline Hba1c (\%) & 1.25 & 1.13 & 1.39 & 0.000 \\
\hline
\end{tabular}

c

FAST-MI (nc-APRIL)

\begin{tabular}{cccc}
\hline \multirow{2}{*}{ Variable } & \multicolumn{3}{c}{ Multivariate } \\
\cline { 2 - 3 } & Death or recurrent myocardial infarction & P-value \\
\hline $3^{\text {rd }}$ Tertile & 1.91 & $1.25-2.91$ & 0.0006 \\
$2^{\text {nd }}$ Tertile & 0.77 & $0.45-1.33$ & $\mathrm{~ns}$ \\
\hline $1^{\text {st }}$ Tertile * & - & - & -
\end{tabular}

*Reference Category

\section{Extended Data Table 1}

